Lucas Machado de Oliveira

\title{
Desenvolvimento de Veículos Autônomos Submarinos para Aplicações Oceanográficas
}

São Paulo 


\section{Lucas Machado de Oliveira}

\section{Desenvolvimento de Veículos Autônomos Submarinos para Aplicações Oceanográficas}

\section{Versão Corrigida}

(Versão original encontra-se na unidade que aloja o Programa de Pós-graduação)

Dissertação apresentada à Escola Politécnica da Universidade de São Paulo para obtenção do Título de Mestre em Ciências.

Área de Concentração: Engenharia de Controle e Automação Mecânica

Orientador: Prof. Dr. Ettore Apolonio de Barros

São Paulo

2018 
Este exemplar foi revisado e corrigido em relação à versão original, sob responsabilidade única do autor e com a anuência de seu orientador.

São Paulo, de de

Assinatura do autor:

Assinatura do orientador:

Catalogação-na-publicação

Oliveira, Lucas

Desenvolvimento de veículos autônomos submarinos para aplicações oceanográficas / L. Oliveira -- versão corr. -- São Paulo, 2018.

$109 \mathrm{p}$.

Dissertação (Mestrado) - Escola Politécnica da Universidade de São Paulo. Departamento de Engenharia Mecatrônica e de Sistemas Mecânicos.

1.Submarinos 2.Submersíveis não tripulados 3.Veículos guiados remotamente 4.Oceanografia I.Universidade de São Paulo. Escola Politécnica. Departamento de Engenharia Mecatrônica e de Sistemas Mecânicos II.t. 
Aos meus avôs e avós 


\section{Agradecimentos}

Agradeço imensamente a todos listados abaixo e outros que posso ter me esquecido de citar, que de forma direta ou indireta me ajudaram nos projetos e trabalhos:

Meus Pais: José Carlos e Mariaceli;

Meus Irmãos: Arthur e Laís;

Meus Avôs: Frantz e Alda, José Carlos e Marina;

Meus Tios, primos e demais familiares;

Minha noiva e família: Manu, Tânia, Moacir e Gabi;

Meus sócios da Immersus Tecnologia: Rodrigo e Diana;

Amigos e frequentadores do LVNT: João, Luciano, Zanoni, William, Persing, Edson, Artur, Franco, Igor, Sarah, Crhistopher, Yunier, Flávio, Alex, Estêvão, Juan;

Professores: Thiago, Pellini, Rubens e Ettore;

Alunos do LAPS: Maiá, Alessandra, Yonara, Claudinha, Carol e Leandro;

Membros da Marinha: André, Neto, Ângelo, Vasconcelos, Vinícius, Pansanato;

Parceiros de projetos: Engler, Edivaldo, Dimas, Álvaro, Adílson;

Técnicos e mecânicos: Carlos, Fidel, Okumura;

Funcionários do tanque de provas da naval, do CEPEUSP e da base do IO em Ubatuba; Apoiadores da Immersus: Ju, Wagner, Renier, Guilherme, Marco. 
Happiness only real when shared

-Alexander Supertramp (Christopher McCandless) 


\section{Resumo}

Devido à grande importância do ambiente aquático sobre a vida humana e às dificuldades inerentes ao seu estudo e exploração, a aplicação de AUVs tem se mostrado bastante benéfica e seu uso vem crescendo ao longo dos anos.

Este trabalho apresenta um estudo sobre o desenvolvimento de veículos autônomos submarinos para realização de missões oceanográficas, com foco nas características de seus sistemas embarcados que permitam atender melhor os requisitos desta aplicação.

Analisando trabalhos publicados nos últimos anos pode-se notar uma grande quantidade de AUVs desenvolvidos ou adaptados para aplicações em oceanografia, com uma grande variedade de soluções aplicadas em seus diversos sistemas, visando a realização de diversos tipos de missões necessárias para tais estudos.

Como estudo de caso, foi apresentada a adaptação do AUV Pirajuba, desenvolvido inicialmente como uma plataforma de testes hidrodinâmicos, para aplicação em missões de levantamento de dados para estudos oceanográficos. Para tal, foi necessário realizar uma série de modificações em seus subsistemas, permitindo a instalação de novos sensores e equipamentos para aumento da segurança nas operações em mar aberto. As modificações necessárias envolveram tanto o sistema hidromecânico do veículo, com instalação de novos módulos no casco, quanto no seu sistema embarcado, implicando no desenvolvimento de uma nova versão do sistema de hardware e uma atualização no software de controle.

Tendo em vista esta necessidade, foi proposto um estudo dos requisitos da aplicação oceanográfica de AUVs e os impactos no seu desenvolvimento. Para isso, foi realizado um levantamento dos requisitos das principais aplicações oceanográficas e seus impactos no desenvolvimento dos veículos, envolvendo os sistemas hidromecânico, energia, navegação, comunicação e controle. Foi realizado também um estudo da arquitetura de controle CANARMES, desenvolvida para o AUV Pirajuba, envolvendo os requisitos de seu projeto e as principais características da arquitetura de controle, que serviu como base para a atualização do veículo para as novas aplicações.

São apresentados os resultados obtidos em testes de campo realizados no litoral de Ubatuba - SP, nos quais foram feitas manobras com movimentação vertical com a aquisição de dados de diversos sensores oceanográficos, utilizados para o estudo de detecção de camadas finas.

Palavras-chave: Veículos submarinos não tripulados, Oceanografia, Veículos autônomos, Arquiteturas de controle, Sistemas embarcados 


\section{Abstract}

Due to the great importance of the aquatic environment on human life and the inherent difficulties of its study and exploration, the application of AUVs has been shown to be very beneficial and its use has been growing over the years.

This work presents a study on the development of autonomous submarine vehicles for the accomplishment of oceanographic missions, focusing on the characteristics of the embedded systems of these vehicles in order to better meet the application requirements.

Analyzing published works in the last five years, it can be noticed a great amount of AUVs developed or adapted for applications in oceanography, with a great variety of solutions applied in their embedded systems, involving both hardware and software, aiming at the accomplishment of several types of missions necessary for such studies.

As a case study, the adaptation of the AUV Pirajuba, initially developed as a platform for hydrodynamic tests, was presented for application in data collection missions for oceanographic studies. For this, it was necessary to make a series of modifications in its subsystems, allowing the installation of new sensors and equipment to increase the safety in the operations in the open sea. The necessary modifications involved both the vehicle's hydromechanical system, with the installation of new modules in the hull, and in its embedded system, requiring the development of a new version of the hardware system and an update in the control software.

Due to this necessities, a study was proposed to better understand the requirements of AUVs for oceanographic application and the impacts on their development. For that, a survey was made of the requirements of the main oceanographic applications and their impacts on the development of the vehicles, involving the hydromechanical, energy, navigation, communication and control systems. A study of the CANARMES control architecture, developed for the Pirajuba AUV, was carried out, involving the requirements of its design and the main characteristics of the control architecture, which served as a basis for updating the vehicle for new applications.

We present the results obtained in field tests conducted in the coastal area of Ubatuba -

SP, Brazil, in which maneuvers were performed with vertical movement, while acquiring data from several oceanographic sensors, used for the study of thin layer detection.

Key-words: Unmanned Underwater Vehicle, Oceanography, Autonomous Vehicles, Control Architectures, Embedded Systems. 


\section{Sumário}

Sumário $\ldots \ldots \ldots \ldots \ldots \ldots \ldots \ldots$

Lista de ilustrações $\ldots \ldots \ldots \ldots \ldots \ldots$

Lista de tabelas $\ldots \ldots \ldots \ldots \ldots \ldots \ldots \ldots$

1 INTRODUÇÃO $\ldots \ldots \ldots \ldots \ldots \ldots \ldots$

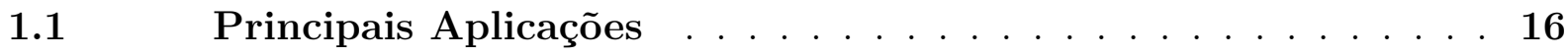

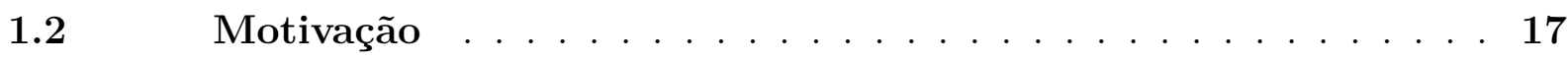

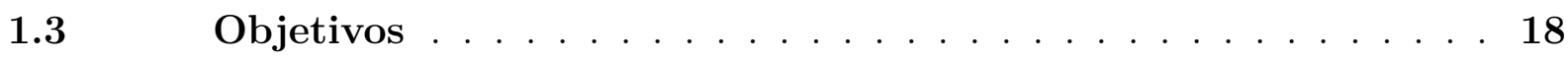

$1.3 .1 \quad$ Objetivo geral $\ldots \ldots \ldots \ldots \ldots \ldots \ldots \ldots$

$\underline{1.3 .2}$ Objetivos específicos $\ldots \ldots \ldots \ldots \ldots \ldots \ldots$

$1.4 \quad$ Organização do trabalho $\ldots \ldots \ldots \ldots \ldots$

2 REQUISITOS DAS APLICAÇÕES OCEANOGRÁFICAS ․ 20

$\underline{2.1}$ Vantagens da aplicação de AUVs $\ldots \ldots \ldots \ldots$

$\underline{2.1 .1}$ Avaliação das plataformas $\ldots \ldots \ldots \ldots \ldots 22$

$\underline{2.1 .1 .1}$ Qualidade dos dados $\ldots \ldots \ldots \ldots \ldots \ldots \ldots \ldots 22$

$\underline{2.1 .1 .2}$ Intervalo de aquisição dos dados $\ldots \ldots \ldots \ldots \ldots \ldots \ldots 22$

$\underline{2.1 .1 .3}$ Distribuição espacial e temporal $\ldots \ldots \ldots \ldots \ldots \ldots 22$

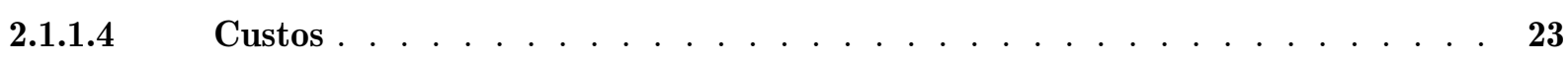

$\underline{2.1 .2}$ Principais aplicações de AUVs em oceanografia $\ldots \ldots \ldots \ldots$

$\underline{2.2}$ Impactos dos requisitos no desenvolvimento de AUVs . . . . . 24

$\underline{2.2 .1}$ Implicações no sistema hidromecânico $\ldots \ldots \ldots \ldots \ldots$

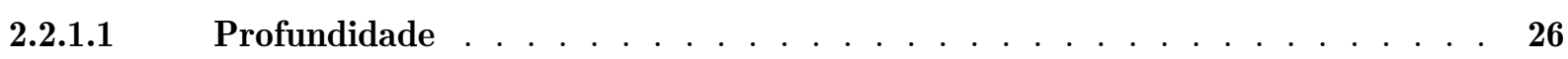

$\underline{\mathbf{2 . 2 . 2}}$ Implicações no sistema de energia $\ldots \ldots \ldots \ldots \ldots \ldots$

$\underline{2.2 .3}$ Implicações no sistema de navegação $\ldots \ldots \ldots \ldots 27$

$\underline{2.2 .4}$ Requisitos do sistema de comunicação $\ldots \ldots \ldots \ldots$

$\underline{2.2 .5}$ Implicações na arquitetura de controle $\ldots \ldots \ldots \ldots 28$

2.2.5.1 Implicações na arquitetura de hardware $\ldots \ldots \ldots \ldots \ldots$

2.2.5.2 Implicações na arquitetura de software $\ldots \ldots \ldots \ldots \ldots$

$\underline{2.2 .5 .3}$ A aplicação da Modularidade $\ldots \ldots \ldots \ldots \ldots \ldots$

$3 \quad$ ESTADO DA ARTE DO DESENVOLVIMENTO DE AUVS • 31

$\underline{3.1}$ Principais Aplicações $\ldots \ldots \ldots \ldots \ldots \ldots$

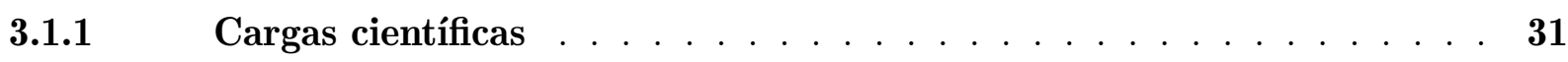

$\underline{3.2 \quad \text { Aspectos hidromecânicos } \ldots \ldots \ldots \ldots \ldots \ldots \ldots \ldots \ldots}$ 


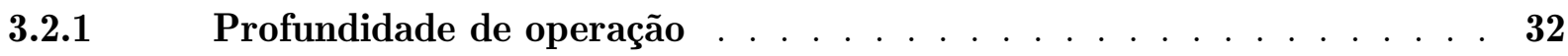

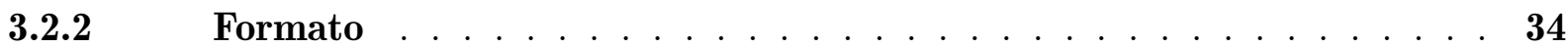

$\mathbf{3 . 2 . 3}$ Tipo de casco $\ldots \ldots \ldots \ldots \ldots \ldots \ldots \ldots \ldots \ldots$

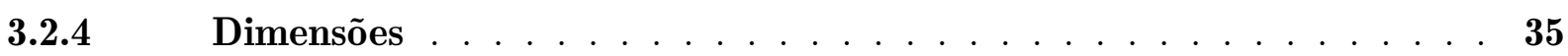

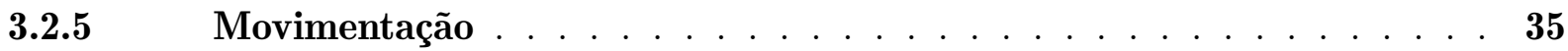

$3.3 \quad$ Sistemas de energia $\ldots \ldots \ldots \ldots \ldots \ldots \ldots$

$3.4 \quad$ Sistemas de navegação $\ldots \ldots \ldots \ldots \ldots \ldots$

3.5 Sistemas de comunicação $\ldots \ldots \ldots \ldots \ldots$

$3.6 \quad$ Arquiteturas de controle $\ldots \ldots \ldots \ldots$

3.6.1 Aspectos das arquiteturas de hardware $\ldots \ldots \ldots \ldots$

3.6.1.1 Topologia da arquitetura $\ldots \ldots \ldots \ldots \ldots$

3.6.1.2 Módulos de Processamento . . . . . . . . . . . . . . . . . . 40

3.6.1.3 Rede interna $\ldots \ldots \ldots \ldots \ldots$. . . . . . . . . . . . 40

3.6.2 Aspectos das arquiteturas de software $\ldots \ldots \ldots \ldots 4$

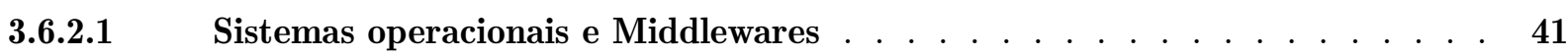

3.6.2.2 Arquiteturas de controle $\ldots \ldots \ldots \ldots \ldots \ldots$. . . . . . . . 42

$4 \quad$ ESTUDO DE CASO: AUV PIRAJUBA $\ldots \ldots \ldots \ldots \ldots 44$

4.1 Descrição da missão $\ldots \ldots \ldots \ldots \ldots \ldots$

4.1.1 Características da manobra $\ldots \ldots \ldots \ldots \ldots \ldots$

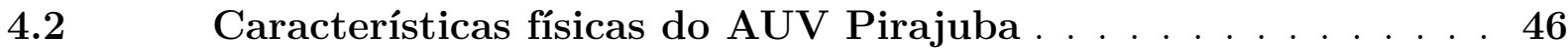

$4.2 .1 \quad$ Vasos de pressão $\ldots \ldots \ldots \ldots \ldots \ldots$

4.2.1.1 Vaso de propulsão $\ldots \ldots \ldots \ldots \ldots \ldots$

4.2.1.2 Vaso de manobra $\ldots \ldots \ldots \ldots \ldots \ldots$

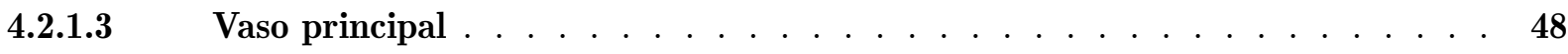

4.2.2 Módulos de expansão $\ldots \ldots \ldots \ldots \ldots \ldots$

4.2.2.1 Módulo de sonar, câmera e iluminação $\ldots \ldots \ldots \ldots$

4.2.2.2 Módulo de sonar de escaneamento lateral . . . . . . . . . . . . . 49

4.2.2.3 Módulo de localização acústica $\ldots \ldots \ldots \ldots 4 \ldots$

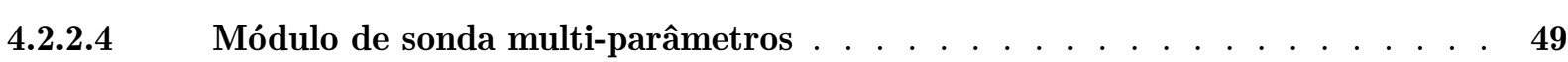

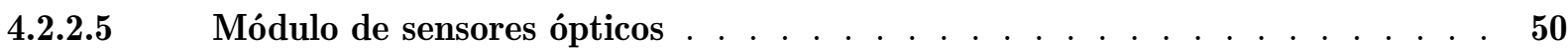

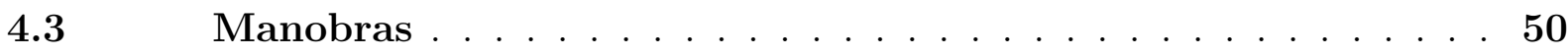

$\underline{4.4 \quad \text { Sistema de energia } \ldots \ldots \ldots \ldots \ldots \ldots \ldots \ldots \ldots \ldots}$

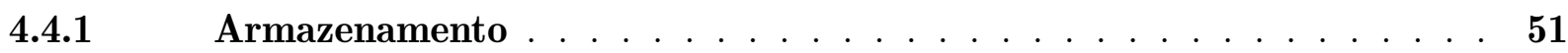

4.4.2 Conversão e distribuição $\ldots \ldots \ldots \ldots \ldots \ldots \ldots$

$4.4 .3 \quad$ Liga/desliga e proteção $\ldots \ldots \ldots \ldots \ldots \ldots \ldots$

$\underline{4.5}$ Sistema de navegação $\ldots \ldots \ldots \ldots \ldots \ldots$

$4.6 \quad$ Sistema de comunicação $\ldots \ldots \ldots \ldots \ldots \ldots \ldots$

$4.7 \quad$ Arquitetura de controle $\ldots \ldots \ldots \ldots \ldots \ldots$

4.7.1 Arquitetura de controle CANARMES $\ldots \ldots \ldots \ldots \ldots$ 
4.7.1.1 Requisitos que orientaram o desenvolvimento $\ldots \ldots \ldots \ldots$

4.7.1.2 Conceito geral da arquitetura . . . . . . . . . . . . . . . . . . 55

4.7.1.3 Arquitetura de hardware . . . . . . . . . . . . . . . . 56

4.7.1.4 Arquitetura de software . . . . . . . . . . . . . . . . 57

4.7.2 Atualização do sistema $\ldots \ldots \ldots \ldots \ldots$

4.7.2.1 Arquitetura de Hardware . . . . . . . . . . . . . . . . . . 59

4.7.2.1.1 Processadores e rede de comunicação $\ldots \ldots \ldots \ldots \ldots$

4.7.2.1.2 Estrutura dos módulos . . . . . . . . . . . . . . . . . . . . . . 59

4.7.2.1.3 Conectores . . . . . . . . . . . . . . . . . . . . . . . . . . . . . 60

4.7.2.1.4 Considerações sobre confiabilidade $\ldots \ldots \ldots \ldots \ldots$. . . . . . . . . 61

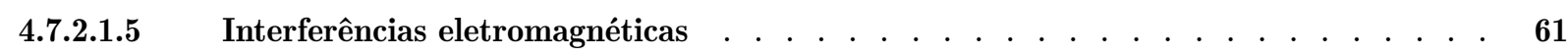

4.7.2.2 Arquitetura de Software . . . . . . . . . . . . . . . 61

4.7.2.2.1 Lógica de controle $\ldots \ldots \ldots \ldots$. . . . . . . . . . . . . 62

4.7.2.3 Distribuição dos equipamentos e funcionalidades $\ldots \ldots \ldots$. . . . . . . . 64

4.7.2.3.1 Módulo Principal $\ldots \ldots \ldots \ldots \ldots \ldots$

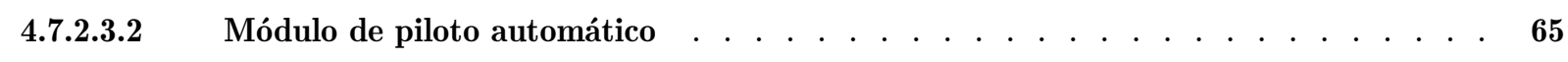

4.7.2.3.3 Módulo de Interface com sensores . . . . . . . . . . . . . . . . . . . . 65

4.7.2.3.4 Módulo de Interface com sistema de navegação $\ldots \ldots \ldots$. . . . . . . . . . . 66

4.7.2.3.5 Módulo de Interface com sensores externos _ . . . . . . . . . . . . . . . . . 66

4.7.2.3.6 Módulo de Interface com atuadores . . . . . . . . . . . . . . . . . . 66

4.7.2.4 Fluxo de dados $\ldots \ldots \ldots \ldots \ldots$

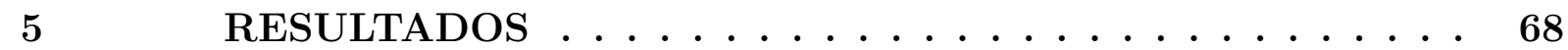

5.1 Resultados dos ensaios . . . . . . . . . . . . 68

5.1.1 Navegação . . . . . . . . . . . . . . . . . 68

$\underline{5.1 .2}$ Controle de Pitch . . . . . . . . . . . . . . . . . 68

5.1.3 Controle de Profundidade $\ldots \ldots \ldots \ldots$

5.1.4 Controle de Rumo . . . . . . . . . . . . . . . . . . 69

5.1.5 Sensores Oceanográficos . . . . . . . . . . . . 70

5.2 Análise do sistema embarcado . . . . . . . . . . . . . . 73

5.2.1 Desempenho da arquitetura de controle $\ldots \ldots \ldots$. . . . . . . . 74

5.2.1.1 Intertravamentos de segurança . . . . . . . . . . . . . . 74

5.3 Análise das operações . . . . . . . . . . . . . 75

5.3.1 Vibrações e impactos . . . . . . . . . . . . . . . 75

5.3.2 Transporte . . . . . . . . . . . . . . . . 78

5.3.3 Facilidade de Manutenção $\ldots \ldots \ldots \ldots$. . . . . . . . . . . . . . .

5.3.3.1 Acesso aos componentes . . . . . . . . . . . . . . . 79

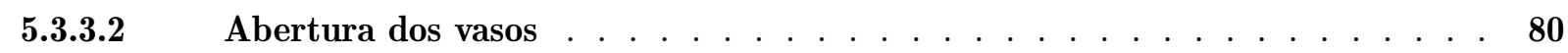

5.3.3.3 Recarga de baterias . . . . . . . . . . . . . . . . 80

5.3.3.4 Reprogramação dos módulos . . . . . . . . . . . . . . . . 80 
5.3.4 Segurança das operações . . . . . . . . . . . . . . . . 81

5.3.4.1 Procedimentos operacionais . . . . . . . . . . . . . . . . . . . . . . . . . . 81

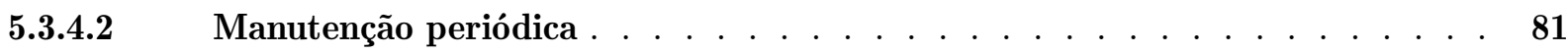

5.3.4.3 Sistemas de localização $\ldots \ldots \ldots$. . . . . . . . . . . . . . . . . . . . 81

5.3.4.3.1 Comunicação a longa distância $\ldots \ldots \ldots \ldots \ldots$. . . . . . . . . . 81

5.3.4.3.2 Localizador Acústico $\ldots \ldots \ldots \ldots$

$6 \quad$ CONSIDERAÇÕES FINAIS . . . . . . . . . . . 83

6.1 Trabalhos Futuros . . . . . . . . . . . . . . . 83

6.1.1 Aumento da capacidade $\ldots \ldots \ldots$

6.1.1.1 Interface Ethernet . . . . . . . . . . . . . . . . . . . 83

6.1.1.2 Atualização dos microcontroladores . . . . . . . . . . . . . . . 83

6.1.1.3 Atualização no sistema de conversão e distribuição de energia $\ldots . . . . . \quad 83$

6.1.1.4 Integrar novas cargas científicas $\ldots \ldots \ldots \ldots$. . . . . . . . 84

6.1.1.5 Alinhamento dos sensores . . . . . . . . . . . . . . . . 84

6.1.1.6 Atuadores dianteiros . . . . . . . . . . . . . . . . . . . . . 84

6.1.1.7 Sistemas de navegação acústica $\ldots \ldots \ldots \ldots \ldots$

6.1.1.8 Novos controladores . . . . . . . . . . . . . . . . . . 84

6.1.2 Aumento da segurança . . . . . . . . . . . . . 85

6.1.2.1 Comunicação acústica . . . . . . . . . . . . . . . . . . 85

6.1.2.2 Manobra de retorno f. . . . . . . . . . . . . . 85

6.1.2.3 Barramento CAN redundante . . . . . . . . . . . . 85

6.1.2.4 Testes de EMI $\ldots \ldots \ldots \ldots \ldots \ldots$

6.1.2.5 Vaso de baterias $\ldots \ldots \ldots \ldots \ldots$

6.1.2.6 Intertravamentos . . . . . . . . . . . . . . . . 86

6.1.2.7 Recuperação de falhas . . . . . . . . . . . . . . . 86

6.1.2.8 Desvio de obstáculos . . . . . . . . . . . . . . . . . . 86

6.1.2.9 Sistema de monitoramento das baterias $\ldots \ldots \ldots \ldots$

6.1.2.10 Estimativa da manobra na interface $\ldots \ldots \ldots \ldots$. . . . . . . . 87

6.1.2.11 Comunicação via satélite $\ldots \ldots \ldots \ldots$. . . . . . . . . 87

6.1.2.12 Lastro de emergência $\ldots \ldots \ldots$. . . . . . . . . . . . . . . 87

6.1.3 Facilitar manutenções . . . . . . . . . . . . . . . . . 87

6.1.3.1 Estrutura tipo rack . . . . . . . . . . . . . . . . . . . 87

6.1.3.2 Fixação da prateleira $\ldots \ldots \ldots \ldots \ldots$

6.1.3.3 Simuladores Hardware-in-the-loop . . . . . . . . . . . . . 88

6.1.3.4 Acesso externo ao barramento principal $\ldots \ldots \ldots$. . . . . . . . . 88

6.2 Experiências de desenvolvimento e manutenção $\ldots . . . . . .88$

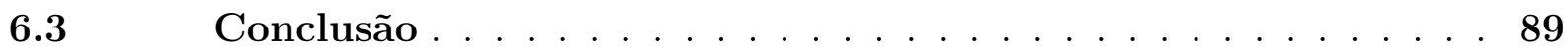

A APÊNDICE $\ldots \ldots \ldots \ldots$ 
A.1 Sugestões para procedimentos operacionais . . . . . . . 90

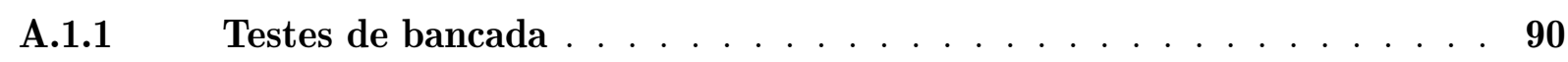

$\underline{\mathbf{A} 1.2}$ Testes em águas confinadas $\ldots \ldots \ldots \ldots$

$\underline{\text { A.1.3 Testes de campo } \ldots \ldots \ldots \ldots \ldots 1}$

A.1.3.1 Transporte ao local de ensaio $\ldots \ldots \ldots \ldots$. . . . . . . 91

$\underline{\text { A.1.3.2 }}$ Montagem e testes do sistema $\ldots \ldots \ldots \ldots \ldots 2$

$\underline{\text { A.1.3.3 Verificações pré-operacionais }} \ldots \ldots \ldots \ldots \ldots \ldots$

A.1.3.4 Acomodação na embarcação $\ldots \ldots \ldots \ldots . \ldots \ldots$

A.1.3.5 Procedimentos de lançamento $\ldots \ldots \ldots \ldots \ldots$

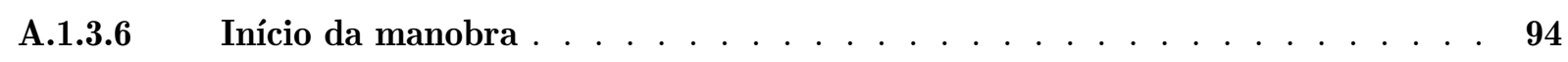

$\underline{\text { A.1.3.7 Localização do veículo } \ldots \ldots \ldots \ldots \ldots \ldots}$

$\underline{\text { REFERÊNCIAS } \ldots \ldots \ldots \ldots \ldots \ldots}$ 


\section{Lista de ilustrações}

Figura 4.1 - AUV Pirajuba durante os ensaios de hidrodinâmica e identificação,

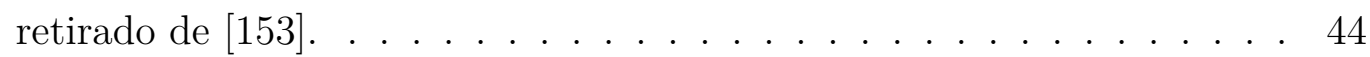

Figura 4.2 - Exemplo de manobra desejada para o estudo em questão, extraída do projeto proposto à FAPESP, processo 13/16669-7. . . . . . . . . . . . 46

Figura 4.3 - Veículo aberto, mostrando o casco do tipo free-flooded, vaso principal e vaso de manobra. . . . . . . . . . . . . . . . . . . 4 47

Figura 4.4 - Pirajuba com módulo de sonar multi-elementos e transdutores do sonar de escaneamento lateral. . . . . . . . . . . . . . . . . . 49 49

Figura 4.5 - Pirajuba com módulo de localização, sensores ópticos e sonda multi-

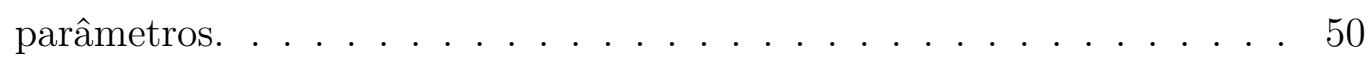

Figura 4.6 - Esquema geral de distribuição e conversão de energia. . . . . . . . . . . . 52

Figura 4.7 - Diagrama simplificado da arquitetura CANARMES, retirado de [11]. $\quad 56$

Figura 4.8 - Módulo de controle montado na caixa e placas que compõe os conjuntos,

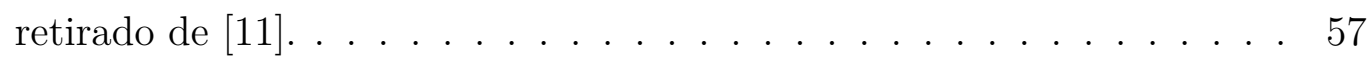

Figura 4.9 - Visão geral com divisão em camadas e módulos do software, adaptado

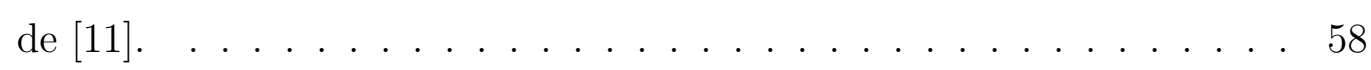

Figura 4.10-Placas desenvolvidas para implementação dos módulos de processamento da arquitetura de controle. . . . . . . . . . . . . . 60 60

Figura 4.11-Divisão em camadas dos módulos implementados em software. . . . . . 63

Figura 4.12-Diagrama da lógica de controle híbrida do sistema. . . . . . . . . . . . 64

Figura 5.13-Posição do veículo estimada pelo sistema de navegação apresentada sobre o mapa da região. . . . . . . . . . . . . . . . . . . . 69

Figura 5.14-Resultado dos algoritmos de navegação por EKF e dead-reckoning através dos dados da AHRS. . . . . . . . . . . . . . . . . . . 70

Figura 5.15-Profundidade, inclinação e ângulo dos profundores durante trecho de controle de pitch. . . . . . . . . . . . . . . . . . . . . . . . 71

Figura 5.16-Profundidade, inclinação e ângulo dos profundores durante trecho de controle de profundidade. . . . . . . . . . . . . . . . 72

Figura 5.17-Rumo obtido da AHRS. . . . . . . . . . . . . . . . . . . . 73

Figura 5.18-Detalhe da variação do rumo e ângulo dos lemes. . . . . . . . . . . . . 74

Figura 5.19-Dados de temperatura e condutividade durante a manobra. . . . . . . . 75

Figura 5.20-Detalhe da variação da profundidade, temperatura e condutividade ao longo do tempo. . . . . . . . . . . . . . . 76

Figura 5.21-Perfil de temperatura ao longo de uma descida. . . . . . . . . . . . 77

Figura 5.22-Comparação da distribuição dos perfis de temperatura da região. $\quad$. . 77 
Figura 5.23-Comparação da distribuição da salinidade em função da temperatura da região. . . . . . . . . . . . . . . . . . 78

Figura 5.24-Dados obtidos pelos sensores ópticos. . . . . . . . . . . . . . . 79 


\section{Lista de tabelas}

Tabela 1 - Tipos de veículos submarinos encontrados. . . . . . . . . . . . . 31

Tabela 2 - Principais tipos de aplicações em oceanografia. . . . . . . . . . . . 32

Tabela 3 - Outras aplicações de AUVs encontradas. . . . . . . . . . . . . . 32

Tabela 4 - Principais sensores de qualidade de água encontrados nos veículos. . . . 33

Tabela 5 - Principais tipos de sonares utilizados. . . . . . . . . . . . 33

Tabela 6 - Limites de profundidade dos veículos estudados. . . . . . . . . . . . . 33

Tabela 7 - Formatos dos veículos. . . . . . . . . . . . . . . . 34

Tabela 8 - Tipos de casco. . . . . . . . . . . . . . 35

Tabela 9 - Dimensões dos veículos submarinos estudados. . . . . . . . . . . . . . 35

Tabela 10 - Mecanismos de movimentação de veículos submarinos. . . . . . . . . . 36

Tabela 11 - Tipos de baterias utilizadas. . . . . . . . . . . . . . . . 37

Tabela 12 - Sensores presentes nos sistemas de navegação dos veículos submarinos. 38

Tabela 13 - Sistemas de comunicação utilizados em veículos submarinos. . . . . . . 39

Tabela 14 - Topologia das arquiteturas de controle. . . . . . . . . . . . . . . 39

Tabela 15 - Principais tipos de módulos de processamento encontrados. . . . . . . 40

Tabela 16 - Principais tipos de rede interna utilizados. . . . . . . . . . . . . . 41

Tabela 17 - Tipos de sistemas operacionais encontrados. . . . . . . . . . . . . . . 42

Tabela 18 - Principais middlewares encontrados. . . . . . . . . . . . . . . . . 42

Tabela 19 - Arquiteturas de controle identificadas. . . . . . . . . . . . . . . 43

Tabela 20 - Principais características do AUV Pirajuba. . . . . . . . . . . . . 47 


\section{Introdução}

O ambiente aquático é de grande importância para o ser humano. Os oceanos cobrem cerca de dois terços da superfície terrestre e continuam sendo pouco explorados devido às dificuldades e riscos que impõem à vida humana, sendo uma área de grande interesse para aplicação de robôs [1]].

Com o avanço da tecnologia, os robôs têm se tornado capazes de desempenhar atividades cada vez mais diversas, reduzindo a exposição humana às situações de risco e permitindo ampliar o conhecimento acerca do ambiente marinho [2] .

A exploração de ambientes marinhos utilizando robôs móveis, embora possua certas facilidades se comparadas a veículos terrestres ou aéreos, como menor incidência de obstáculos e dinâmicas usualmente mais lentas, precisa lidar com outras dificuldades como altas pressões, baixa visibilidade e a grande atenuação de sinais eletromagnéticos no meio aquático, impossibilitando o uso de sistemas como GPS e comunicações de rádio frequência em longas distâncias enquanto submerso.

Assim, o campo da robótica marinha tem se destacado dos demais com soluções próprias, e pesquisadores e instituições dedicadas ao seu desenvolvimento []].

Neste contexto, diferentes tipos de robôs marítimos vêm sendo desenvolvidos ao longo dos anos. Em geral, os robôs marinhos são classificados em veículos de superfície ou submarinos, com suas variantes autônomas e remotamente operadas. No entanto, recentemente, diversas pesquisas têm se direcionado para o desenvolvimento de veículos híbridos, misturando características autônomas e de operação remota[]ㅡ].

O presente trabalho procura tratar mais especificamente dos veículos autônomos submarinos (doravante denominados por AUVs, acrônimo de Autonomous Underwater Vehicles), embora os estudos realizados e o sistema desenvolvido possam ser estendidos para outros tipos de veículos.

\subsection{Principais Aplicações}

As aplicações dos AUVs são bastante variadas, envolvendo áreas diversas como engenharia civil, oceanografia, indústria de petróleo, além de diversas aplicações militares [1], [2].

Os veículos autônomos submarinos podem ser classificados de diferentes formas. Os autores de [4] citam duas possibilidades de classificação: de acordo com sua característica operacional básica, como operação sob gelo, em águas rasas e em águas profundas, ou de acordo com sua fonte de financiamento: ciência, defesa ou indústria.

O financiamento de AUVs para ciência em geral visa atender requisitos de caracterização ambiental, como mapeamento do fundo oceânico, estudo de produtores primários, e mode- 
lagem de fenômenos submarinos de caráter geológico ou geofísico[4]].

As aplicações militares de AUVs por outro lado se caracterizam pelo desenvolvimento de veículos altamente capazes e de grande confiabilidade, frequentemente com custos bastante elevados. Os veículos em geral não têm grandes restrições de tamanho, podendo ser operados de navios, com grande disponibilidade de pessoal.

Existem diversas aplicações de AUVs na área de defesa, como detecção e instalação de minas e sensores, supervisão e monitoramento de portos, detecção de submarinos e missões de inspeção[]ㅡ.

Uma das principais aplicações industriais de AUVs está na indústria de petróleo, com suas missões sendo realizadas em profundidades cada vez maiores, e atividades como seguimento de dutos e cabos para inspeção, mapeamento e levantamento batimétrico [] .

\subsection{Motivação}

Apesar do Brasil possuir uma das principais reservas de água doce do mundo e grandes bacias hidrográficas, um litoral extenso e demandas de exploração submarina provenientes da indústria petrolífera, ainda existem poucos trabalhos dedicados à área de robótica submarina.

Nos últimos anos o Laboratório de Veículos Não Tripulados (LVNT) da Escola Politécnica da USP tem atuado em trabalhos de robótica submarina através do desenvolvimento do AUV Pirajuba e do ROV Mandi, possibilitando estudos em diversas áreas como hidrodinâ-

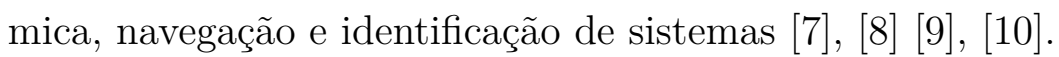

Uma vez tendo uma plataforma básica estabelecida para o AUV Pirajuba proposta em [11], iniciou-se um processo de adaptação do veículo para realização de estudos oceanográficos, através de uma parceria com o LAPS (Laboratory of Planktom Systems), do Instituto Oceanográfico da Universidade de São Paulo.

Uma das aplicações específicas é o auxílio no estudo de detecção e caracterização de camadas finas, tema do projeto "Detecção de camadas finas por veículo autônomo submersível em um ecossistema costeiro - Projeto ECOAUV", financiado pela Fundação de Amparo à Pesquisa do Estado de São Paulo (FAPESP).

Tendo em vista estas novas aplicações, viu-se a necessidade de um estudo para desenvolvimento de uma série de modificações no sistema embarcado, permitindo a realização de manobras mais complexas em ambientes de mar aberto e transporte de novos equipamentos como sonares e sensores para medição de parâmetros da água, como condutividade e temperatura.

Apoiado, inicialmente, nessa necessidade específica, este trabalho propõe a análise do desenvolvimento de AUVs voltados à realização de missões oceanográficas. 


\subsection{Objetivos}

\subsubsection{Objetivo geral}

O objetivo geral deste trabalho é estudar diversos requisitos relacionados às aplicações oceanográficas de AUVs e seus impactos no desenvolvimento dos sistemas embarcados e na arquitetura de controle destes veículos

\subsubsection{Objetivos específicos}

Os objetivos específicos são:

- Analisar os requisitos da aplicação de AUVs em estudos oceanográficos, sob o ponto de vista do desenvolvimento de seus sistemas, da arquitetura de controle e dos principais componentes do sistema embarcado.

- Analisar o desempenho da arquitetura de controle proposta para o AUV Pirajuba na aplicação do veículo para realização de missões oceanográficas.

- Propor diretrizes para o desenvolvimento dos sistemas embarcados desta classe específica de AUVs.

- Propor recomendações para procedimentos operacionais na realização de missões.

\subsection{Organização do trabalho}

No capítulo dois é feito um estudo de requisitos provenientes das aplicações oceanográficas e suas implicações sobre os diversos sistemas que compõe um AUV.

O capítulo três apresenta uma revisão do estado da arte no desenvolvimento de veículos autônomos submarinos, analisando uma série de artigos publicados e diversos aspectos de seu desenvolvimento.

O capítulo quatro apresenta então um estudo de caso da aplicação do AUV Pirajuba para realização de missões oceanográficas, combinando os resultados dos capítulos anteriores. Neste capítulo é apresentada também a arquitetura de controle CANARMES, desenvolvida para aplicação no AUV Pirajuba, identificando os principais requisitos que foram levados em conta para seu desenvolvimento e uma visão geral da estrutura de hardware e software do sistema desenvolvido, bem como as modificações que foram realizadas ao longo do estudo.

O capítulo cinco apresenta os resultados obtidos com o veículo após a realização de ensaios no mar e uma série de considerações a respeito das operações, que devem servir como base para o estabelecimento de procedimentos operacionais. 
Finalmente, o capítulo seis apresenta as sugestões de trabalhos futuros e as conclusões do trabalho.

As figuras apresentadas no trabalho, quando não referenciadas, são de própria autoria. 


\section{Requisitos das aplicações oceanográfi- cas}

Este capítulo trata inicialmente dos impactos e necessidades da aplicação de AUVs em oceanografia, identificando suas vantagens e desvantagens com relação aos outros métodos e comparando uma série de características. É apresentado então um levantamento das principais aplicações de AUVs em oceanografia.

A seguir é feito um estudo de como estas aplicações estão relacionadas aos principais componentes de desenvolvimento dos veículos, envolvendo sistema hidromecânico, energia, navegação, comunicação e na arquitetura de controle.

\subsection{Vantagens da aplicação de AUVs}

Uma das áreas de aplicação de AUVs atualmente é no auxílio de estudos oceanográficos. Uma das limitações atuais para o desenvolvimento da oceanografia é a escassez de dados para validação de estudos [12].

A medição de parâmetros no oceano com gradientes temporais e espaciais de alta resolução permite aprimorar os modelos numéricos e identificar dinâmicas de altas ordens, contribuindo para os estudos de previsibilidade dos fenômenos ambientais [13].

Com o avanço de áreas como eletrônica, computação, materiais e óptica houve grandes evoluções nos sensores utilizados em oceanografia. As plataformas para aquisição de dados, no entanto, foram pouco desenvolvidas ao longo dos últimos anos [13].

Atualmente as principais plataformas utilizadas para coleta de dados em oceanografia são $[14],[13],[15]$ :

- Fundeios

- Boias fixas e de deriva

- Navios, embarcações e submarinos tripulados

- Satélites

- Veículos submarinos operados remotamente (ROVs)

- Gliders e Veículos autônomos submarinos (AUVs)

Fundeios são plataformas fixas, instaladas no fundo oceânico, abrigando sensores, baterias e um sistema de aquisição de dados. Os equipamentos ficam presos a uma boia e ligados a 
um lastro através de um liberador, que pode ser pré-programado ou acionado através de um sinal acústico. Usualmente são lançados de embarcações com sua posição marcada através de GPS e/ou boias, e ficam instalados por longos períodos fazendo amostragem de parâmetros.

Boias fixas são análogas aos fundeios, mas permitem que os equipamentos fiquem na superfície ou à meia água, enquanto boias de deriva acompanham a corrente oceânica transportando consigo os sensores.

Navios, embarcações e submarinos tripulados usualmente são utilizados na forma de missões de oportunidade, ou seja, aproveitando uma viagem que já seria realizada para fazer os estudos em seu trajeto.

Satélites são uma importante fonte de informação para estudos oceanográficos, fornecendo, por exemplo, dados visuais das correntes marítimas.

Veículos submarinos operados remotamente são robôs submarinos que são ligados à superfície através de um cabo umbilical e operados por um piloto. Possuem uma ou mais câmeras e neles pode ser instalado uma variedade de sensores e atuadores.

Gliders são veículos submarinos que se caracterizam por possuir uma movimentação quase vertical, realizada através de sistemas de propulsão baseados na variação de flutuabilidade, com baixo consumo de energia. Estes veículos podem ter autonomias muito elevadas, realizando missões com duração de anos [16].

Veículos autônomos submarinos são robôs submarinos que operam através de missões pré-programadas, sem necessidade de um piloto. Estes veículos não possuem umbilical e carregam todos os equipamentos necessários para realização da missão, incluindo sua fonte energética. Podem carregar diferentes tipos de sensores e possuem autonomia limitada.

O uso de AUVs como plataformas de coletas de dados possui diversas vantagens, pois são plataformas mais estáveis do que ROVs ou instrumentos de arraste devido à ausência de um cabo umbilical, permitindo a obtenção de imagens de câmeras e sonares com maior qualidade.

O uso de veículos móveis permite a aplicação do conceito de "Oceanografia Tática", no qual a coleta de dados é adaptada ao fenômeno em tempo real permitindo, por exemplo, que o veículo mude sua trajetória seguindo um determinado parâmetro [12].

Devido à operação autônoma, é possível utilizar os AUVs para coleta de dados durante situações de perigo como tempestades. Além disso, AUVs podem operar em águas rasas e profundas, com movimentação tridimensional [17] [1] []․

Os AUVs vêm no sentido de completar as outras técnicas, possuindo capacidades distintas. ROVs, por exemplo, possuem maior capacidade de manipulação e visualização em tempo real, enquanto boias e fundeios permitem monitoramentos contínuos de maior prazo [18]. 


\subsubsection{Avaliação das plataformas}

Uma forma de avaliar o desempenho das plataformas é a análise do valor dos dados coletados em relação ao custo de coleta. Para definir o valor dos dados é necessário levar em conta sua importância, sua quantidade e a sua qualidade, determinada por fatores como exatidão, duração, distribuição espacial e temporal [12].

\subsubsection{Qualidade dos dados}

AUVs possuem a vantagem de não terem sua dinâmica influenciada pelos fenômenos das ondas, como em boias, navios e ROVs, permitindo aumentar a qualidade dos dados gerados por sonares e câmeras. Por outro lado, podem reduzir a exatidão das informações de localização do dado devido às dificuldades de navegação no meio submarino, sem a disponibilidade de sinais para preciso controle do posicionamento, como o GPS.

\subsubsection{Intervalo de aquisição dos dados}

Comparativamente às suas alternativas, AUVs possuem as maiores limitações de duração da coleta de dados, devido às limitações tecnológicas dos sistemas de armazenamento de energia. Com o avanço na tecnologia de baterias, bem como redução do consumo dos AUVs, essa desvantagem tende a ser reduzida.

ROVs em geral possuem duração limitada apenas pelo operador. O uso de operadores trabalhando em turnos pode superar essa limitação, tornando viáveis operações de longas durações. Boias e fundeios também dependem de fontes de energia elétrica como baterias. No caso de fundeios há poucas limitações com relação ao volume ocupado por baterias. Já boias podem contar com sistemas de recarga através de energia solar, viabilizando operações mais longas.

\subsubsection{Distribuição espacial e temporal}

A distribuição espacial dos dados coletados por AUVs é uma de suas principais vantagens. ROVs possuem grande capacidade de obtenção de dados com boa distribuição espacial, limitadas em geral pelo comprimento do seu cabo umbilical.

A operação em navios geralmente é feita de duas formas: perfilamentos e arrastes. A distribuição espacial dos perfilamentos é boa na vertical, mas não na horizontal. A técnica de arraste permite maior distribuição espacial, tendo implicações, no entanto, na acurácia dos dados. Boias e fundeios são plataformas fixas, com distribuição espacial limitada à uma coluna.

A distribuição temporal dos dados obtidos em geral é função da frequência de amostragem dos sensores ou dos sistemas de armazenamento de dados utilizados. 


\subsubsection{Custos}

O custo de utilização de um AUV envolve um valor elevado de aquisição do veículo, que é compensado pela redução nos seus custos de operação.

O custo de operação de ROVs é geralmente bastante elevado, envolvendo tanto o custo do veículo como o de operação com uma embarcação.

Fundeios tem custo muito baixo para a plataforma, exigindo embarcações, esporadicamente, para instalação e manutenção.

Boias possuem custos razoavelmente baixos, porém estão sujeitas a furtos, implicando na perda de dados e equipamentos.

\subsubsection{Principais aplicações de AUVs em oceanografia}

As principais aplicações dos AUVs em estudos oceanográficos estão relacionadas a atividades de mapeamento ou caracterização de parâmetros da água. Dentro destas categorias podemos citar uma série de missões que podem ser realizadas, independentemente ou de forma conjunta: [ $[\underline{5}]$

- Mapeamento do fundo oceânico;

Imageamento acústico;

Imageamento óptico;

Levantamento de perfis do fundo oceânico (Sub-bottom profiling);

- Caracterização da coluna d'água;

Levantamento de parâmetros numa região;

Localização da origem de um fenômeno;

Para realização das missões acima podem ser utilizados diversos sensores e equipamentos, considerados como cargas científicas sob o ponto de vista do AUV. Alguns comumente utilizados são:

- ADCPs (Acoustic Doppler Current Profilers), que fornecem medidas de perfis de velocidade da coluna d'água ;

- Câmeras;

- Sensores de Condutividade, temperatura e profundidade (CTDs);

- Sensores de Oxigênio dissolvido; 
- Sonares de varredura lateral e batimetria;

- Sub-bottom profilers;

- Sensores ópticos de pH, retro espalhamento e clorofila, fluorímetros, contadores de plâncton, medidores de gás carbônico dissolvido, bioluminescência [12];

- Magnetômetros.

Os equipamentos de carga científica têm implicações em diversas áreas, como navegação e controle, instrumentação, dimensões, energia, interfaces e armazenamento de dados.

\subsection{Impactos dos requisitos no desenvolvimento de AUVs}

Conforme pode ser observado, existe um grande número de estudos diferentes que podem ser feitos utilizando AUVs como plataforma, implicando numa grande quantidade de missões e manobras distintas.

Uma característica que varia conforme o estudo realizado é a natureza da manobra necessária. Muitas missões são realizadas com controle de profundidade em manobras conhecidas como corte de relva, composta por segmentos de reta paralelos, como pode ser visto na Figura $\underline{4.2}$, como no mapeamento do leito submarino.

Outras missões podem necessitar de manobras realizadas a uma distância constante do fundo, como estudos de flora [12], ou até mesmo manobras com deslocamento vertical, como detecção de camadas finas [19], [20].

Além da natureza da manobra, tais estudos têm requisitos distintos com relação aos sensores utilizados, autonomia e alcance desejados, frequência de realização das missões, profundidade máxima de operação, velocidade de deslocamento e outros.

Há ainda funcionalidades especiais, tais como veículos capazes de hibernar, desviar de obstáculos, adaptar a manobra de acordo com os dados coletados, seguir gradientes e outros [13].

Os autores de [18] apresentam um exemplo de otimização da velocidade em função do alcance da missão. Neste caso a velocidade decorre do casamento entre a potência gasta com a propulsão e a potência gasta com a carga cinetífica (payload).

Outro exemplo apresenta a otimização da velocidade para maximizar a quantidade de dados úteis obtidos por um sonar, feita através de uma análise de um modelo de entropia dos dados do sonar.

Tais características variam de acordo com o estudo a ser realizado, com requisitos, por vezes, contraditórios. De forma geral, para atender as necessidades da aplicação em oceanografia, desejam-se veículos pequenos, baratos, e com grande eficiência energética[12], [13]. 


\subsubsection{Implicações no sistema hidromecânico}

De forma geral, os AUVs de aplicação oceanográficas devem ser pequenos e leves. O desejo por AUVs de pequeno porte é justificado por uma série de motivos: veículos pequenos podem ser construídos com técnicas mais baratas e podem reduzir os custos de infraestrutura e de operação, podendo ser lançados de barcos e lanchas.

Seu transporte é mais fácil, possuem alta manobrabilidade, robustez em caso de colisões e têm menor potencial de causar danos nestas ocorrências. Além disso, a redução nas dimensões permite reduzir o arrasto do veículo, aumentando assim sua eficiência energética [17], [18], [12], [13].

O formato mais comum dos AUVs de uso geral atualmente é o tipo torpedo. O formato de torpedo procura reduzir o arrasto hidrodinâmico, com movimentação através de superfícies de controle [21], [18].

Existem diversas exceções a esse formato, como formas mais achatadas, quadradas ou mesmo dois ou três torpedos conectados, que possuem vantagens específicas para determinadas missões.

Em [13] estabelece-se uma referência de dimensões para os veículos. Estipula-se que os AUVs devem ter entre 1 e 3 metros de comprimento, com diâmetro de aproximadamente 0.2 a 0.8 metros.

Essa estimativa se baseia no fato de que veículos menores que isso são pouco flexíveis para desempenhar as diversas aplicações necessárias, e veículos muito grandes terão o custo de fabricação, transporte e operação muito elevados.

Uma decisão importante relacionada ao projeto hidromecânico é a adoção de uma configuração do tipo estanque ou inundada, conhecida como free-flooded.

A configuração inundada é caracterizada por utilizar vasos de pressão abrigados por um casco hidrodinâmico que opera alagado, sem a necessidade de ser resistente à pressão.

Na outra configuração, estanque, os vasos de pressão são utilizados como casco hidrodinâmico, sem partes alagadas. Veículos estanques frequentemente possuem algumas partes alagadas, como a popa e a proa.

Visando a aplicação oceanográfica, a configuração free-flooded permite uma maior flexibilidade para desenvolvimento de novos módulos e integração de diferentes equipamentos. Além disso, quando o equipamento que será instalado já é resistente à pressão, muito comum nos sensores oceanográficos, o custo de desenvolvimento de uma nova seção para o veículo é bastante reduzido.

A independência dos formatos do casco e dos vasos de pressão facilita o desenvolvimento de cascos com formas mais hidrodinâmicas e de vasos de pressão com tampas retas, facilitando a instalação de conectores marinizados.

A configuração estanque por sua vez viabiliza o desenvolvimento de veículos mais compactos e é bastante utilizada em veículos comerciais, já consolidados. Outra vantagem está relacionada à maior previsibilidade da sua flutuabilidade, facilitando o processo de 
regulagem dos lastros do veículo. No entanto, é preciso um esforço maior para integração de novos equipamentos e o desenvolvimento de novos módulos, já que é preciso desenvolver novas seções com resistência à pressão e mecanismos de vedação.

\subsubsection{Profundidade}

A profundidade de operação é uma das principais características de missão, influenciando diversas características do projeto de AUVs, principalmente sobre as dimensões do veículo, que precisa ter estrutura mecânica forte o bastante para suportar às pressões impostas pela coluna d'água. Diversos estudos oceanográficos são realizados em regiões costeiras, que possuem grande biodiversidade[22],[23] [24]. Grande parte dos estudos oceanográficos são realizados na plataforma continental, que representa uma região próxima à costa. No Brasil, a maior parte da plataforma está em profundidades de até 200 metros.

\subsubsection{Implicações no sistema de energia}

A eficiência energética é um parâmetro importante dos AUVs pois estes veículos devem carregar suas próprias fontes de energia. O aumento da eficiência energética do veículo é responsável por aumentar a sua autonomia e a área de cobertura das missões, entretanto, a propulsão do veículo consome boa parte da energia necessária para seu funcionamento. Para minimizar o consumo de energia, procura-se aumentar a eficiência de hélices, minimizar as perdas por friç̧ão na transmissão e nos sistemas de vedação, aumentar a eficiência dos motores e de seus sistemas de acionamento. Uma área de pesquisa atual procura desenvolver veículos e sistemas de propulsão biomiméticos, como os inspirados na propulsão de peixes, que podem ter elevada eficiência [25] $[\underline{14}]$.

$\mathrm{Na}$ área de energia identificam-se algumas características desejadas para os sistemas de armazenamento de energia [13]:

- Alta densidade de energia, representada em W.h/kg;

- Alta densidade de potência, representada por $\mathrm{W} / \mathrm{kg}$;

- Comportamento de recarga conhecido;

- Modos de falha não catastróficos;

- Capacidade de operação em baixas temperaturas.

A frequência de uso tem grande influência no sistema de energia. Usualmente os estudos são feitos em missões únicas, embora existam casos em que é necessária uma operação diária. Para isso, é necessário levar em conta também a robustez e o tempo de recarga das baterias utilizadas. 


\subsubsection{Implicações no sistema de navegação}

Existem diversas técnicas empregadas atualmente para solucionar o problema de navegação de veículos submarinos, sendo este um tema de pesquisa constante.

Podem-se classificar os sistemas de navegação como sistemas com auxílio externo, como os sistemas acústicos, e sistemas internos ao veículo, como navegação inercial [13], [12].

Os sistemas de posicionamento acústicos têm a vantagem de permitir obtenção de maior precisão no posicionamento do veículo, sem a degradação do conhecimento ao longo do tempo. Para isso eles utilizam alguma referência de posicionamento conhecido. As abordagens utilizadas são classificadas de acordo com o posicionamento destas referências. As três principais abordagens são: Long Baseline, Short Baseline e Ultra Short Baseline.

Sistemas Long Baseline utilizam transdutores instalados no fundo do mar, em posições conhecidas, que emitem sinais captados pelos veículos.

Sistemas Short Baseline são instalados nos cascos dos navios, cuja posição é determinada a partir de sistemas de GPS e DGPS.

Os sistemas Ultra Short Baseline possuem três transdutores muito próximos, posicionados no navio, que calculam, por triangulação, a posição de um transmissor instalado no veículo, e funcionam em conjunto com um sistema de comunicação acústica para transmitir essa posição ao mesmo.

Uma característica marcante dos sistemas de navegação internos é a degradação da sua informação ao longo do tempo. As técnicas de navegação utilizadas atualmente envolvem fundamentalmente a integração de grandezas de movimentação medidas, como velocidades lineares e angulares e acelerações lineares. Os principais sensores utilizados para navegação são acelerômetros, giroscópios, magnetômetros, sensores de velocidade de efeito doppler, também chamados de DVLs (Doppler Velocity Loggers) e profundímetros.

Usualmente, veículos submarinos possuem unidades de medição inercial, que são compostas por três acelerômetros e três giroscópios. Podem possuir também equipamentos conhecidos como AHRS (Advanced Heading Reference Systems), que combinam estes sensores com magnetômetros através de algoritmos de fusão de sinais para determinar uma estimativa da atitude, e DVLs, que fazem medição da velocidade do veículo em relação ao leito ou em relação à água.

Diversas aplicações oceanográficas são realizadas em águas rasas. Como o gasto de energia do veículo para emergir à superfície e submergir novamente não é elevado como em águas profundas, podem-se combinar algoritmos de navegação embarcados com um sistema de GPS, que realiza correções quando o veículo sobe à superfície.

A determinação do intervalo de tempo entre as correções necessárias é função do desempenho do algoritmo, dos sensores, e da exatidão necessária para o estudo realizado.

Os requisitos de posicionamento podem ser bastante diferentes em função da missão realizada. Estudos de mapeamento submarino utilizando sonares de varredura lateral requerem alta precisão de posicionamento, além de medidas de deslocamentos de alta 
frequência do veículo para aprimoramento das suas leituras. Além disso, impõem requisitos de controle como limites para ângulos de rolagem e inclinação [17].

\subsubsection{Requisitos do sistema de comunicação}

A comunicação com os AUVs pode ser feita quando ele se encontra na superfície ou submerso, através de tecnologias diferentes.

Quando submerso, devido à dificuldade de propagação das ondas eletromagnéticas na água, emprega-se o uso de comunicações acústicas.

As tecnologias atuais de comunicação acústica caracterizam-se por alcances de alguns quilômetros, com taxas de transferência baixas, que caem conforme aumenta o alcance necessário [13], [12].

$\mathrm{Na}$ superfície, é frequente o uso de duas abordagens diferentes utilizando ondas eletromagnéticas: tecnologias de longo alcance, como GPRS e Iridium, utilizadas para transferência de pequenas quantidades de dados e principalmente comandos, e tecnologias de baixo alcance, como Wi-Fi, para transferência de maiores quantidades de dados. Algumas tecnologias como comunicações de rádio nas frequências de $900 \mathrm{MHz}$ são soluções intermediárias, tanto em alcance quanto em taxas de transferência.

Os requisitos de comunicação impostos pela oceanografia em geral estão relacionados à descarga dos dados coletados. Alguns estudos geram grandes volumes de dados, necessitando de unidades de armazenamento de alta capacidade e de taxa de transferência elevada, influenciando na construção dos veículos, que podem ter vasos de pressão dedicados exclusivamente a dispositivos de armazenamento de dados, permitindo uma transferência rápida $[\underline{26}]$.

\subsubsection{Implicações na arquitetura de controle}

Por arquitetura de controle entende-se todo o sistema embarcado e algoritmos utilizados para controle e gerenciamento das missões. O estudo foi feito considerando uma arquitetura de hardware e uma arquitetura de software.

\subsubsection{Implicações na arquitetura de hardware}

As interfaces de comunicação mais comumente utilizadas para os sensores são: Ethernet, RS-232, RS-422, RS-485 e interfaces analógicas. O tipo de interface influência diretamente na arquitetura de hardware, como seleção dos módulos de processamento e estrutura de hardware.

Os sistemas embarcados beneficiam-se da utilização de um sistema distribuído e barramentos únicos. O uso de um barramento único de comunicação permite uma colaboração entre o veículo e sua carga científica, já que, por um lado, o veículo pode utilizar dados 
fornecidos pela carga científica para melhorar seu desempenho como, por exemplo, a utilização da medida de temperatura da água para aprimorar a medição de profundidade, ou a utilização de medidas de velocidade do som na água para aumentar o desempenho dos sistemas de navegação. Por outro lado, a carga científica também pode se beneficiar do acesso aos dados do veículo. Frequentemente os veículos submarinos possuem unidades de medição inercial de alto desempenho, utilizadas para navegação, que podem fornecer dados de movimentação úteis para sensores como sonares melhorarem a qualidade de suas imagens.

\subsubsection{Implicações na arquitetura de software}

Podem-se identificar implicações na arquitetura de software provenientes da necessidade de flexibilidade e modularidade, devido à grande diversidade de missões e equipamentos utilizados.

A modularidade pode ser obtida no software através da adoção de arquiteturas com divisão em camadas e separação dos códigos em módulos. Assim, facilita-se o desenvolvimento de funcionalidades, interface com novos equipamentos, e atualização dos sistemas embarcados. Outra necessidade por parte da oceanografia é a de veículos capazes de realizar missões complexas e com objetivos abstratos [13]. Para isso, uma solução é a adoção de arquiteturas de controle híbridas, capazes de combinar objetivos de longo prazo com necessidades de curto prazo.

Diversas capacidades relacionadas à inteligência, com implicações na área de software podem ser identificadas, tais como as mostradas em [13]: Rendez-vous e docking, seguimento de gradientes, desvio de obstáculos, amostragem adaptativa, seguimento do relevo, detecção e recuperação de falhas.

\subsubsection{A aplicação da Modularidade}

Uma das formas de se aumentar a capacidade dos veículos é através do conceito de modularidade. A modularidade pode ser aplicada em diversas áreas, como na estrutura mecânica, sistemas de hardware e funcionalidades de software.

Embora seja impraticável desenvolver um veículo contendo todos os equipamentos e funcionalidades, através da modularidade é possível desenvolver uma plataforma básica que pode ser adaptada em função das necessidades de cada missão. Este conceito fornece uma solução para uma necessidade marcante dos estudos oceanográficos, que é a grande diversidade de sensores e equipamentos utilizados, bem como a variedade de tipos de manobras realizadas.

Outra vantagem de utilizar uma arquitetura modular está na possibilidade de desenvolvimento de módulos distribuídos por diferentes pessoas, cada uma com suas habilidades, necessidades e aplicações, que se comunicam através de interfaces padronizadas.

Outro argumento em favor da modularidade pode ser encontrado em [17], que apresenta 
um estudo da determinação do número ótimo entre AUVs utilizados e número de cargas pagas que cada um carrega. Através de uma comparação entre o custo do AUV e o custo dos cargas pagas, chega-se a conclusão de ser benéfico utilizar alguns AUVs com grande quantidade de instrumentos. 


\section{Estado da arte do desenvolvimento de AUVs}

Este capítulo procura identificar o estado da arte e os principais avanços e tendências no desenvolvimento de AUVs através do estudo de trabalhos publicados entre os anos de 2010 e 2017. Este período foi selecionado com o objetivo de dar continuidade ao estudo realizado em [11], que estuda aspectos da arquitetura de controle de uma série de trabalhos desenvolvidos até 2010.

Nestes últimos anos, é possível verificar uma grande quantidade de veículos submarinos desenvolvidos com diversas finalidades. Entre os artigos estudados, foi possível identificar o desenvolvimento ou aplicação de aproximadamente 90 diferentes veículos.

Além de trabalhos sobre AUVs tradicionais, foi possível notar algumas outras tendências, como o desenvolvimento de gliders, veículos biomiméticos e três diferentes tipos de veículos híbridos: entre ROV e AUV, entre ASV e AUV e entre glider e AUV.

A Tabela $\underline{1}$ apresenta esses artigos:

Tabela 1 - Tipos de veículos submarinos encontrados.

\begin{aligned} & \hline Tipo Referências \\ & \hline Biomiméticos ${[\underline{21}],[\underline{27}],[\underline{28}],[\underline{29}],[\underline{30}],[\underline{25}] } \\ &$ Gliders ${[\underline{31}],[\underline{32}],[\underline{23}],[\underline{33}],[\underline{34}],[\underline{35}],[\underline{36}],[\underline{16}],[\underline{37}],[\underline{38}] } \\ &$ Híbrido ROV-AUV ${[\underline{39}],[\underline{40}],[\underline{41}],[\underline{42}],[\underline{43}],[\underline{44}],[\underline{45}],[\underline{46}] } \\ &$ Híbrido ASV-AUV ${[\underline{38}],[\underline{47}] } \\ &$ Híbrido Glider-AUV ${[\underline{31}] } \\ &$\hline\end{aligned}

\subsection{Principais Aplicações}

Analisando as publicações foi possível verificar que a maior parte está relacionada a estudos oceanográficos, com diferentes tipos de missões. A Tabela $\underline{2}$ apresenta as principais aplicações encontradas em oceanografia. Outras aplicações de AUVs que foram encontradas são apresentadas na Tabela $\underline{3}$. Alguns trabalhos tratam também do desenvolvimento de veículos para ambientes específicos, como operação sob geleiras [느, 41] e operações em altas profundidades $[\underline{40}, \underline{39}, \underline{42}, \underline{54}, \underline{88}, \underline{89}, \underline{90}, \underline{91}, \underline{92}, \underline{49}, \underline{61}, \underline{93}]$.

\subsubsection{Cargas científicas}

Foi feito um levantamento das principais cargas científicas utilizadas nos veículos e nota-se que, em geral, elas podem ser agrupadas em três grandes grupos: Câmeras, sonares e 
Tabela 2 - Principais tipos de aplicações em oceanografia.

\begin{aligned} & \hline Tipos de missões Referências \\ & \hline Detecção de fenômenos ${[\underline{48}] } \\ &$ Exploração e mapeamento ${[\underline{49}],[\underline{50}],[\underline{26}],[\underline{51}],[\underline{52}],[\underline{53}],[\underline{54}],[\underline{55}],[\underline{56}],[\underline{57}],[\underline{58}] } \\ &$ Monitoramento ambiental ${[\underline{49}],[\underline{59}],[\underline{60}],[\underline{61}],[\underline{28}],[\underline{62}],[\underline{58}],[\underline{38}] } \\ &$ Estudos de planktons ${[\underline{63}],[\underline{19}],[\underline{20}],[\underline{64}],[\underline{48}],[\underline{\underline{15}}],[\underline{65}],[\underline{66}],[\underline{1}],[\underline{67}],[\underline{2}],[\underline{20}] } \\ &$ Análise de qualidade de água ${[\underline{48}],[\underline{15}],[\underline{51}],[\underline{68}],[\underline{36}],[\underline{69}],[\underline{60}],[\underline{54}],[\underline{55}],[\underline{28}],[\underline{56}] } \\ &$ Coleta de amostras de água ${[\underline{15}],[\underline{69}],[\underline{70}],[\underline{19}],[\underline{20}] } \\ &$\hline\end{aligned}

Tabela 3 - Outras aplicações de AUVs encontradas.

\begin{aligned} & \hline Aplicação Referências \\ & \hline Estudos para arqueologia ${[\underline{71}],[\underline{30}],[\underline{72}] } \\ &$ Inspeção visual de estruturas ${[\underline{73}],[\underline{43}],[\underline{74}],[\underline{75}],[\underline{76}] } \\ &$ Veículos de intervenção ${[\underline{77}],[\underline{78}],[\underline{79}],[\underline{80}],[\underline{46}] } \\ &$ Veículos para competições ${[\underline{81}] } \\ &$ Plataformas de desenvolvimento ${[\underline{82}],[\underline{83}],[\underline{84}],[\underline{85}],[\underline{86}],[\underline{35}] } \\ &$ Assistência à mergulhadores ${[\underline{87}] } \\ &$\hline\end{aligned}

sensores de parâmetros da água.

Os sensores mais comumente utilizados em AUVs são do tipo CTDs, para medição de temperatura e condutividade da água em função da profundidade. Este tipo de sensor é bastante utilizado em estudos oceanográficos tradicionais, embora tenham sido identificados também outros parâmetros medidos como Clorofila, Oxigênio Dissolvido (O.D.), CO2 e CDOM (Colored dissolved organic matter), conforme apresentados na Tabela 4 .

Conforme pode ser visto na Tabela $\underline{5}$, os principais tipos de sonares utilizados são sidescans, sonares de batimetria, multi-feixe e sub-bottom profilers.

Sidescans são sonares que utilizam dois transdutores, instalados em cada lado do veículo, os quais produzem imagens do leito oceânico, cobrindo grandes áreas. Sonares multi-feixe em geral são instalados na proa do veículo, sendo utilizados para funcionalidades de desvio de obstáculos. Sonares de batimetria também são sonares multi-feixe, mas utilizados para levantamento do relevo do leito oceânico. Os sub-bottom profilers são utilizados para caracterizar as camadas de sedimentos que compõem o leito.

\subsection{Aspectos hidromecânicos}

\subsubsection{Profundidade de operação}

Pode-se observar que a maior parte dos veículos são desenvolvidos para operação em profundidades de até $1000 \mathrm{~m}$, como é o caso de 21 trabalhos. Nesta faixa, os limites mais comuns são $100 \mathrm{~m}, 200 \mathrm{~m}$ e $500 \mathrm{~m}$. Foram verificados 16 veículos desenvolvidos para 
Tabela 4 - Principais sensores de qualidade de água encontrados nos veículos.

\begin{aligned} \hline Sensor & Referências \\ \hline CTD & ${[\underline{84}],[\underline{94}],[\underline{49}],[\underline{95}],[\underline{50}],[\underline{46}],[\underline{96}],[\underline{69}],[\underline{97}],[\underline{31}],[\underline{98}],[\underline{54}],[\underline{55}] \\ & , {[\underline{32}],[\underline{81}],[\underline{89}],[\underline{23}],[\underline{33}],[\underline{99}],[\underline{51}],[\underline{60}],[\underline{93}],[\underline{22}],[\underline{100}],[\underline{39}],[\underline{101}] \\ & , {[\underline{102}],[\underline{70}],[\underline{103}],[\underline{104}],[\underline{58}] } \\$ CDOM & ${[\underline{22}],[\underline{101}],[\underline{24}]][[\underline{56}],[\underline{65}],[\underline{69}],[\underline{81}],[\underline{20}],[\underline{64}],[\underline{99}],[\underline{22}],[\underline{101}],[\underline{24}] \\$, Clorofila & ${[\underline{54}],[\underline{51}],[\underline{105}],[\underline{36}],[\underline{20}] } \\ & {[\underline{106}],[\underline{19}],[\underline{56}],[\underline{2}],[\underline{46}],[\underline{37}] } \\$ CO2 & ${[\underline{93}],[\underline{54}],[\underline{55}],[\underline{51}],[\underline{28}],[\underline{81}],[\underline{48}],[\underline{70}],[\underline{56}],[\underline{37}] } \\$ O.D. & ${[\underline{93}],[\underline{54}],[\underline{36}],[\underline{69}],[\underline{6}}\end{aligned}$

Tabela 5 - Principais tipos de sonares utilizados.

\begin{aligned} \hline Tipo & Referência \\ \hline Sidescan & ${[\underline{26}],[\underline{23}],[\underline{107}],[\underline{102}],[\underline{60}],[\underline{58}],[\underline{108}] } \\$ Batimetria & ${[\underline{93}],[\underline{107}],[\underline{109}],[\underline{79}],[\underline{22}],[\underline{40}],[\underline{24}],[\underline{73}],[\underline{51}],[\underline{105}],[\underline{26}],[\underline{88}],[\underline{85}] \\ & , {[\underline{102}],[\underline{110}],[\underline{111}] } \\$ Multi-feixe & ${[\underline{26}],[\underline{87}],[\underline{49}],[\underline{112}],[\underline{50}],[\underline{100}],[\underline{63}],[\underline{23}],[71],[\underline{58}],[\underline{108}] } \\$ Sub-bottom Profilers & ${[\underline{81}],[\underline{90}],[\underline{94}],[\underline{58}] }\end{aligned}$

aplicações acima de $1000 \mathrm{~m}$, sendo o limite mais comum 3000m de profundidade.

Um dos trabalhos apresenta o desenvolvimento de um veículo para profundidade de $11000 \mathrm{~m}$, capaz de suportar as maiores profundidades encontradas nos oceanos.

A Tabela $\underline{6}$ apresenta a classificação dos artigos com os limites de profundidades estabelecidos.

Tabela 6 - Limites de profundidade dos veículos estudados.

\begin{aligned} & \hline Profundidade \multicolumn{1}{c}{ Referências } \\ & \hline $100 \mathrm{~m} {[\underline{76}],[\underline{86}],[\underline{81}],[\underline{113}],[\underline{22}],[\underline{43}],[\underline{83}],[\underline{59}] } \\ & 200 \mathrm{~m} {[\underline{98}],[\underline{75}], \underline{70}],[\underline{114}],[\underline{74}],[\underline{71}],[\underline{45}] } \\ & 500 \mathrm{~m} {[\underline{107}],[\underline{115}],[\underline{53}],[\underline{110}] } \\ & 1000 \mathrm{~m} {[\underline{49}],[\underline{73}] } \\ & 2000 \mathrm{~m} {[\underline{109}],[\underline{100}] } \\ & 3000 \mathrm{~m} {[\underline{93}],[\underline{91}],[\underline{94}],[\underline{97}],[\underline{55}],[\underline{51}],[\underline{61}],[\underline{54}],[\underline{46}] } \\ & 3500 \mathrm{~m} {[\underline{90}] } \\ & 4000 \mathrm{~m} {[\underline{40}] } \\ & 6000 \mathrm{~m} {[\underline{89}],[\underline{84}] } \\ & 11000 \mathrm{~m} {[\underline{42}] } \\ &$\hline\end{aligned}




\subsubsection{Formato}

O formato mais comum dos veículos observados é o tipo "torpedo", com algumas variações como veículos achatados ou cascos axissimétricos de formato hidrodinâmico. Este formato é predominante por possuir bom desempenho hidrodinâmico, permitindo a otimização do consumo de energia e proporcionando maior autonomia. Além disso, o uso de um corpo cilíndrico proporciona uma maior facilidade construtiva do que os perfis hidrodinâmicos ou achatados, à custa de um menor volume interno para instalação dos componentes.

É possível encontrar também veículos com estrutura de dois torpedos alinhados verticalmente. Estes geralmente usam o casco inferior para abrigar os componentes de maior peso como baterias, e o superior para transportar a carga científica, aumentando assim sua estabilidade de rolagem $[\underline{107}, \underline{100}, \underline{53}, \underline{81}$.

Algumas variações encontradas entre os veículos de múltiplos cascos são o uso de três cascos, como nos artigos [116] e [109, $\underline{73}]$, e um veículo com dois cascos alinhados horizontalmente [75, 74], utilizado para inspeção visual com câmeras estéreo, uma em cada casco.

Alguns veículos possuem outros formatos, como os bio-miméticos, com estrutura em forma de peixes, arraias ou tartarugas. A motivação para usá-los, entre outras, foi a pesquisa acadêmica em propulsão e percepção animal, investigação de alternativas bio-inspiradas para o aumento da eficiência energética na locomoção de AUVs, e pesquisa de novos sensores.

Outro tipo de estrutura encontrada é a de envelope aberto (open-frame), em geral com diversos graus de liberdade, utilizados principalmente para missões de menores deslocamentos, como inspeção e intervenção. Este formato, embora possua menor desempenho hidrodinâmico, pode facilitar a instalação, substituição ou combinação de diferentes cargas científicas.

A Tabela 7 apresenta a classificação dos artigos em função dos formatos dos veículos.

Tabela 7 - Formatos dos veículos.

\begin{tabular}{|c|c|}
\hline Formatos & Referências \\
\hline Torpedo & $\begin{array}{l}{[\underline{82}],[\underline{115}],[\underline{114}],[\underline{47}],[\underline{70}],[\underline{93}],[\underline{117}],[\underline{71}],[\underline{63}],[\underline{110}],} \\
{[\underline{64}],[\underline{68}],[\underline{106}],[\underline{94}],[\underline{118}],[\underline{51}],[\underline{60}],[\underline{61}],[\underline{119}],[\underline{83}],[\underline{85}],}\end{array}$ \\
\hline $\begin{array}{l}\text { Axissimétricos de per- } \\
\text { fil hidrodinâmico }\end{array}$ & {$[\underline{102}],[\underline{89}],[\underline{90}],[\underline{40}],[\underline{39}],[\underline{42}]$} \\
\hline Múltiplos cascos & $\begin{array}{l}{[\underline{107}],[\underline{75}],[\underline{100}],[\underline{53}],[\underline{74}],[\underline{79}],[\underline{81}],[\underline{109}],[\underline{22}],[\underline{73}],[\underline{39}],}\end{array}$ \\
\hline Biomiméticos & {$[\underline{120}],[\underline{28}],[\underline{25}],[\underline{27}],[\underline{21}],[\underline{30}]$} \\
\hline Envelope aberto & {$[76],[77],[87],[81],[113],[43],[121]$} \\
\hline
\end{tabular}




\subsubsection{Tipo de casco}

Podem ser verificados veículos desenvolvidos com cascos do tipo inundado (conhecidos como free-flooded) e veículos com casco estanque, eventualmente com a proa e/ou popa inundados. É possível notar, na Tabela $\underline{8}$, que a solução de casco inundado é mais comum, possivelmente devido à maior facilidade de construção dos vasos de pressão. No entanto, não há uma diferença tão significativa, indicando que há um equilíbrio aproximado entre suas vantagens e desvantagens relativas.

Tabela 8 - Tipos de casco.

\begin{tabular}{|c|c|}
\hline Tipo de casco & Referências \\
\hline Inundados & $\begin{array}{l}{[\underline{26}],[\underline{107}],[\underline{102}],[\underline{86}],[\underline{90}],[\underline{47}],[\underline{70}],[\underline{89}],[\underline{40}],[\underline{100}],[\underline{21}],} \\
{[\underline{91}],[\underline{49}],[\underline{22}],[\underline{63}],[\underline{94}],[\underline{97}],[\underline{42}],[\underline{51}],[\underline{45}],[\underline{54}],[\underline{84}],}\end{array}$ \\
\hline Estanques & 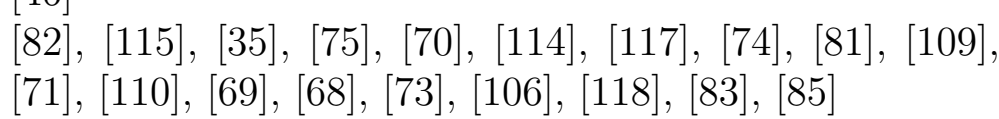 \\
\hline
\end{tabular}

\subsubsection{Dimensões}

Conforme pode ser visto na Tabela $\underline{9}$, a maior parte dos veículos estudados possui dimensões pequenas, ou seja, entre 1 e 3 metros de comprimento e diâmetro de 0,2 a 0,8 metros (como apresentado na Seção 2.2.1). Os veículos desenvolvidos para altas profundidades, em geral, possuem maiores dimensões para poder acomodar os vasos de pressão e equipamentos dimensionados para maiores profundidades.

Tabela 9 - Dimensões dos veículos submarinos estudados.

\begin{tabular}{cc}
\hline Tamanho & Referências \\
\hline Pequenos & {$[\underline{82}],[\underline{76}],[\underline{115}],[\underline{35}],[\underline{75}],[\underline{66}],[\underline{70}],[\underline{114}],[\underline{47}],[\underline{117}]$,} \\
& {$[\underline{100}],[\underline{21}],[\underline{53}],[\underline{74}],[\underline{87}],[\underline{81}],[\underline{71}],[\underline{113}],[\underline{22}],[\underline{30}],[\underline{110}]$,} \\
& {$[\underline{69}],[\underline{68}],[\underline{106}],[\underline{25}],[\underline{118}],[\underline{60}],[\underline{119}],[\underline{121}],[\underline{83}],[\underline{85}]$,} \\
Grandes & {$[\underline{45}],[\underline{59}],[\underline{102}],[\underline{90}],[\underline{89}],[\underline{40}],[\underline{93}],[\underline{109}],[\underline{63}],[\underline{94}],[\underline{97}],[\underline{55}]$,} \\
& {$[\underline{42}],[\underline{51}],[\underline{54}],[\underline{46}]$} \\
\hline
\end{tabular}

\subsubsection{Movimentação}

Para movimentação é possível verificar duas principais soluções: lemes ou propulsores. O uso de um ou mais propulsores fixos na popa e lemes para movimentação lateral e vertical foi observado em 22 trabalhos. A solução de utilizar propulsores para movimentação lateral 
ou vertical ao invés de lemes é bastante utilizada, como pode ser verificado em 32 artigos. O uso de lemes usualmente possui uma maior eficiência energética, maximizando assim a autonomia de operação. Já a opção de utilizar propulsores extras para movimentação lateral ou vertical dá uma maior flexibilidade nas manobras, permitindo que o veículo se movimente nestes graus de liberdade mesmo quando não está se deslocando no sentido longitudinal.

Foram encontradas também algumas outras soluções menos convencionais, como a movimentação do propulsor em um ou dois graus de liberdade ou o uso de lemes fixos, e um sistema interno para variação do centro de gravidade. Gliders em geral movimentam-se através do uso de lemes e da variação de sua flutuabilidade, que pode ser proporcionada por atuadores eletromecânicos ou aproveitando a variação da temperatura na coluna d'água. Veículos biomiméticos costumam utilizar a solução de perfis hidrodinâmicos oscilantes (oscilating fins), semelhante a peixes. Um trabalho apresenta uma solução diferente, com uso de um propulsor cicloidal, também conhecido como Voith-Schneider.

A Tabela 10 apresenta a classificação dos artigos com relação à solução de movimentação utilizada.

Tabela 10 - Mecanismos de movimentação de veículos submarinos.

\begin{aligned} \hline Mecanismo de movimentação & \multicolumn{1}{c}{ Referências } \\ \hline Propulsor e lemes & ${[\underline{98}],[\underline{115}],[\underline{102}],[\underline{70}],[\underline{114}],[\underline{90}],[\underline{117}],[\underline{89}],[\underline{69}],[\underline{63}] \\ & , {[\underline{106}],[\underline{55}],[\underline{94}],[\underline{97}],[\underline{118}],[\underline{51}],[\underline{60}],[\underline{119}],[\underline{83}],[\underline{54}],[\underline{66}] \\$, Múltiplos propulsores & ${[\underline{122}],[\underline{107}],[\underline{76}],[\underline{75}],[\underline{86}],[\underline{44}],[\underline{47}],[\underline{93}],[\underline{40}],[\underline{100}],[\underline{53}] \\ & , {[\underline{74}],[\underline{77}],[\underline{91}],[\underline{87}],[\underline{81}],[\underline{109}],[\underline{71}],[\underline{113}],[\underline{22}],[\underline{49}],[\underline{123}] \\ & , {[\underline{68}],[\underline{73}],[\underline{43}],[\underline{42}],[\underline{61}],[\underline{121}],[\underline{85}],[\underline{45}],[\underline{124}],[\underline{59}] } \\$ Propulsor móvel & ${[\underline{26}],[\underline{82}] } \\$ Variação do CG & ${[\underline{82}] } \\$ Propulsor cicloidal & ${[\underline{21}] }\end{aligned}$

\subsection{Sistemas de energia}

É possível observar que é frequente o uso de baterias de lítio como fontes de energia para os AUVs estudados, principalmente Lítio-Ion (encontrada em 26 trabalhos) e Lítio-Polímero (encontrada em 16 trabalhos).

Conforme apresentado na Seção 2.2.2, a densidade de energia é uma característica importante dos AUVs, permitindo maiores autonomias com menores dimensões e peso, sendo uma motivação para o uso destas tecnologias de baterias. Outros parâmetros que podem orientar a decisão da tecnologia utilizada são o custo, perfil de autonomia, segurança e disponibilidade no mercado. 
Foram encontrados alguns veículos com baterias de Ni-MH (Níquel Metal Hidreto), possivelmente devido ao seu custo reduzido. Um dos veículos utiliza baterias de Ni-MH para desenvolvimento e baterias primárias de lítio para a sua operação [102]. Esta opção é justificada pois este veículo é desenvolvido para operações de longo alcance, e as baterias primárias em geral possuem maiores densidades de energia do que as secundárias, além de terem maior confiabilidade.

Tabela 11 - Tipos de baterias utilizadas.

\begin{aligned} & \hline Tecnologia utilizada \multicolumn{1}{c}{ Referências } \\ & \hline Lítio-Polímero ${[\underline{82}],[\underline{27}],[\underline{114}],[\underline{89}],[\underline{21}],[\underline{81}],[\underline{71}],[\underline{113}],[\underline{95}],[\underline{99}],[\underline{49}] \\ &, {[\underline{43}],[\underline{42}],[\underline{61}],[\underline{84}],[\underline{59}] } \\ &$ Lítio-Ion ${[\underline{19}],[\underline{1}],[\underline{107}],[\underline{102}],[\underline{28}],[\underline{34}],[\underline{75}],[\underline{86}],[\underline{90}],[\underline{93}],[\underline{40}] \\ &, {[\underline{38}],[\underline{74}],[\underline{125}],[\underline{109}],[\underline{22}],[\underline{110}],[\underline{73}],[\underline{31}],[\underline{94}],[\underline{97}],[\underline{55}] \\ &, {[\underline{118}],[\underline{62}],[\underline{45}],[\underline{54}] } \\ &$ Níquel Metal Hidreto ${[\underline{102}],[\underline{34}],[\underline{111}],[\underline{62}] } \\ &$\hline\end{aligned}

\subsection{Sistemas de navegação}

Os sistemas de navegação dos veículos submarinos são compostos por sensores e algoritmos que utilizam seus dados para gerar uma estimativa da atitude e posição.

É possível verificar duas principais soluções com relação aos sensores de rumo: veículos com sensores inerciais e bússolas digitais independentes ou veículos com unidades AHRS (Attitude and Heading Reference System), que já integram os dados dos acelerômetros e giroscópios com os magnetômetros fornecendo uma estimativa da atitude. Foram verificados também 12 veículos utilizando giroscópios de fibra-óptica (FOG, Fiber Optic Gyroscope). A maior parte dos veículos possui também DVLs (Doppler Velocity Loggers) ou ADCPs (Acoustic Doppler Current Profilers) para estimativa de velocidade, conforme verificado em 69 casos. É comum também o uso de GPS para obter a posição do veículo quando este se situa na superfície, verificado em 82 artigos. A Tabela 12 apresenta os principais sensores utilizados para navegação.

Os algoritmos de navegação identificados são baseados em abordagens de dead-reckoning, que podem utilizar diversos tipos de algoritmos, como Filtro de Kalman, Filtro de Kalman Estendido (EKF),Unscented Kalman Filter (UKF), Filtro de Partículas, Integração Pura, etc. Muitos trabalhos não citam o tipo de algoritmo utilizado.

Dos artigos estudados, 10 citam explicitamente o uso de algoritmo do tipo EKF (Extended

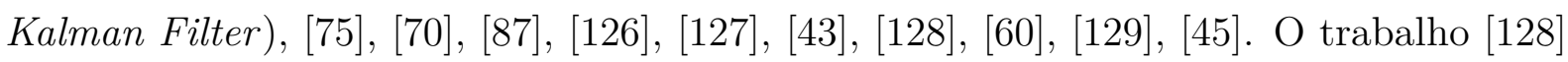
apresenta uma comparação entre o uso dos algoritmos de EKF e UKF. 
Tabela 12 - Sensores presentes nos sistemas de navegação dos veículos submarinos.

\begin{tabular}{|c|c|}
\hline Sensores & Referências \\
\hline $\begin{array}{l}\text { IMU e Magnetômetros } \\
\text { independentes }\end{array}$ & $\begin{array}{l}{[\underline{96}],[130],[\underline{108}],[\underline{34}],[114],[21],[\underline{81}],[\underline{95}],[71],[\underline{69}],} \\
{[104],[127],[124]}\end{array}$ \\
\hline Unidades AHRS & $\begin{array}{l}{[\underline{107}],[\underline{115}],[\underline{75}],[\underline{80}],[\underline{86}],[\underline{23}],[\underline{53}],[\underline{74}],[\underline{79}],[\underline{36}],[\underline{126}],} \\
{[\underline{110}],[\underline{43}],[\underline{85}],[\underline{84}],[\underline{59}]}\end{array}$ \\
\hline $\begin{array}{l}\text { Giroscópios de fibra } \\
\text { óptica }\end{array}$ & $\begin{array}{l}{[\underline{107}],[\underline{76}],[\underline{75}],[\underline{74}],[109],[71],[126],[\underline{68}],[73],[118],}\end{array}$ \\
\hline DVL ou ADCP & 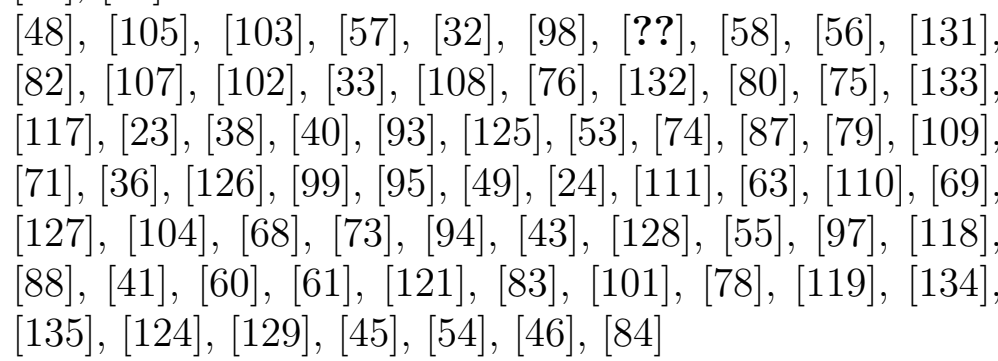 \\
\hline Receptores de GPS & 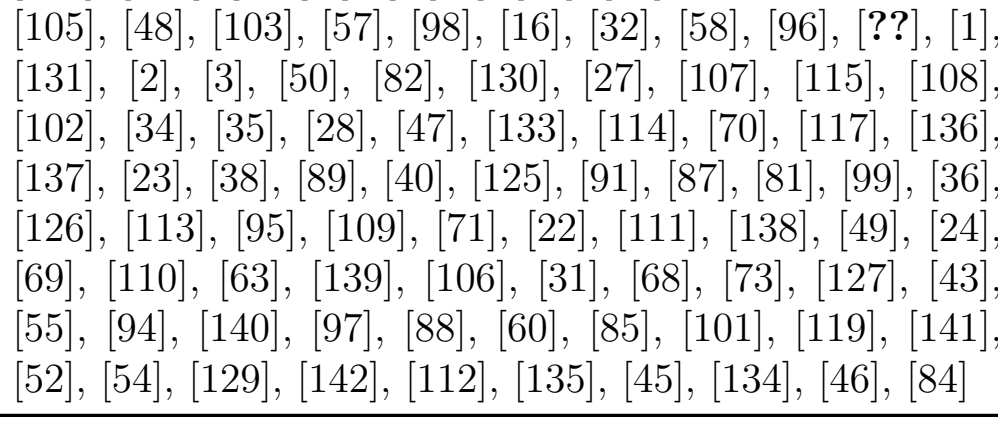 \\
\hline
\end{tabular}

\subsection{Sistemas de comunicação}

Foram observadas diversas soluções para comunicação entre a estação de controle e o veículo quando este se encontra na superfície. A maior parte dos veículos utiliza sistemas de comunicação sem fio, como WiFi, XBee, Rádio UHF e Rádio VHF.

É comum também o uso de sistemas de comunicação acústica e sistemas de comunicação via satélite, como Iridium. A Tabela $\underline{13}$ apresenta a classificação dos artigos com relação às tecnologias de comunicação empregadas:

\subsection{Arquiteturas de controle}

\subsubsection{Aspectos das arquiteturas de hardware}

\subsubsection{Topologia da arquitetura}

Uma característica fundamental das arquiteturas de controle é a sua topologia, podendo ser do tipo centralizada, com um único processador responsável pelo gerenciamento do veículo, ou distribuída, com dois ou mais processadores, cada um responsável por parte do sistema. 
Tabela 13 - Sistemas de comunicação utilizados em veículos submarinos.

$\left.\begin{array}{rl}\hline \text { Tecnologia } & \multicolumn{1}{c}{\text { Referências }} \\ \hline \text { Wi-Fi } & {[\underline{98}],[\underline{96}],[\underline{143}],[\underline{107}],[\underline{102}],[\underline{115}],[\underline{75}],[\underline{23}],[\underline{125}],[\underline{91}],} \\ & {[\underline{87}],[\underline{71}],[\underline{95}],[\underline{99}],[\underline{22}],[\underline{49}],[\underline{30}],[\underline{110}],[\underline{43}],[\underline{25}],[\underline{88}],} \\ & {[\underline{60}],[\underline{11}],[\underline{27}]} \\ \text { Xbee } & {[\underline{47}]} \\ \text { UHF } & {[\underline{47}]} \\ \text { VHF } & {[\underline{142}],[\underline{50}]} \\ \text { Acústica } & {[\underline{144}],[\underline{1}],[\underline{131}],[\underline{50}],[\underline{130}],[\underline{107}],[\underline{115}],[\underline{75}],[\underline{145}],[\underline{23}],} \\ & {[\underline{89}],[\underline{93}],[\underline{125}],[\underline{74}],[\underline{87}],[\underline{126}],[\underline{71}],[\underline{111}],[\underline{49}],[\underline{30}],} \\ & {[\underline{110}],[\underline{63}],[\underline{68}],[\underline{104}],[\underline{39}],[\underline{88}],[\underline{42}],[\underline{60}],[\underline{61}],[\underline{83}],[\underline{59}]} \\ \text { Satélite } & {[\underline{105}],[\underline{48}],[\underline{96}],[\underline{1}],[\underline{3}],[\underline{50}],[\underline{115}],[\underline{102}],[\underline{40}],[\underline{23}],[\underline{38}],} \\ & {[\underline{125}],[\underline{111}],[\underline{49}],[\underline{110}],[\underline{63}]}\end{array}\right]$

Arquiteturas centralizadas possuem algumas facilidades relativas à sincronização dos processos e menor número de componentes de hardware. Já arquiteturas distribuídas requerem um maior esforço de implementação, envolvendo uma estrutura de rede para comunicação entre os módulos e a necessidade de sincronizar suas atividades.

Apesar destas dificuldades, este tipo de topologia facilita a expansão do sistema, possibilitando a adição de novos módulos, sem afetar o sistema já desenvolvido, e sem consumir recursos computacionais limitados.

Dentre os artigos estudados, as arquiteturas de hardware são em sua maioria distribuídas, sendo que 16 utilizam dois processadores e 24 três ou mais.

A adoção de arquiteturas centralizadas também é bastante comum, verificada em 19 trabalhos, e parece ser uma solução mais utilizada em AUVs comerciais, que possuem funcionalidades mais definidas, enquanto nos projetos de pesquisa e desenvolvimento há uma tendência de uso das arquiteturas distribuídas.

Tabela 14 - Topologia das arquiteturas de controle.

\begin{tabular}{|c|c|}
\hline Topologia & Referências \\
\hline Centralizada & $\begin{array}{l}{[31],[47],[118],[28],[124],[\underline{68}],[113],[107],[30],[115],} \\
{[21],[60],[59],[\underline{87}],[\underline{80},[\underline{39}],[\underline{70}],[106],[109]}\end{array}$ \\
\hline Distribuida em 2 módulos & $\begin{array}{l}{[\underline{117}],[\underline{83}],[\underline{138}],[\underline{131}],[\underline{27}],[\underline{116}],[\underline{74}],[\underline{81}],[\underline{130}],[\underline{84}],} \\
{[\underline{138}],[\underline{25}],[\underline{710}],[\underline{75}],[\underline{145}],[\underline{45}],[\underline{43}],[\underline{52}],[\underline{121}],[\underline{88}],[\underline{42}],[\underline{82}],[\underline{49}],[\underline{91}],} \\
{[\underline{86}],[\underline{34}],[\underline{61}],[\underline{102}],[\underline{95}],[\underline{22}],[\underline{54}],[\underline{85}],[\underline{141}],[\underline{55}],[\underline{134}],} \\
{[\underline{69}],[\underline{46}]}\end{array}$ \\
\hline
\end{tabular}




\subsubsection{Módulos de Processamento}

As arquiteturas de hardware podem ser implementadas utilizando diversos tipos de processadores, como FPGAs, microprocessadores, circuitos lógicos customizados e outros.

Circuitos customizados são bastante eficientes e seguros na execução de suas funções, porém, sua expansibilidade e flexibilidade de aplicação são muito pequenas, não sendo vantajosos para as aplicações.

Os sistemas baseados em FPGAs por sua vez possuem enorme flexibilidade, podendo ser reprogramadas para executar diversas funções e com alto desempenho. No entanto, os custos envolvidos para implementação e desenvolvimento ainda são elevados.

Microprocessadores, utilizados na forma de microcontroladores, têm flexibilidade razoável através de mudanças no programa e adição de módulos externos utilizando interfaces de rede. A expansibilidade é favorecida através do uso de microcontroladores, que possuem menor custo que FPGAs, permitindo a adição de novos módulos sem grandes gastos [146]. Podem ser identificadas arquiteturas de hardware utilizando diferentes tipos de módulos de processamento, conforme apresentado na Tabela $\underline{15}$. É possível verificar que a maior parte dos trabalhos utiliza processadores Intel, sendo bastante comum também o uso de microcontroladores de arquiteturas ARM e AVR.

Tabela 15 - Principais tipos de módulos de processamento encontrados.

\begin{tabular}{|c|c|}
\hline Processador & Referências \\
\hline AMD Geode & {$[\underline{116}],[\underline{47}],[\underline{86}]$} \\
\hline Intel Atom & {$[118],[81],[84],[68],[61],[73],[145],[22],[107],[49],[117],[109]$} \\
\hline Intel Core & {$[74],[109],[147],[75],[21]$} \\
\hline AVR & {$[\underline{69}],[\underline{106}],[\underline{81}],[\underline{16}],[\underline{113}],[\underline{95}],[\underline{96}],[\underline{79}],[\underline{45}],[\underline{34}],[\underline{25}]$} \\
\hline $\begin{array}{r}\mathrm{ARM} \\
\mathrm{PIC}\end{array}$ & {$[\underline{95}],[\underline{34}],[\underline{25}],[\underline{30}],[\underline{54}],[\underline{61}],[\underline{102}],[\underline{59}],[\underline{110}],[\underline{49}],[\underline{91}],[\underline{130}],[\underline{148}]$} \\
\hline DSP & {$[52],[121],[82],[130],[16]$} \\
\hline FPGA & [70], [124] \\
\hline Outros & {$[\underline{31}],[45],[\underline{62}],[\underline{141}],[\underline{27}]$} \\
\hline
\end{tabular}

\subsubsection{Rede interna}

Existem diferentes tipos de redes internas utilizadas para comunicação entre os módulos de controle, sendo as mais comuns Ethernet e CAN. Existem ocorrências de uso de comunicação RS-232, principalmente quando o sistema é distribuído em 2 módulos. A Tabela 16 apresenta os principais protocolos encontrados.

Ethernet é um dos protocolos de rede mais comuns, sendo utilizados em diversos tipos de aplicações. Tem capacidade de transmissão de uma grande quantidade de dados e mecanismos para lidar com conflitos bastante eficientes. 
O protocolo Ethernet, em sua implementação tradicional, trata-se de um protocolo não determinístico, ou seja, sem garantia de entrega de mensagens. Algumas variações atuais visam solucionar este problema, como no caso do protocolo EtherCat.

Uma desvantagem está ligada ao seu protocolo físico mais comum, utilizando cabos de rede com 4 pares trançados e conectores RJ-45, que costumam ter baixa flexibilidade e dificultam a instalação em volumes reduzidos. Além disso, uma área considerável das placas de circuito impresso precisa ser sacrificada para comportar seus conectores e circuitos necessários [7], [11].

O protocolo de rede CAN apresenta características que o tornam bastante atrativo para a aplicação em robótica. Trata-se de uma rede determinística, com garantia de entrega de mensagens baseada em prioridades, com taxas de transmissão superiores ao RS-232, pequeno volume ocupado nas placas de circuito impresso, topologia de barramento que é prática para adição de novos módulos e utiliza apenas dois fios, minimizando problemas de gerenciamento de cabos [11].

Tabela 16 - Principais tipos de rede interna utilizados.

\begin{tabular}{rr}
\hline Tipo de rede & Referências \\
\hline Ethernet & {$[\underline{46}],[\underline{117}],[\underline{138}],[\underline{116}],[\underline{97}],[\underline{54}],[\underline{55}]$} \\
CAN & {$[\underline{121}],[\underline{88}],[\underline{42}],[\underline{49}],[\underline{91}],[\underline{61}],[\underline{85}],[\underline{141}],[\underline{134}]$} \\
RS-232 & {$[\underline{110}],[\underline{52}],[\underline{130}],[\underline{45}]$} \\
RS-485 & {$[\underline{102}]$} \\
I2C & {$[\underline{69}],[\underline{25}]$} \\
\hline
\end{tabular}

\subsubsection{Aspectos das arquiteturas de software}

\subsubsection{Sistemas operacionais e Middlewares}

Nos artigos estudados foi possível identificar o uso de sistemas operacionais tradicionais, como Windows e Linux, na maior parte dos trabalhos. Alguns artigos citam o uso de sistemas operacionais de tempo real, como QNX [136] e VxWorks [느. A Tabela 17 apresenta a classificação dos artigos com relação ao uso de sistemas operacionais.

Uma tendência observada atualmente na área de robótica é o uso de Middlewares para desenvolvimento, sendo os mais comumente encontrados o ROS e o MOOS.

O uso de Middlewares permite facilitar a comunicação entre os diversos módulos, com estabelecimento de mensagens pré-definidas. Além disso, podem ser encontrados diversos pacotes pré-desenvolvidos para implementação de funcionalidades, como algoritmos de navegação e guiagem.

A Tabela 18 apresenta os middlewares encontrados nos artigos estudados. 
Tabela 17 - Tipos de sistemas operacionais encontrados.

\begin{aligned} & \hline Sistema operacional \multicolumn{1}{c}{ Referências } \\ & \hline Windows ${[\underline{130}],[\underline{145}],[\underline{84}],[\underline{86}],[\underline{68}],[\underline{73}],[\underline{102}],[\underline{149}],[\underline{43}],[\underline{109}] \\ &$, Linux ${[\underline{117}],[\underline{110}],[\underline{97}],[\underline{130}],[\underline{125}],[\underline{34}],[\underline{145}],[\underline{23}],[\underline{107}],[\underline{115}] \\ &, {[\underline{54}],[\underline{21}],[\underline{148}] } \\ &$ Nenhum (Firmware) ${[\underline{69}]] } \\ &$ RTOS ${[\underline{145}],[\underline{85}],[\underline{134}],[\underline{136}],[\underline{42}],[\underline{124}] } \\ &$\hline\end{aligned}

Tabela 18 - Principais middlewares encontrados.

\begin{tabular}{|c|c|}
\hline Middleware & Referências \\
\hline COLA2 & [107], [129], [79] \\
\hline ConSys & [149], [68] \\
\hline DSAAV & {$[\underline{119}],[\underline{132}$} \\
\hline Huxley & {$[112]$} \\
\hline MOOS & {$[117],[131],[\underline{49}],[140],[61],[60]$} \\
\hline OROCOS & [40], [41] \\
\hline ROS & {$[117],[87],[72],[140],[\underline{21}],[79]$} \\
\hline
\end{tabular}

\subsubsection{Arquiteturas de controle}

Ao longo dos anos, uma grande quantidade de arquiteturas de controle foi desenvolvida para robôs móveis, seguindo diferentes lógicas de funcionamento. Os autores de [150] citam quatro tipos de arquiteturas notáveis desenvolvidas, que demonstram uma certa evolução ao longo do tempo: hierárquicas ou deliberativas, comportamentais e híbridas. As arquiteturas hierárquicas se caracterizam por um processo sequencial, no qual um modelo do ambiente, programado no robô, é atualizado utilizando os dados dos sensores para então efetuar o processamento das informações, definir uma ação e finalmente enviar os comandos de controle aos atuadores.

Uma das desvantagens desta arquitetura é que este processo costuma ser lento, e arquiteturas deste tipo tendem a demorar para responder às mudanças imprevistas no ambiente. A principal vantagem desta arquitetura está na previsibilidade das ações, facilitando a verificação da controlabilidade e estabilidade do sistema.

As arquiteturas reativas ou comportamentais por sua vez são caracterizadas por possuírem comportamentos reativos que operam de forma paralela. A saída do sistema é definida através de prioridades ou por ponderação das saídas de cada comportamento.

Estas arquiteturas não utilizam conhecimentos do mundo e não possuem nenhuma forma de planejamento, assim têm respostas rápidas aos dados fornecidos pelos sensores, mas não garantem que são tomadas boas reações.

As arquiteturas híbridas foram propostas como uma solução para combinar as características das duas arquiteturas anteriores. Um sistema de alto nível, com uma arquitetura 
deliberativa, processa o ambiente e determina os objetivos de longo prazo, enquanto comportamentos reativos atuam em baixo nível, controlando os objetivos de curto prazo como desvio de obstáculos, controle dos atuadores, etc.

É possível identificar uma grande tendência ao uso de arquiteturas de controle híbridas, conforme encontrado em treze dos artigos estudados, sendo quatro baseados na arquitetura back-seat/front-seat.

Outra arquitetura notável encontrada nos trabalhos é baseada na divisão de atividades segundo a estratégia de submarinos tripulados, conforme apresentado nos artigos [78] e [129]. Esta estratégia torna as atividades organizadas, permitindo identificar responsáveis pelos problemas que venham a ocorrer.

Analisando estes artigos, é possível verificar que a adoção do esquema back-seat/front-seat é uma possível solução quando esta arquitetura começa a sofrer do problema de fat-agent, ou seja, quando um módulo começa a concentrar muitas funcionalidades.

A Tabela 19 apresenta as principais arquiteturas de controle citadas nos artigos estudados.

Tabela 19 - Arquiteturas de controle identificadas.

\begin{tabular}{rr}
\hline Arquiteturas de controle & Referências \\
\hline Agent-based & {$[\underline{132}],[\underline{98}],[\underline{119}]$} \\
Backseat-Frontseat & {$[\underline{132}],[\underline{131}],[\underline{140}],[\underline{41}]$} \\
Comportamental & {$[\underline{59}],[\underline{83}],[\underline{27}],[\underline{72}],[\underline{151}],[\underline{44}]$} \\
Híbrida & {$[\underline{152}],[\underline{43}],[\underline{80}],[\underline{84}],[\underline{112}],[\underline{145}],[\underline{107}],[\underline{129}],[\underline{79}]$} \\
Hierárquica & {$[\underline{59}],[\underline{76}],[\underline{85}]$} \\
\hline
\end{tabular}




\section{Estudo de caso: AUV Pirajuba}

O AUV Pirajuba é um veículo autônomo submarino que vem sendo desenvolvido no Laboratório de Veículos Não Tripulados (LVNT) da Escola Politécnica da Universidade de São Paulo. Foi concebido originalmente como um modelo para levantamento de dados para estudos de hidrodinâmica, evoluindo então para uma plataforma de pesquisas na área de robótica submarina, tendo sido utilizado para estudos nas áreas de CFD (Computational Fluid Dynamics), controle, navegação, arquiteturas de controle, projeto mecânico e marinização de equipamentos.

A Figura $\underline{4.1}$ apresenta a configuração do veículo durante os ensaios para estudos de hidrodinâmica e identificação realizados em Angra dos Reis - SP. Atualmente o veículo está sendo adaptado para realização de missões de levantamento de dados para auxílio em estudos oceanográficos, mais especificamente para o um projeto de detecção e estudo de camadas finas na região de Ubatuba-SP.

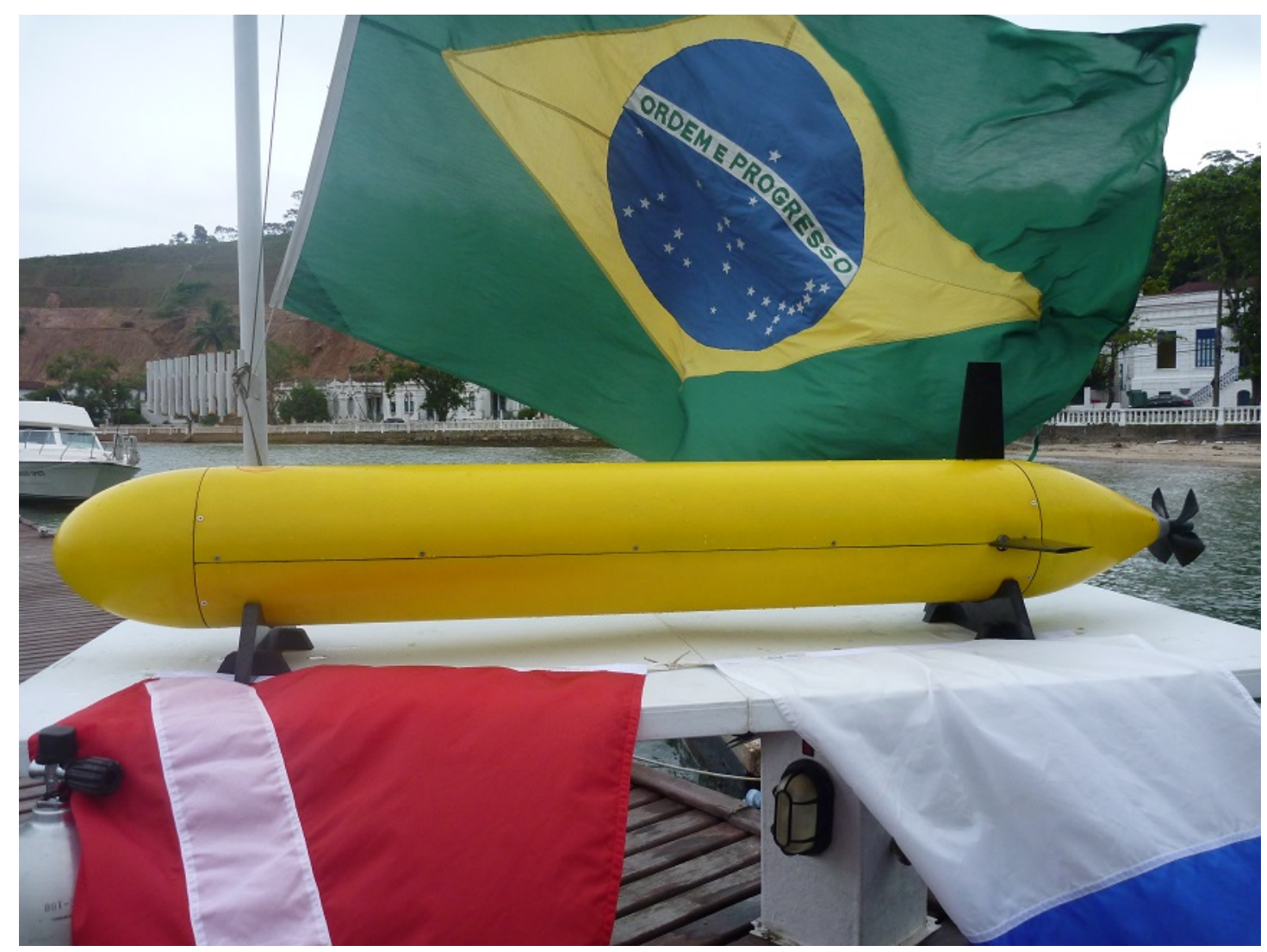

Figura 4.1 - AUV Pirajuba durante os ensaios de hidrodinâmica e identificação, retirado de $[\underline{153}]$. 


\subsection{Descrição da missão}

As camadas finas são seções da coluna d'água de pequena espessura vertical, cuja estratificação se dá devido à diferença de temperatura, e caracterizam-se por possuir uma grande concentração de material particulado e organismos planctônicos. São consideradas como camadas finas as regiões de grande concentração de organismos com espessuras menores que cinco metros. Estudos atuais indicam que a maior parte possui no máximo três metros de espessura, e é frequente que se formem com alguns centímetros, dificultando a sua deteç̧ão devido às limitações das técnicas de amostragem tradicionais, como garrafas e redes, com baixa resolução espacial e temporal.

Para realização deste estudo foi proposta a utilização do AUV Pirajuba através da realização de manobras no formato de zigue-zague no plano vertical, carregando uma carga científica composta de uma sonda de qualidade de água com sensores de condutividade, temperatura e pressão (CTD), e sensores ópticos para medição de clorofila, ficoeritrina, matéria orgânica em suspensão e retroespalhamento óptico.

A manobra de zigue-zague vertical foi proposta com o objetivo de fazer com que o veículo cobrisse uma região extensa, de forma a atravessar a camada em diversos pontos, enquanto registra os dados dos sensores para sua identificação.

Os estudos foram realizados na região de Ubatuba-SP, nas proximidades da base do Instituto Oceanográfico da USP. As profundidades nas regiões escolhidas ficam em torno de 20 metros.

A Figura $\underline{4.2}$ apresenta um exemplo da manobra desejada para estudo na região.

\subsubsection{Características da manobra}

Para realização da manobra de zigue-zague foi implementado um algoritmo de controle de inclinação, com referências que se alternam em função de limites de profundidades superior e inferior estabelecidos pelo operador. Para garantir a detecção das camadas de pequena espessura foi necessário determinar o ângulo de inclinação e a velocidade de deslocamento em função da frequência de aquisição dos sensores oceanográficos e do número de amostras numa dada espessura de camada.

A taxa de aquisição dos sensores é limitada pelos equipamentos disponíveis e pelo tempo de resposta dos sensores. Para os equipamentos utilizados, a taxa de aquisição foi estabelecida em $6 \mathrm{~Hz}$.

A velocidade de deslocamento do veículo influencia na sua capacidade de controle e na sua autonomia. Foi definida uma velocidade de $1,5 \mathrm{~m} / \mathrm{s}$ para realizar a missão, com base em critérios de autonomia e manobrabilidade.

Estabeleceu-se como satisfatória a obtenção de pelo menos quatro pontos numa camada de 30 centímetros de espessura.

Assim, estabeleceu-se a realização da manobra com $17^{\circ}$ de inclinação, que satisfaz os 


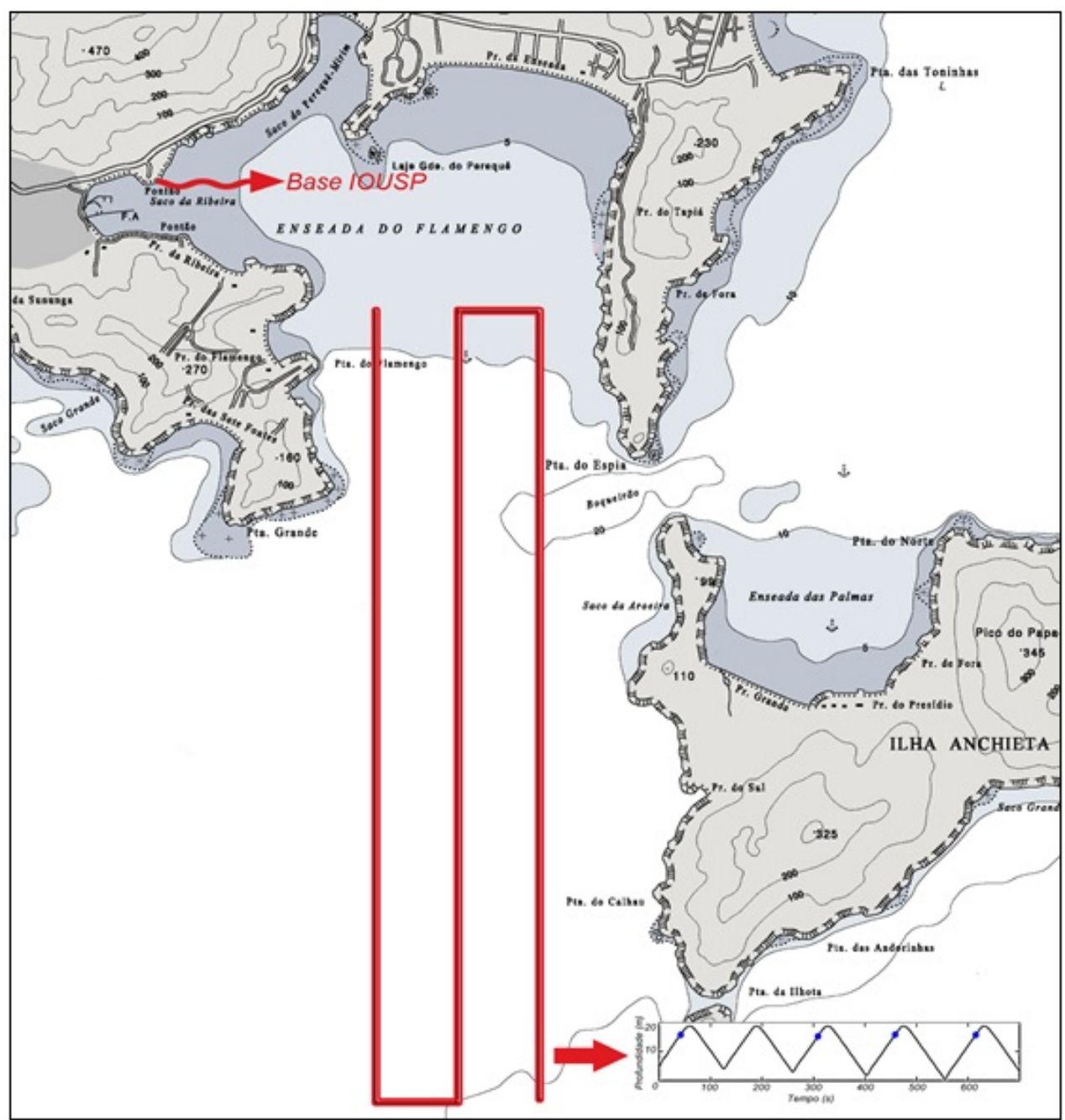

Figura 4.2 - Exemplo de manobra desejada para o estudo em questão, extraída do projeto proposto à FAPESP, processo 13/16669-7.

requisitos acima. A duração das manobras foi de aproximadamente quatro horas, permitindo cobrir uma região de aproximadamente $4 \mathrm{~km} \times 1 \mathrm{~km}$, considerada satisfatória para os estudos pelos pesquisadores envolvidos.

\subsection{Características físicas do AUV Pirajuba}

O veículo possui formato do tipo torpedo, originalmente possuía o corpo liso, com 1,80m de comprimento e $324 \mathrm{~mm}$ de diâmetro. Atualmente tem uma superestrutura para comportar as antenas de comunicação e GPS, e o comprimento do veículo varia de acordo com o módulo acoplado, podendo chegar a 2,5m de comprimento. Seu peso seco varia entre 30 e $45 \mathrm{~kg}$ de acordo com a configuração montada e a regulagem dos lastros, para água doce ou salgada.

A configuração é do tipo free-flooded, ou seja, possui um casco hidrodinâmico que opera alagado e não precisa ser resistente à pressão, com vasos de pressão no seu interior para 


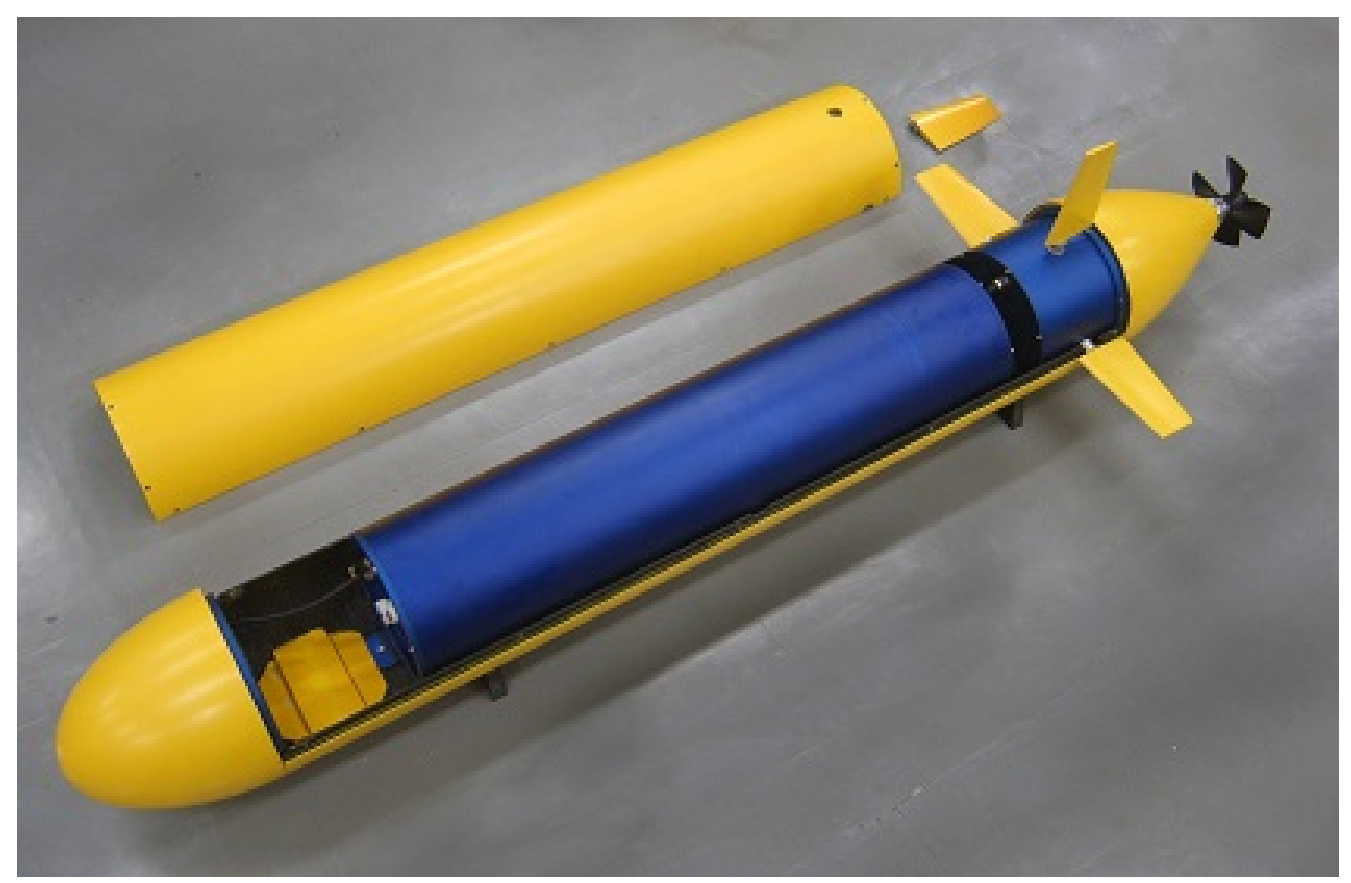

Figura 4.3 - Veículo aberto, mostrando o casco do tipo free-flooded, vaso principal e vaso de manobra.

abrigar os equipamentos e sistemas eletrônicos.

A Tabela 20 apresenta algumas das principais características do AUV Pirajuba, e a Figura 4.3 permite visualizar o veículo com a tampa superior removida, exemplificando a configuração do tipo free-flooded e visualizar dois dos vasos de pressão.

Tabela 20 - Principais características do AUV Pirajuba.

\begin{tabular}{lr}
\hline Formato & Torpedo \\
Comprimento & 1,80 a $2,5 \mathrm{~m}$ \\
Diâmetro & $324 \mathrm{~mm}$ \\
Peso seco & 30 a $45 \mathrm{~kg}$ \\
Tipo de casco & Free-flooded \\
Profundidade máxima & $100 \mathrm{~m}$ \\
Autonomia & $8 \mathrm{~h}$ \\
Velocidade Máxima & $2 \mathrm{~m} / \mathrm{s}$ \\
\hline
\end{tabular}

\subsubsection{Vasos de pressão}

Atualmente o veículo possui três vasos de pressão no seu interior, abrigando o sistema de propulsão, o sistema de manobras e o sistema principal. 


\subsubsection{Vaso de propulsão}

O sistema de propulsão é composto por um motor CC com escovas, acoplado a um redutor planetário, e um tacômetro para controle de rotação. Possui também um sensor de inundação, lido pelo sistema de manobra. Foram desenvolvidas versões com vedação do eixo rotativo através de selos mecânicos e retentores.

\subsubsection{Vaso de manobra}

O sistema de manobra abriga dois conjuntos de motores com redutores planetários e encoders, dois circuitos de acionamento para controle de posição e um para controle de rotação para o propulsor, além de um microcontrolador, um conversor CC-CC para alimentação dos equipamentos e um sensor de inundação.

\subsubsection{Vaso principal}

O sistema principal contém as baterias e conversores CC-CC, módulos de navegação, controle e interface com equipamentos, sensores de navegação, como IMU (Inertial Measurement Unit), AHRS, profundímetro, bem como dois sensores de inundação, módulo de GPS, módulo de comunicação RF e módulo de comunicação Wi-Fi e GPRS.

\subsubsection{Módulos de expansão}

Ao longo dos anos, novos equipamentos foram adquiridos, além de módulos desenvolvidos para integrá-los ao veículo para realização de missões, como:

- módulo contendo sonar multi elementos, câmera e iluminação, para aplicações de inspeção de dutos submarinos.

- módulo de sonar de escaneamento lateral, composto por transdutores instalados na lateral do veículo e eletrônica instalada no interior do vaso principal.

- módulo de localização acústica, contendo um transmissor acústico independente para localização do veículo em situações de emergência

- módulo para sonda multi-parâmetros contendo sensores de Condutividade, Temperatura e Pressão (CTD)

- módulo com sensores ópticos de qualidade de água: Clorofila, ficoeritrina, matéria orgânica em suspensão e retroespalhamento óptico

\subsubsection{Módulo de sonar, câmera e iluminação}

O módulo de sonar, câmera e iluminação foi desenvolvido como uma proa do veículo, que pode ser instalado no local da proa lisa ou da proa contendo a sonda multi-parâmetros. A 


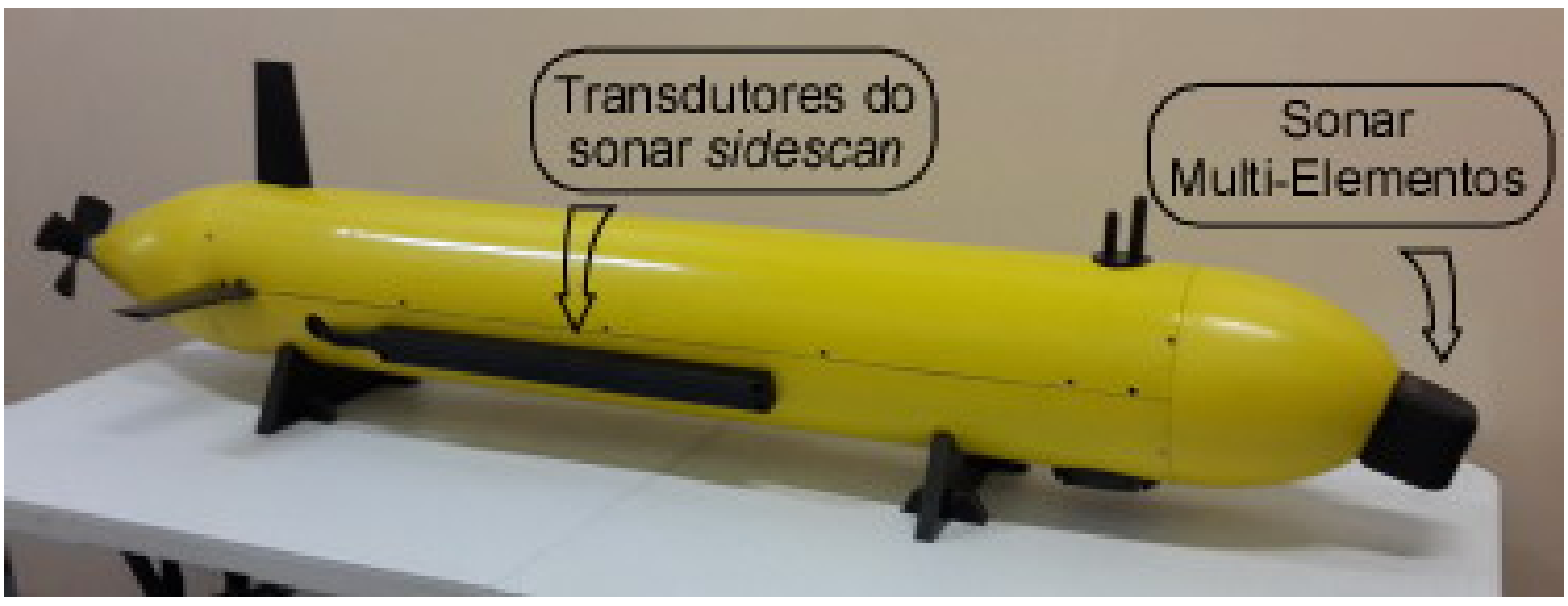

Figura 4.4 - Pirajuba com módulo de sonar multi-elementos e transdutores do sonar de escaneamento lateral.

fabricação foi feita a partir de um molde, em fibra de vidro, com estruturas internas para fixação dos equipamentos.

\subsubsection{Módulo de sonar de escaneamento lateral}

Para instalação do sonar de escaneamento lateral, foi fabricado um novo casco inferior para a seção paralela do veículo, com furos para fixação dos transdutores e para passagem dos cabos, e conectores instalados na tampa traseira do vaso principal. No interior do vaso principal foi disponibilizado um espaço para instalação da eletrônica do sonar.

A Figura $\underline{4.4}$ apresenta o veículo com o módulo de sonar multi-elementos e transdutores do sonar de escaneamento lateral.

\subsubsection{Módulo de localização acústica}

O módulo de localização acústica foi feito por um processo de torneamento num tubo de polipropileno. A principal vantagem deste material em relação à fibra é possuir densidade menor que a da água, evitando a adição de mais flutuadores em seu interior. Como desvantagem pôde-se observar a baixa aderência em adesivos, dificultando a fixação de estruturas em seu interior. Além disso, para manter a resistência mecânica, foi necessário fazer paredes mais grossas, aumentando assim o peso do módulo fora da água.

\subsubsection{Módulo de sonda multi-parâmetros}

O módulo da sonda multi-parâmetros, assim como o do sonar e câmera, foi feito na proa do veículo. Essa opção foi feita para evitar a interferência da turbulência gerada pelo veículo nas medições de temperatura e salinidade, fundamental para a aplicação de detecção de 


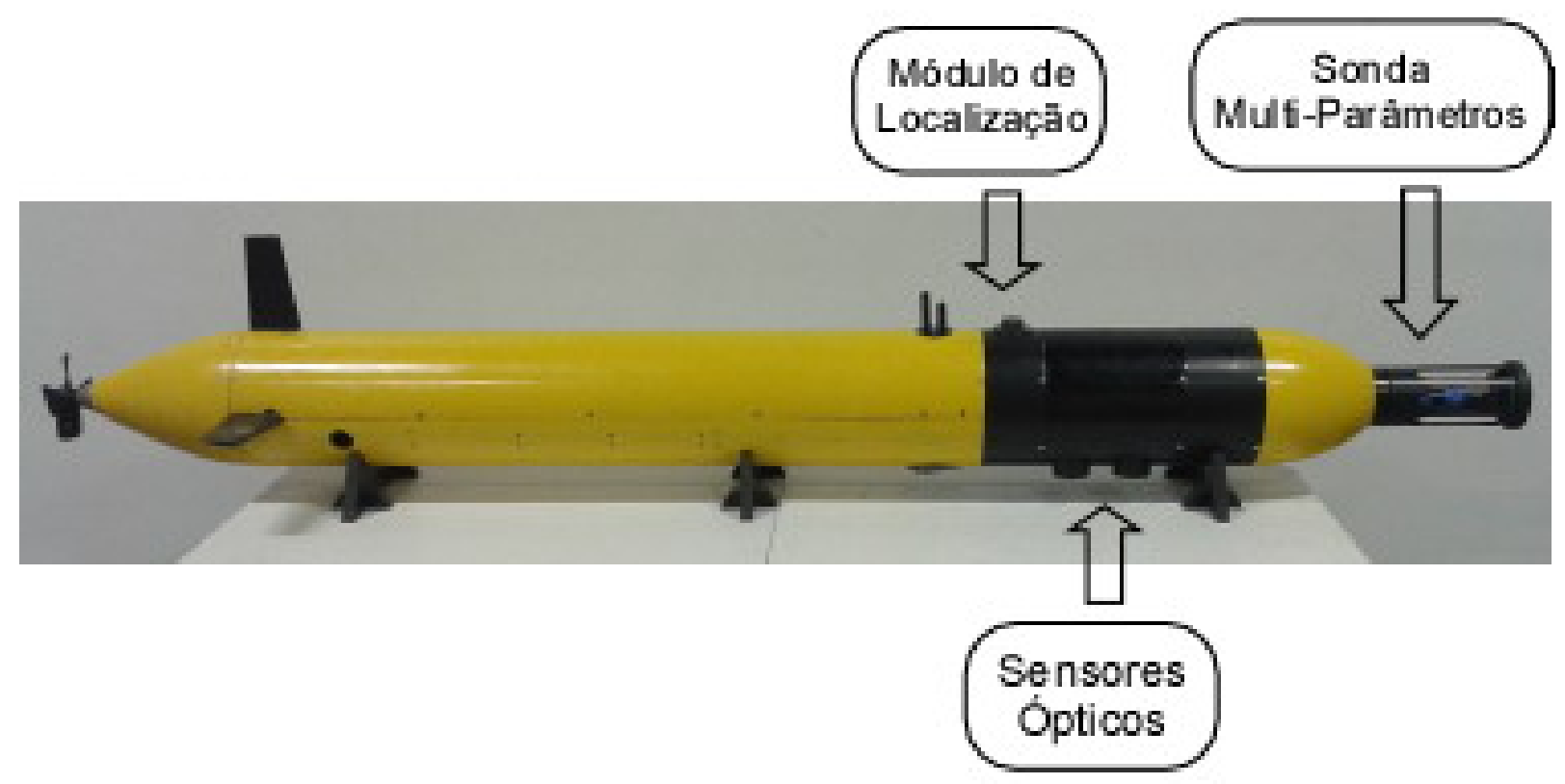

Figura 4.5 - Pirajuba com módulo de localização, sensores ópticos e sonda multiparâmetros.

camadas finas.

\subsubsection{Módulo de sensores ópticos}

Para instalação dos sensores ópticos foi desenvolvida uma seção do corpo paralelo em fibra de vidro com estruturas internas para fixação dos equipamentos. Os sensores foram instalados voltados para baixo, evitando interferência da luz solar. Outra necessidade observada foi instalar os sensores de clorofila e matéria orgânica com uma angulação de 30 graus entre eles, pois ambos operam com comprimentos de onda semelhantes e causam interferência entre si.

A Figura 4.5 mostra o veículo montado com o módulo de localização acústica, módulo de sensores ópticos e módulo da sonda multi-parâmetros.

\subsection{Manobras}

Originalmente foram implementadas quatro manobras para o veículo, permitindo a realização de ensaios para estudos de hidrodinâmica: controle de rumo, Zigue-zague, Giro e manobra tipo U. Atualmente existem diferentes manobras implementadas para realização de missões, seguindo a seguinte estrutura: A primeira parte da manobra executada visa submergir o veículo até uma pequena profundidade, uma vez que a simples utilização de um algoritmo de controle de profundidade muitas vezes não é suficiente para fazer com o que o veículo saia da superfície da água. 
Uma vez atingida uma profundidade suficiente, segue-se um período de controle de profundidade e rumo, visando atingir a profundidade e rumos de referência programados para a missão. Segue-se então o período de manobra, que pode ser composto por retas com controle de rumo, curvas com ângulo de leme constante, manobras do tipo zigue-zague no plano horizontal e no plano vertical através do controle do ângulo de inclinação.

Para controle de profundidade, rumo e ângulo de inclinação foram utilizados controladores do tipo PID, regulados experimentalmente.

Após a realização da manobra, segue-se um período de emersão, na qual o veículo fixa seus lemes em ângulo para subida até a superfície e, uma vez atingida a profundidade mínima, reduz a rotação do propulsor.

\subsection{Sistema de energia}

\subsubsection{Armazenamento}

O sistema de armazenamento de energia é composto por quatro conjuntos em paralelo de baterias com oito células de lítio polímero em série, fornecendo em torno de $30 \mathrm{~V}$, com capacidade nominal de 40 A.h. Para evitar a descarga excessiva das baterias, foi estabelecido um limite inferior de tensão pro conjunto, considerando uma margem de segurança para considerar desbalanceamento entre as tensões de cada célula. Com este sistema, o veículo possui autonomia de aproximadamente oito horas, operando em velocidades de aproximadamente 1,5 a $2 \mathrm{~m} / \mathrm{s}$

\subsubsection{Conversão e distribuição}

A tensão fornecida pelas baterias é convertida através de conversores CC-CC. Este tipo de conversor foi escolhido devido à sua alta eficiência na conversão de energia e pela disponibilidade de conversores industriais de alta confiabilidade já encapsulados, de fácil integração. Como desvantagem, estes tipos de conversores costumam gerar maiores interferências eletromagnéticas, fazendo necessária a adoção de medidas para compatibilização com os níveis aceitáveis no sistema. A Figura $\underline{4.6}$ apresenta o esquema geral da arquitetura de distribuição de energia.

No vaso principal, a tensão fornecida pelas baterias é convertida em dois barramentos de tensão, um de $12 \mathrm{~V}$ e um de $24 \mathrm{~V}$. O barramento de $12 \mathrm{~V}$ é utilizado para alimentação dos módulos de processamento e da maior parte dos sensores. Este barramento é ligado juntamente com o veículo e permanece sempre ativo. O barramento de $24 \mathrm{~V}$ é utilizado para alimentação do DVL e da sonda de qualidade de água. Este barramento é ligado apenas durante a execução de uma manobra através de um sinal gerado por um dos módulos de controle.

No vaso de manobra a tensão das baterias é utilizada para alimentação do propulsor, e é 


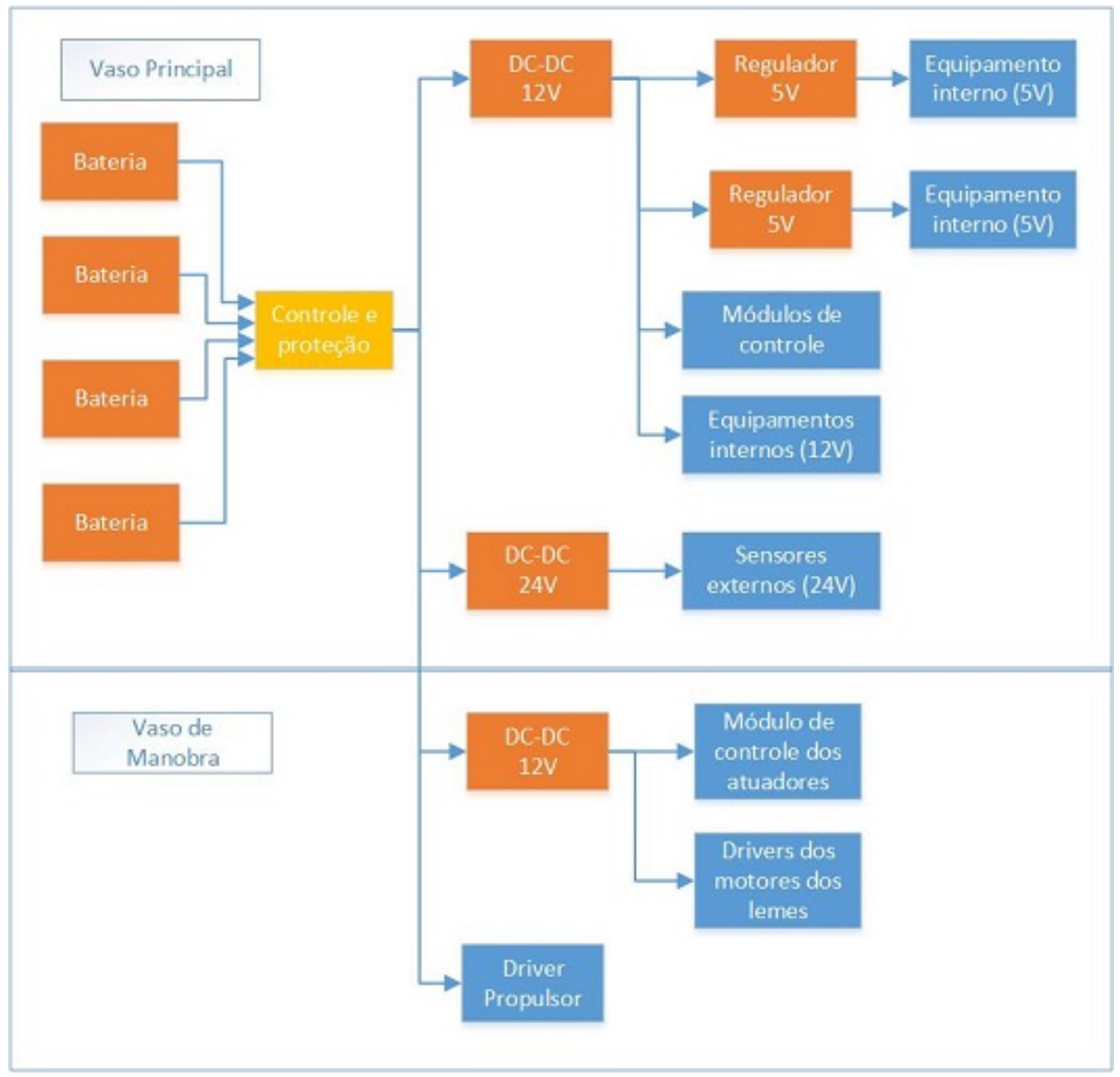

Figura 4.6 - Esquema geral de distribuição e conversão de energia.

convertida num barramento de $12 \mathrm{~V}$ para alimentação dos servomotores e do módulo de processamento através de um conversor CC-CC independente.

Nos módulos de controle a tensão de $12 \mathrm{~V}$ é convertida localmente para as tensões de $5 \mathrm{~V}$ e $3.3 \mathrm{~V}$, utilizadas para alimentação dos circuitos integrados e dos microcontroladores.

A conversão de energia para alimentação dos equipamentos que operam em $5 \mathrm{~V}$ é feita individualmente, através de reguladores lineares. Como estes equipamentos consomem pouca energia, o uso de reguladores se mostra uma solução robusta e barata, implicando em perdas aceitáveis.

\subsubsection{Liga/desliga e proteção}

Para ligar o veículo foi utilizado um circuito de relés de estado sólido cujo acionamento é feito através da conexão de dois polos de um conector externo ao vaso, realizada 
através de um plugue pré-moldado. Como o acesso a esse conector requer a abertura do casco hidrodinâmico do veículo, foi instalado um reed-switch em série com este conector, permitindo desligar o veículo ao se posicionar um ímã numa região específica do casco externo do veículo.

Cada conjunto de baterias possui um fusível para evitar danos à placa de ligação das baterias. Estes conjuntos são ligados a uma placa de distribuição e controle para o ligar e desligar o veículo. Nesta placa são utilizados fusíveis para limitar a corrente de cada pack, protegendo os relés de estado sólido utilizados para ligar e desligar o veículo. Cada placa de conversor CC-CC possui também um fusível na entrada para sua proteção.

\subsection{Sistema de navegação}

A realização dos ensaios para estudos oceanográficos foi feita paralelamente ao desenvolvimento de algoritmos de navegação, temas de pesquisa de dois alunos do LVNT. Para isso, foram integrados à arquitetura de controle dois módulos realizando estratégias e algoritmos independentes. Um dos módulos, baseado num microcontrolador de arquitetura ARM9, foi utilizado para implementar um filtro de Kalman estendido. O desenvolvimento deste sistema é tema do trabalho [154], e faz uma fusão dos dados fornecidos por diversos sensores para obter uma estimativa da posição do veículo.

Outro módulo, implementado no mesmo hardware dos módulos de controle, com microcontrolador de núcleo ARM7, executa um algoritmo de dead-reckoning baseado na integração das velocidades fornecidas pelo DVL e estimativas de atitude obtidas através da IMU e AHRS. Este módulo foi interligado diretamente à rede CAN e desenvolvido utilizando a mesma base de sistema operacional e ambiente de desenvolvimento dos módulos de controle. Para evitar interferências na arquitetura, tomou-se o cuidado de não permitir que o módulo de navegação enviasse dados ao barramento de rede CAN, utilizando a rede apenas para ter acesso aos dados dos sensores. Para isso, este módulo possui seu próprio cartão de memória para armazenamento dos seus resultados.

\subsection{Sistema de comunicação}

Foi estabelecido o uso de três alternativas para comunicação externa com o veículo: $\mathrm{O}$ sistema de comunicação principal utiliza um rádio que opera na frequência de $900 \mathrm{MHz}$, com interface RS-232 e taxas de transmissão de até 115200kbps. Este rádio possui maior alcance e é utilizado para configuração das manobras, podendo ser utilizado também para descarga dos dados, embora sua taxa de transmissão seja limitada.

Um roteador foi instalado no veículo para comunicação via Wi-Fi, de curto alcance e taxas de transferência maiores. Este roteador está ligado através de uma interface Ethernet a um módulo responsável por armazenar os dados da missão. Este canal de comunicação é 
utilizado exclusivamente para descarga dos dados através de um protocolo TCP/IP, não sendo utilizado para configuração ou envio de comandos ao veículo.

O mesmo módulo que possui interface Ethernet possui também um módulo de comunicação via GPRS, utilizado para receber um SMS enviado pelo operador e responder com a posição obtida através do sistema de GPS quando o veículo se encontra na superfície. Este canal de comunicação é utilizado para localização do veículo ao final da execução das manobras. Foi prevista também a possibilidade de adicionar um canal de comunicação acústica para envio de comandos ao veículo submarino, permitindo obter sua localização estimada ao longo da manobra e enviar comandos para iniciar ou abortar a missão.

\subsection{Arquitetura de controle}

\subsubsection{Arquitetura de controle CANARMES}

A arquitetura de controle CANARMES [11] foi desenvolvida como uma opção para realizar o controle de um AUV que permitisse atender os requisitos de desenvolvimento de um laboratório de pesquisa universitário, apresentados a seguir, utilizando componentes encontrados no mercado nacional quando possível.

A arquitetura foi desenvolvida tendo em vista a aplicação no AUV Pirajuba, utilizado neste período como uma plataforma para realização de estudos de hidrodinâmica, através de algumas manobras simples e de curta duração [155], [156], [157].

Para seu desenvolvimento, foram utilizados conceitos provenientes da Engenharia de Sistemas, caracterizando um sistema composto por módulos e interfaces bem definidas distribuídos dentro do veículo. Esses conceitos se refletem tanto na arquitetura de software quanto na arquitetura de hardware.

\subsubsection{Requisitos que orientaram o desenvolvimento}

A maior parte dos requisitos considerados no desenvolvimento são provenientes da restrição impostas pelo ambiente de pesquisa e desenvolvimento de um laboratório universitário nacional. Os principais requisitos e restrições identificados em [11] são:

- Rotatividade de pessoal

- Inexperiência dos alunos

- Dificuldades de importação

- Orçamento limitado

- Prazos apertados

- Burocracias administrativas 
Tendo em vista atender tais requisitos, foi estabelecida uma série de características desejadas para a arquitetura de controle desenvolvida. As principais características do projeto original são apresentadas a seguir:

- Modularidade;

- Robustez;

- Facilidade de desenvolvimento;

- Baixo custo;

- Baixo consumo energético;

- Pequeno volume;

- Baixo tempo de desenvolvimento;

- Alta segurança e disponibilidade;

- Expansibilidade;

- Flexibilidade, e;

- Continuidade do desenvolvimento;

\subsubsection{Conceito geral da arquitetura}

A arquitetura CANARMES foi baseada na ideia proposta em [158], similar à proposta em [159]. Trata-se de uma arquitetura distribuída, na qual diversos módulos de processamento baseados em microcontroladores de arquitetura ARM se comunicam através de uma rede CAN para realização das funções necessárias para o funcionamento do veículo.

É proposto o uso de um nó central, com maior capacidade de processamento, para realizar as funcionalidades que requerem cálculos de maior complexidade, como navegação, mapeamento e planejamento de trajetórias. A Figura $\underline{4.7}$ apresenta um diagrama simplificado do sistema.

A arquitetura tem uma natureza modular, e é proposta uma organização de acordo com a classificação funcional destes módulos. Aqueles que possuem funcionalidades vitais para a operação do veículo são desenvolvidos atendendo requisitos de sistemas de tempo real, além de possuírem maiores restrições relativas à qualidade do software, seguindo normas provenientes da indústria automobilística (MISRA-C).

Os módulos de funcionalidades não-vitais podem ser desenvolvidos com menores restrições, uma vez que a segurança geral do sistema não é afetada diretamente por falhas nesses módulos. 


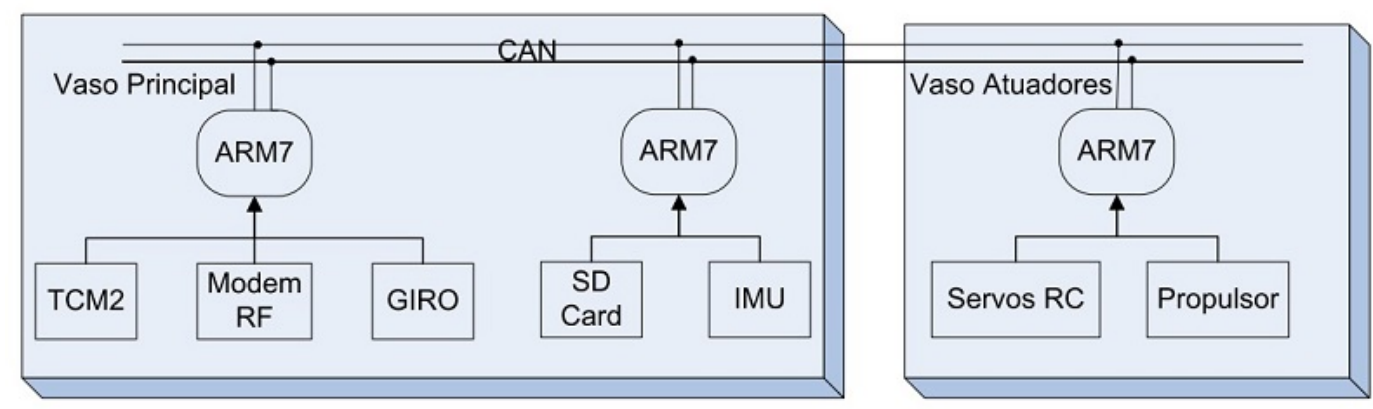

Figura 4.7 - Diagrama simplificado da arquitetura CANARMES, retirado de [11].

\subsubsection{Arquitetura de hardware}

Para a implementação da arquitetura de hardware foi proposta a utilização de microcontroladores LPC2148, de arquitetura ARM7 e fabricados pela NXP, devido à disponibilidade no mercado nacional e a relação custo-benefício em termos de memória e periféricos.

Uma vez que estes microcontroladores não possuem módulos controladores de rede CAN, foi utilizado o circuito integrado MCP2515 como controlador de rede e o transceiver MCP2551 para conversão dos níveis de tensão e compatibilidade com o barramento veicular.

Para realizar o restante das interfaces necessárias, analógicas e digitais, foram implementados circuitos de condicionamento e conversão de sinais utilizando circuitos integrados de uso comum, como o transceiver MAX232 para interfaces de rede RS-232, amplificadores operacionais e de instrumentação.

Os módulos eram dispostos em uma pilha contendo, usualmente, duas a três placas conectadas através de um conector de barramento com 64 pinos. Este arranjo em pilhas é similar ao utilizado entre os módulos Arduíno e seus shields

A primeira placa da pilha continha o microcontrolador e seus circuitos básicos de alimentação e osciladores. A segunda placa da pilha continha um conector de alimentação, circuitos e conectores para duas interfaces RS-232, e uma interface com o barramento de rede CAN utilizado para comunicação entre os módulos. A última placa da pilha continha os circuitos de interfaces mais específicas para cada módulo, como o de interface com um sistema de acionamento do motor do propulsor, envolvendo geração e aquisição de sinais analógicos para setpoint de rotação, leitura do sensor de rotação e leitura da corrente do motor.

Outra placa foi desenvolvida contendo um cartão de memória do tipo SD-card para armazenamento dos dados da missão e uma bateria de lítio para o relógio de tempo real.

Para proteção dos circuitos e aumento da confiabilidade do sistema foram propostas medidas para reduzir a temperatura e umidade do ar, como o acondicionamento de cada módulo numa caixa plástica selada, contendo sacos de sílica-gel no seu interior, e conexão com equipamentos e outros módulos através de conectores circulares.

A Figura $\underline{4.8}$ mostra um módulo completo na caixa e as placas individuais desenvolvidas 

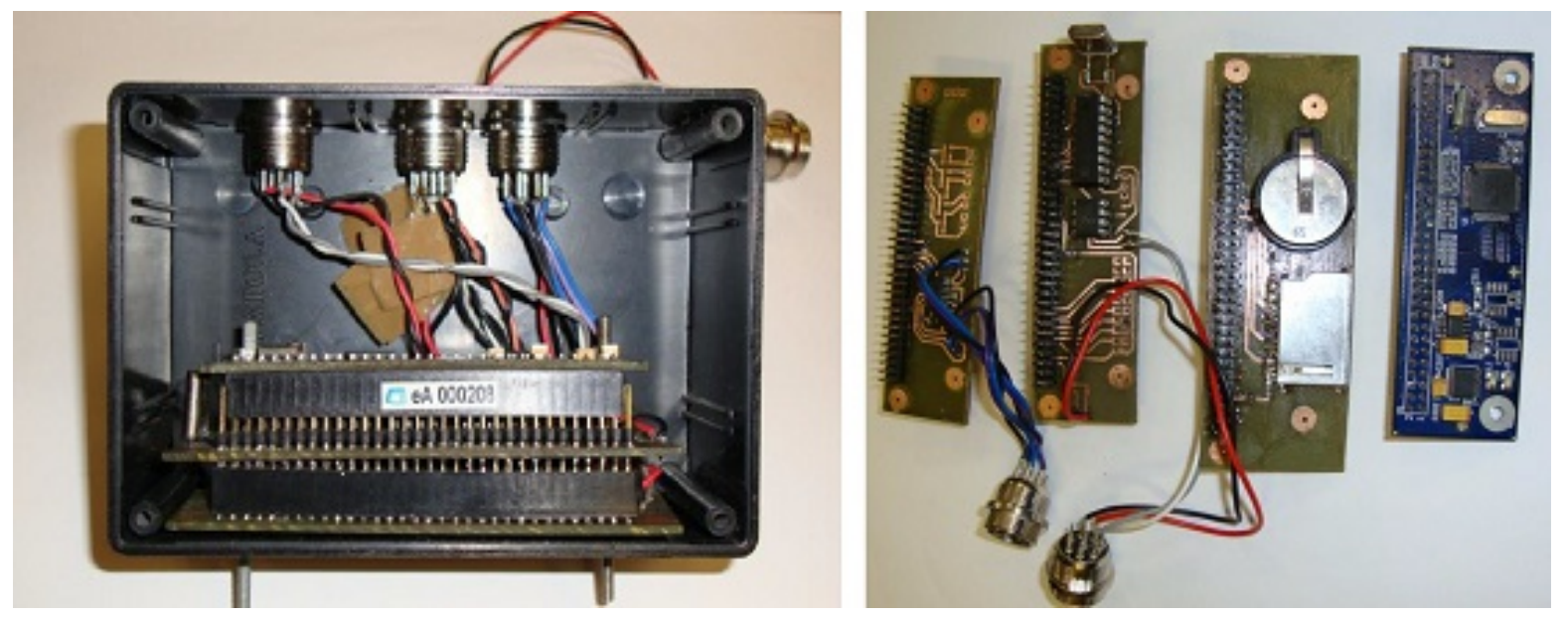

Figura 4.8 - Módulo de controle montado na caixa e placas que compõe os conjuntos, retirado de [11].

\subsubsection{Arquitetura de software}

A arquitetura de software desenvolvida é caracterizada pela divisão de módulos de software em camadas, e tem o objetivo de prover uma biblioteca de funções para futuros desenvolvimentos. A Figura $\underline{4.9}$ apresenta a visão geral da arquitetura e sua respectiva divisão em módulos e camadas.

A camada inferior, denominada de Interface com periféricos, contém os módulos necessários para comunicação com os periféricos do próprio microcontrolador e das placas, além de módulos de interface com sensores e atuadores e o sistema operacional.

O desenvolvimento dos módulos de interface com os periféricos foi inspirado na filosofia de orientação a objetos, com cada periférico relacionado a um objeto, contendo atributos e métodos para seu controle.

Os módulos de interface com sensores e atuadores possuem as funções necessárias para inicialização e operação dos equipamentos, envolvendo a leitura de mensagens e envio de comandos. O módulo do sistema operacional contém as funcionalidades relativas à criação, controle, sincronização e comunicação de tarefas, como semáforos, mailboxes, mutexes, etc. Na camada de intermediária, denominada camada de comunicação, está o objeto utilizado para realizar a comunicação entre os módulos da camada superior e destes com os objetos da camada inferior.

O objeto "Shared Memory"disponibiliza funções para escrita e leitura de mensagens definidas, e faz a sincronização destes dados entre os diferentes módulos automaticamente através da rede CAN. As mensagens definidas devem possuir formato compatível com os frames utilizados na rede CAN, limitadas a 8 bytes de dados por mensagem, e são diretamente relacionadas aos identificadores utilizados na rede. Na camada superior estão os objetos relativos ao gerenciamento da missão, envolvendo o controle das manobras e a interface com o usuário. 


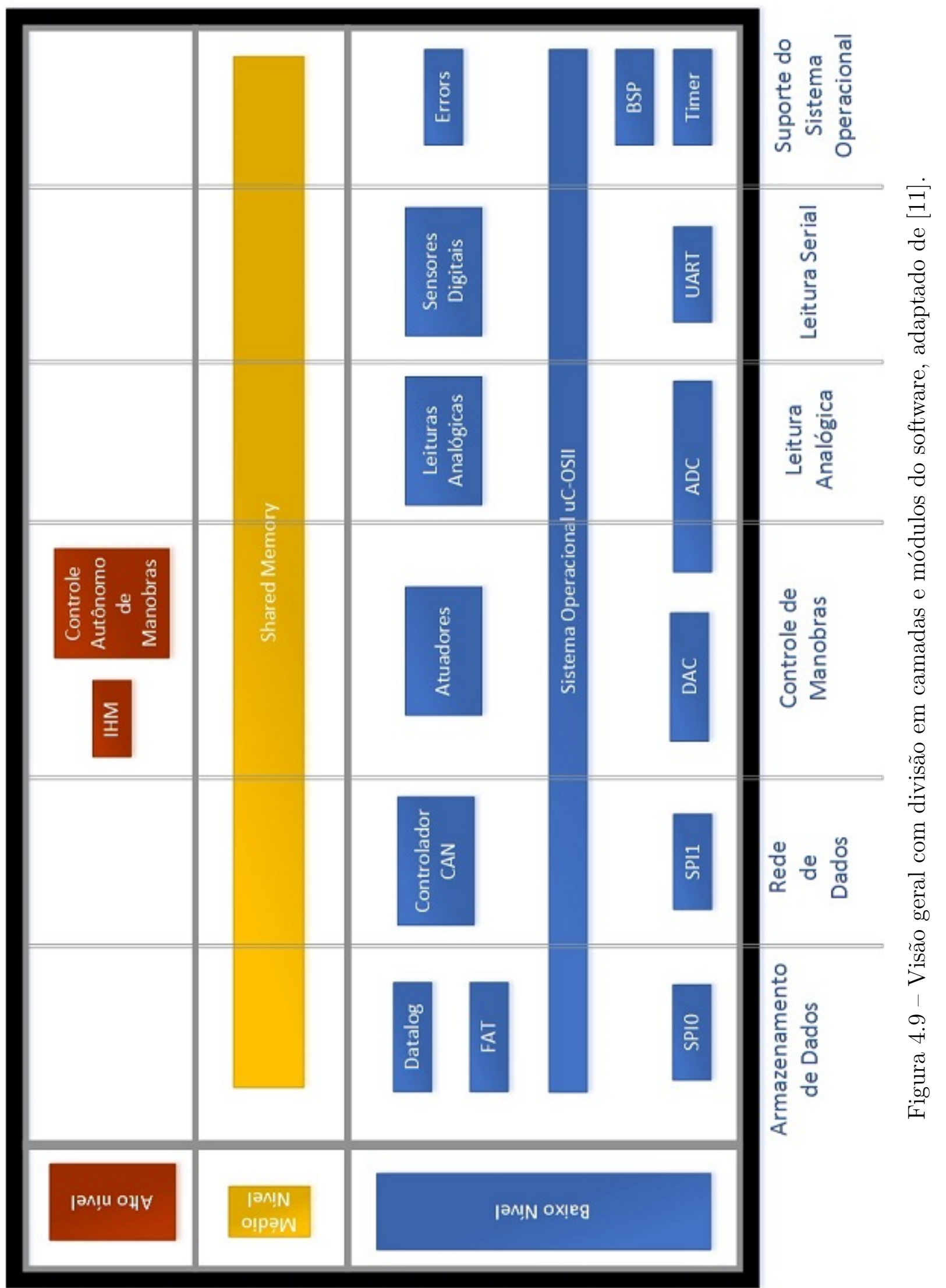




\subsubsection{Atualização do sistema}

\subsubsection{Arquitetura de Hardware}

\subsection{Processadores e rede de comunicação}

Para implementação dos módulos de controle optou-se por manter o uso dos microcontroladores LPC2148, que vinham sendo utilizados desde o desenvolvimento inicial da arquitetura, embora tenha sido abandonado o uso das placas comerciais, que foram descontinuadas pelo fabricante. A rede CAN também continuou sendo utilizada para comunicação entre os módulos, tendo em visa suas características adequadas ao desenvolvimento de sistemas com requisitos de tempo real, e com respaldo obtido através da revisão bibliográfica.

\subsection{Estrutura dos módulos}

Para permitir a instalação de novos equipamentos ao veículo, foi observada uma impossibilidade de continuar utilizando os módulos de processamento acondicionados em caixas plásticas como propostos na arquitetura inicial, demandando o desenvolvimento de uma nova versão para o hardware do sistema. Com o desenvolvimento do projeto, foi sendo observada uma tendência ao uso de interfaces padronizadas para a maior parte dos equipamentos utilizados em robótica submarina.

É possível observar que grande parte dos equipamentos continua utilizando interfaces no padrão RS-232, como é o caso da AHRS, da IMU, sistemas de acionamento dos atuadores, módulo de rádio, sonda de qualidade de água e GPS. Equipamentos com maior quantidade de dados, como câmeras, sonares de escaneamento lateral, sonar multi-elementos costumam utilizar interfaces do padrão Ethernet.

É comum o uso de sinais digitais para acionamento de equipamentos ou leitura de sensores de inundação. Interfaces analógicas ainda são utilizadas, porém sua quantidade vem se reduzindo, por exemplo, os sensores de pressão utilizando interfaces analógicas com sinal de corrente, de 4 a $20 \mathrm{~mA}$, de forma a ser menos susceptível a ruídos e interferências eletromagnéticas.

Tendo em vista estes fatos, foi proposto o desenvolvimento de uma nova versão dos módulos de controle do veículo, composto por dois tipos de placas englobando todas as funcionalidades necessárias.

Uma das placas desenvolvidas é utilizada nos módulos principal e no de interface com atuadores, contendo circuitos para interfaces de rede CAN e RS-232 e canais de leitura analógica para interface com o sistema de acionamento do propulsor. Foi implementado também um circuito para conversão do sinal gerado pelo conversor D/A do microcontrolador nos sinais compatíveis com o acionamento do propulsor.

Além disso, este modelo de placa possui ainda um conector para instalação de um cartão 


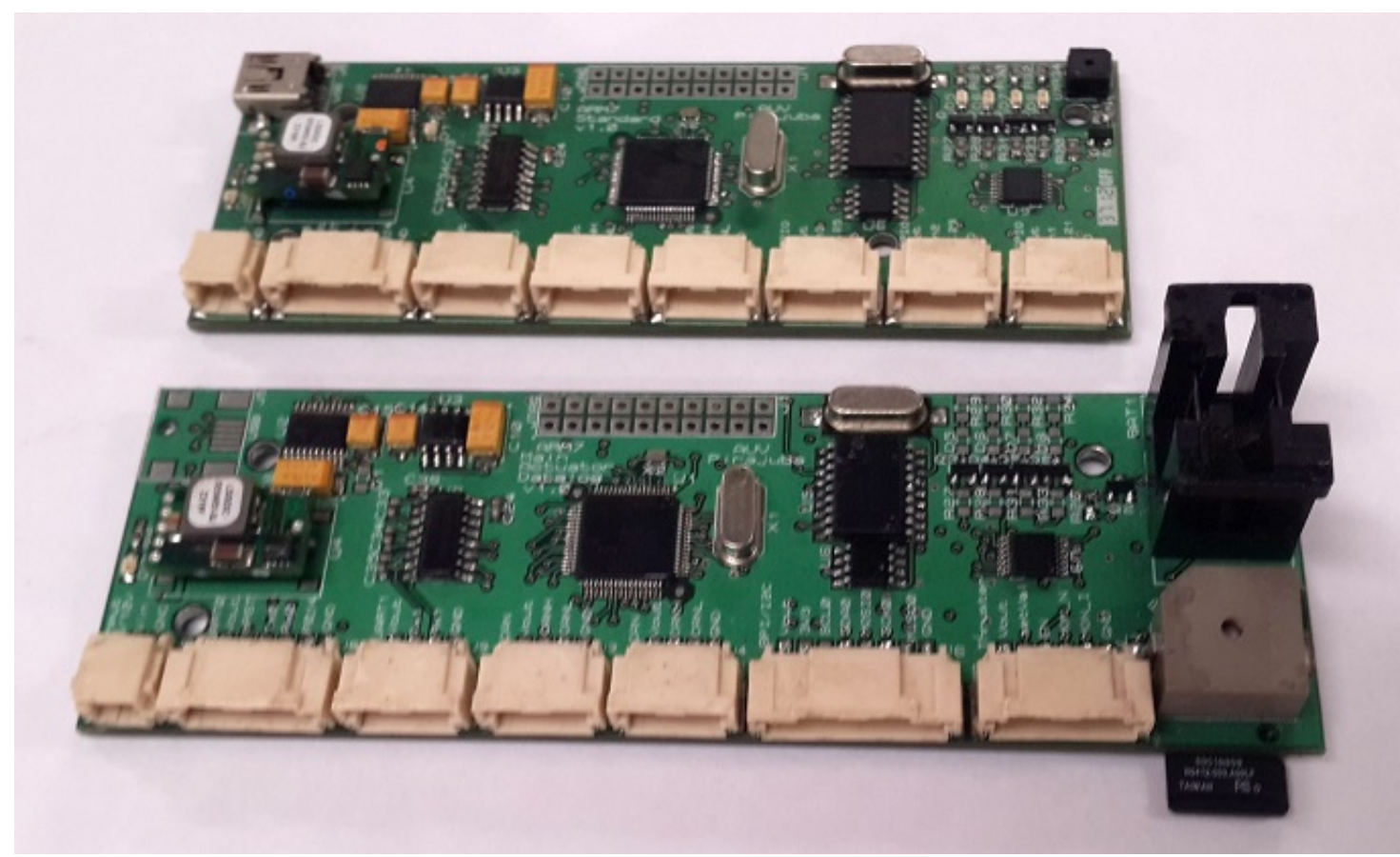

Figura 4.10 - Placas desenvolvidas para implementação dos módulos de processamento da arquitetura de controle.

de memória tipo micro-SD, utilizado para armazenamento de dados da missão, e um conector para uma bateria de lítio do tipo CR3032, utilizada para o módulo de real time clock. A segunda placa desenvolvida é utilizada no restante dos módulos, tem dimensões menores e possui as interfaces de rede CAN e RS-232 e conectores com interfaces digitais simples, para acionamento dos conversores de energia e leitura dos sensores de inundação. A Figura $\underline{4.10}$ apresenta os dois modelos de placas projetados para os módulos de processamento do veículo após a fabricação e montagem.

\subsection{Conectores}

Os conectores utilizados nesta nova versão do hardware foram selecionados tendo em vista duas características principais: área de placa ocupada e robustez a vibrações.

Conectores de Sinal e Comunicação Optou-se por utilizar o mesmo tipo de conector para ligações de sinal e de comunicação, englobando todas as ligações de baixa potência e interfaces do microcontrolador. Foram selecionados os conectores da série Duraclik, da fabricante Molex, com variantes de dois a oito pinos.

Estes conectores possuem um mecanismo de trava audível, permitindo ao operador se certificar de que foram inseridos corretamente, além de evitar a desconexão com vibrações e impactos. A corrente máxima aceitável é de 1A por pino, suficiente para as funções utilizadas. Os conectores são polarizados, impedindo que sejam montados na orientação errada. 
Conectores de Potência Os conectores de alimentação utilizados no barramento de tensão das baterias foram selecionados da série MicroFit3.0, do mesmo fabricante, que possuem variantes para conexão entre fios ou entre fio e placa.

Estes conectores são feitos em diversos formatos e são polarizados, com capacidade de 8.5 A por pino. As conexões de energia entre os vasos foram feitas através de conectores com quantidades de pinos diferentes, impossibilitando a ligação errada.

\subsection{Considerações sobre confiabilidade}

Para reduzir o volume ocupado pelos módulos de controle, foi descartada a opção de utilizar caixas individuais para acondicionamento dos módulos. Para evitar uma perda significativa de confiabilidade devido às condições ambientais favoráveis à corrosão, foram aplicadas camadas de um verniz de proteção de base acrílica.

Embora menos efetiva que o condicionamento dos módulos em caixas contendo sílica-gel para reduzir a umidade, esta solução se mostrou robusta o bastante e capaz de reduzir consideravelmente o volume ocupado pelos módulos, permitindo liberar um grande espaço no vaso de pressão para instalação de equipamentos de carga-científica.

\subsection{Interferências eletromagnéticas}

Ao longo das operações, foram observadas falhas esporádicas que ocorriam nas comunicações entre os equipamentos, ou a reinicialização de alguns módulos de controle, que era detectada pelos intertravamentos de segurança.

Através de um estudo do sistema, foi observado que, com o aumento do número de equipamentos e sensores instalados no veículo, ocorria o superaquecimento dos conversores CC-CC dos barramentos de tensão principais. Tal aquecimento não chegava a provocar a falha ou desligamento dos conversores, mas aumentava a incidência de ruídos nos barramentos de tensão. Para solucionar este problema foram instalados dissipadores de calor nos conversores.

O estudo mostrou também que os conversores utilizados nas placas dos módulos eram muito susceptíveis a interferências eletromagnéticas, causando uma queda em sua tensão de saída. Para evitar este problema, estes conversores foram substituídos por reguladores lineares que, embora tenham menor eficiência na conversão energética, são menos afetados por interferências eletromagnéticas.

\subsubsection{Arquitetura de Software}

A arquitetura de software continua utilizando uma distribuição em camadas, no entanto optou-se por adicionar uma camada de interface com os equipamentos, facilitando a organização, adição e substituição destes.

Para os atuadores, foi criado um nível de abstração nos módulos, de forma que a alteração 
dos atuadores não interfira nos módulos da camada acima. Esta modificação se mostrou benéfica para a substituição dos atuadores dos lemes, que eram servomotores simples de interface PWM e passaram a ser feitos através de conjuntos motor-redutor-sensor com sistemas de acionamento de interface digital.

Outro caso onde esta camada se mostrou benéfica foi durante a realização de testes com um propulsor comercial da empresa Tecnadyne, permitindo que a mudança no software fosse feita facilmente, limitando a tensão do sinal de referência gerado para os níveis utilizados pelo propulsor, sem necessidade de modificações no hardware.

Além da inclusão desta camada, foi adicionada uma série de módulos implementando novas funcionalidades. Uma das funcionalidades de maior impacto no sistema foi a adição de um módulo para gerenciamento de máquinas de estados, aplicado em todas as unidades de processamento.

Esta funcionalidade facilita a sincronização dos processos e a adição de ações que devam ser executadas durante estados ou transições específicas, como ligar e desligar o conversor do barramento de $24 \mathrm{~V}$ durante o início e fim da manobra, ou alterar a frequência com que os dados são salvos no cartão de memória, que eram realizados através de máquinas de estados independentes em cada módulo, dificultando a sincronização das ações. A Figura $\underline{4.11}$ apresenta os módulos e sua divisão em camadas.

\subsection{Lógica de controle}

A lógica de controle utilizada no sistema pode ser considerada do tipo híbrida, com características de arquiteturas deliberativas e reativas. O funcionamento típico do sistema, incluindo gerenciamento da missão, sequenciamento de manobra e distribuição das funcionalidades de controle e leitura de sensores é feito de forma semelhante à arquitetura baseada em agentes $[\underline{132}, \underline{119}]$, podendo-se identificar três principais módulos, com as funções de "Capitão", "Timoneiro"e "Piloto".

O módulo "Capitão", conhecido como Main, é responsável por ordenar o início e fim de manobra, enviar os parâmetros utilizados e sequenciar uma máquina de estados que sincroniza todos os módulos. O módulo "Piloto", conhecido como Auto, realiza o sequenciamento da manobra realizada e os algoritmos de controle necessários para sua realização, enviando comandos para o módulo "Timoneiro", como ângulos de lemes e rotações do propulsor. O módulo "Timoneiro", conhecido como Actuator, recebe as ordens de referências para os atuadores e executa a comunicação com os sistemas de acionamento destes.

As ações de característica reativas foram implementadas na forma de intertravamentos de segurança programados no módulo "Timoneiro", pois este se comunica diretamente com os atuadores e pode executar ações rapidamente, mesmo com falhas no barramento de comunicação principal.

As ações reativas tem como objetivo evitar que o veículo ultrapasse limites de segurança, 


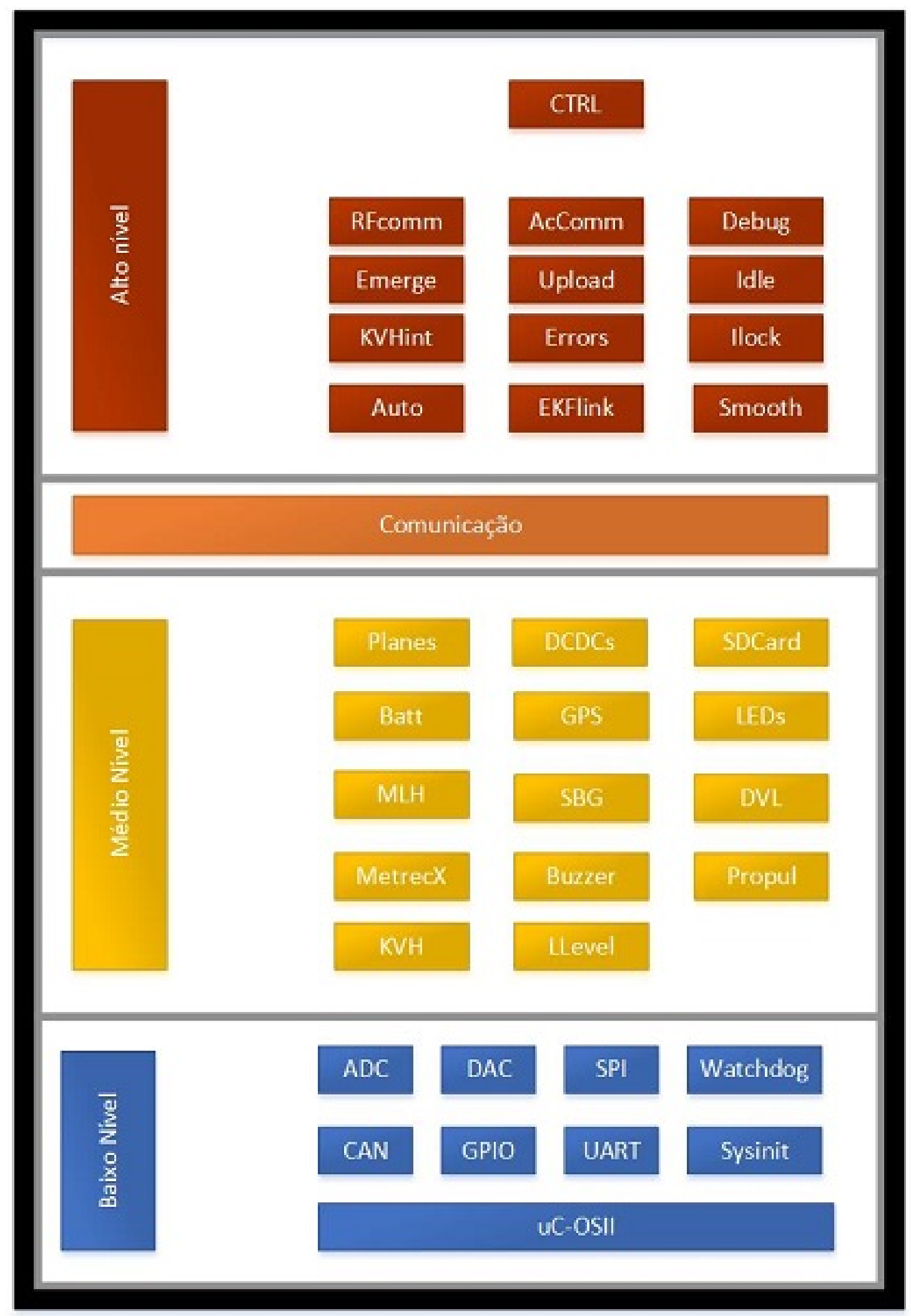

Figura 4.11 - Divisão em camadas dos módulos implementados em software. 


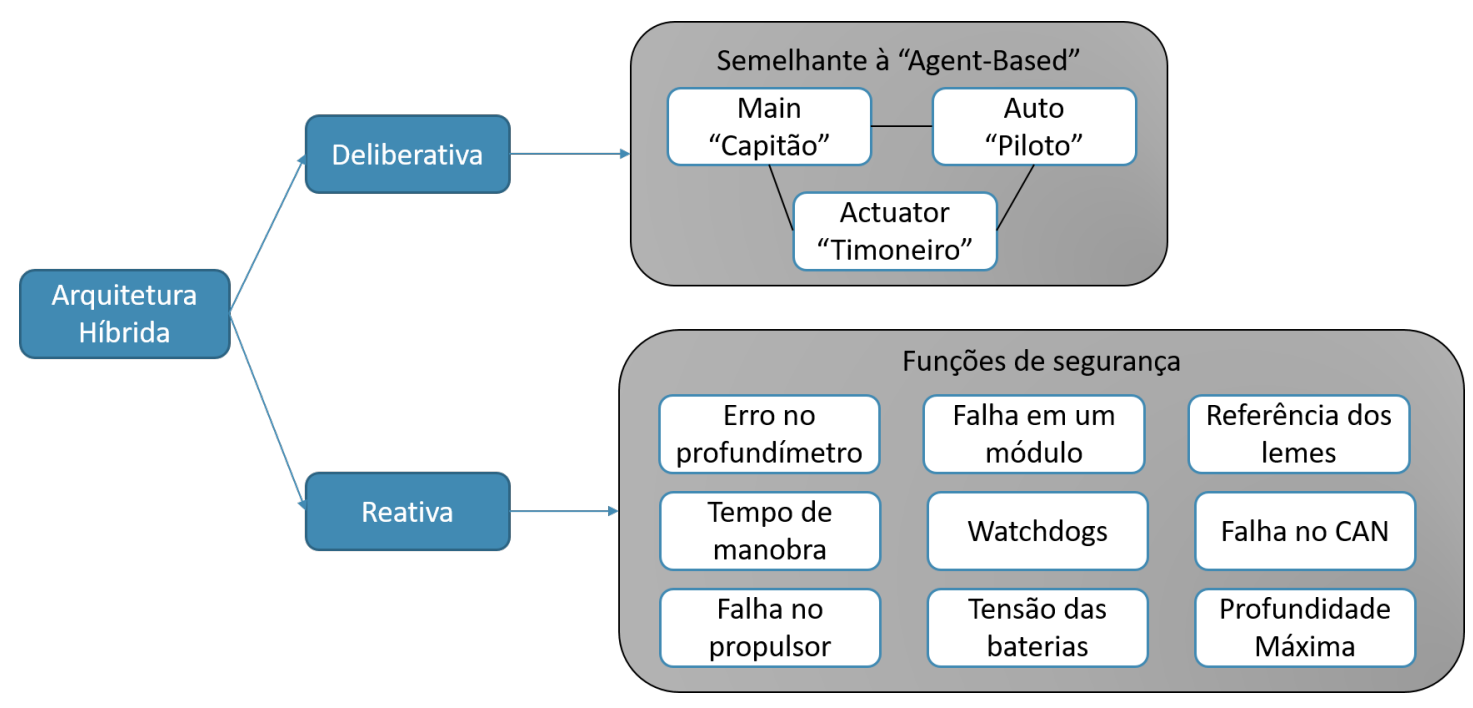

Figura 4.12 - Diagrama da lógica de controle híbrida do sistema.

ou retorne à superfície em caso de falhas de comunicação, inundação, etc. A seguir são apresentados os possíveis problemas detectados:

- Erro de leitura do profundímetro;

- Falha de comunicação de algum módulo do sistema;

- Ausência de referência de posição dos lemes;

- Tempo de manobra excessivo;

- Identificação de reinicialização em algum módulo de controle;

- Falha no barramento principal de comunicação;

- Falha no propulsor;

- Tensão excessivamente baixa nas baterias;

- Profundidade superior ao limite estabelecido para a missão.

A Figura 4.12 exemplifica as características da arquitetura de controle híbrida utilizada:

\subsubsection{Distribuição dos equipamentos e funcionalidades}

A distribuição das interfaces com os equipamentos e funcionalidades entre os módulos foi feita procurando agrupar as responsabilidades semelhantes em torno de um mesmo módulo, mas respeitando os limites impostos pela quantidade de interfaces disponíveis em cada módulo. O principal limitante observado ao longo dos anos foi o número de portas de comunicação serial RS-232, uma vez que a maior parte dos equipamentos utilizados 
até hoje utiliza este protocolo de comunicação. Atualmente, são utilizados seis módulos de processadores no veículo, além dos dois utilizados para realização dos algoritmos de navegação.

\subsection{Módulo Principal}

O módulo principal exerce a função semelhante à de capitão do veículo, coordenando as transições de estado, início e fim da manobra. Este módulo possui também as funcionalidades de comunicação através do canal de rádio e do canal acústico, permitindo receber os comandos e parâmetros do operador e retransmitindo aos outros módulos através da rede CAN quando necessário.

Outra funcionalidade deste módulo é o registro de dados da manobra no cartão de memória. Esta funcionalidade foi incumbida à este módulo para facilitar a descarga dos dados através do canal de rádio, sem a necessidade de transmitir todos os dados armazenados via rede CAN. Além disso, durante a execução da manobra este módulo possui poucas responsabilidades, tendo capacidade de processamento suficiente para realizar a função de armazenamento dos dados. Durante os períodos entre manobras a frequência de armazenamento de dados é reduzida, liberando o processador para executar as funções de comunicação.

\subsection{Módulo de piloto automático}

O módulo de piloto automático não possui interface com nenhum equipamento, seja sensor ou atuador. Ele é responsável unicamente pela execução dos algoritmos de controle e do sequenciamento das manobras pré-programadas. Estas funcionalidade foram isoladas num módulo de forma a aumentar a estabilidade do código dos outros módulos, uma vez que ao longo do desenvolvimento verificou-se que era a funcionalidade com maior numero de alterações e expansões.

A disponibilidade de canais de comunicação via RS-232 permite que este módulo seja utilizado para implementar um esquema do tipo back-seat/front-seat, que pode ser necessário caso a complexidade das missões aumente e seja observado o fenômeno do fat-agent.

\subsection{Módulo de Interface com sensores}

Um dos módulos de controle é responsável apenas por leitura de alguns sensores, são eles: AHRS, GPS, sensor de pressão e sensores de inundação. Este módulo possui poucas funcionalidades e seu código é bastante estável, praticamente não sendo necessária sua reprogramação. 


\subsection{Módulo de Interface com sistema de navegação}

Foi utilizado um módulo para fazer a interface com o processador que implementa um filtro de Kalman estendido para estimativa de posição, através de uma comunicação RS-232.

Este módulo faz também a leitura da IMU, que opera em frequência de $100 \mathrm{~Hz}$. A concentração destas duas funcionalidades permite que os dados da IMU sejam enviados na frequência máxima para o módulo de $\mathrm{EKF}$, mas enviados numa frequência menor para o barramento CAN, evitando consumo excessivo de banda. Atualmente, os dados da IMU são enviados ao barramento numa frequência de $25 \mathrm{~Hz}$.

\subsection{Módulo de Interface com sensores externos}

Um módulo faz a interface com os sensores externos do veículo, DVL e sonda de qualidade d'água. Estes equipamentos, embora possam ser utilizados para os sistemas de navegação e controle, são também cargas-científicas, e por isso foram agrupados num único módulo.

\subsection{Módulo de Interface com atuadores}

Finalmente, o último módulo é responsável pela interface com o sistema de propulsão e com os atuadores do leme. Este módulo fica instalado no vaso de manobra e recebe do veículo os valores de referência (set-points) de ângulos dos lemes e rotação do propulsor através da rede CAN, encaminhando-os aos sistemas de acionamento através de sinais analógicos, no caso do propulsor, ou por comunicação RS-232, no caso dos lemes. Neste módulo foram também colocadas as funcionalidades de segurança, uma vez que é o único que faz interface com os atuadores e tem alguma capacidade de resposta em caso de falhas de comunicação entre os vasos.

\subsubsection{Fluxo de dados}

Através de uma interface gráfica, é possível configurar os parâmetros da manobra que será realizada. Cada parâmetro é enviado ao veículo e em seguida é realizada uma leitura dos parâmetros armazenados no veículo para conferência do sucesso da configuração. O canal de comunicação utilizado é o link de rádio, que se liga ao módulo principal. Uma vez recebidos os parâmetros, eles são enviados à memória compartilhada e sincronizados automaticamente entre todos os módulos através da rede CAN.

As leituras de sensores são realizadas automaticamente pelos módulos e enviadas para a memória compartilhada. Através da interface gráfica é possível solicitar a leitura dos dados das mensagens definidas na memória compartilhada. Os comandos disponíveis para iniciar e parar manobras são enviados ao módulo principal, que atua então na camada 
de gerenciamento de estados do veículo. Alguns comandos são enviados ao barramento CAN através de uma mensagem dedicada para isso, como zerar posição dos lemes e zerar a leitura de profundidade. 


\section{Resultados}

\subsection{Resultados dos ensaios}

Foram realizadas seis incursões de testes de mar, cada uma com duração aproximada de uma semana. Foi selecionada uma manobra de longa duração para análise dos resultados. Todos os dados apresentados a seguir, exceto aqueles que combinam dados de vários dias, referem-se a essa mesma manobra. Os gráficos foram gerados a partir dos dados salvos do sistema de data-log do veículo, armazenados num cartão de memória. A frequência de aquisição utilizada foi de $10 \mathrm{~Hz}$, e os ensaios foram realizados com o intuito de fazer o levantamento de dados para os estudos oceanográficos, bem como validar a arquitetura e testar seu funcionamento em campo.

A manobra analisada é composta por cinco trechos, identificados na Figura 5.14. Nos segmentos "A-B", "C-D"e "E-F"foi realizada a manobra de movimentação vertical, visando a coleta de dados para identificação das camadas finas. Os trechos "B-C"e "D-E"foram realizados com controle de profundidade e visavam distanciar os trechos de coleta de dados para aumentar a área de estudo.

\subsubsection{Navegação}

A Figura $\underline{5.13}$ permite visualizar o resultado da manobra realizada com a estimativa da trajetória executada apresentada sobre o mapa da região, obtido através do Google Earth. A Figura $\underline{5.14}$ apresenta o resultado obtido nos sistemas de navegação embarcados. Pode-se notar que houve uma falha interna módulo de navegação através do filtro de Kalman, que parou seu funcionamento a partir do instante identificado por uma seta no trecho "C-D".

O uso de um algoritmo de dead-reckoning mais simples em paralelo, estimando a posição pela integração da velocidade rotacionada de acordo com a atitude do veículo fornecida por uma $A H R S$, permitiu obter uma estimativa da posição durante o restante da manobra.

\subsubsection{Controle de Pitch}

A Figura $\underline{5.15}$ mostra a variação da profundidade e o resultado do controle de pitch durante parte do trecho "C-D", com manobra de movimentação vertical. Os limites de profundidade utilizados para alternância da referência de pitch foram 2 e 12 m. Os set-points utilizados 


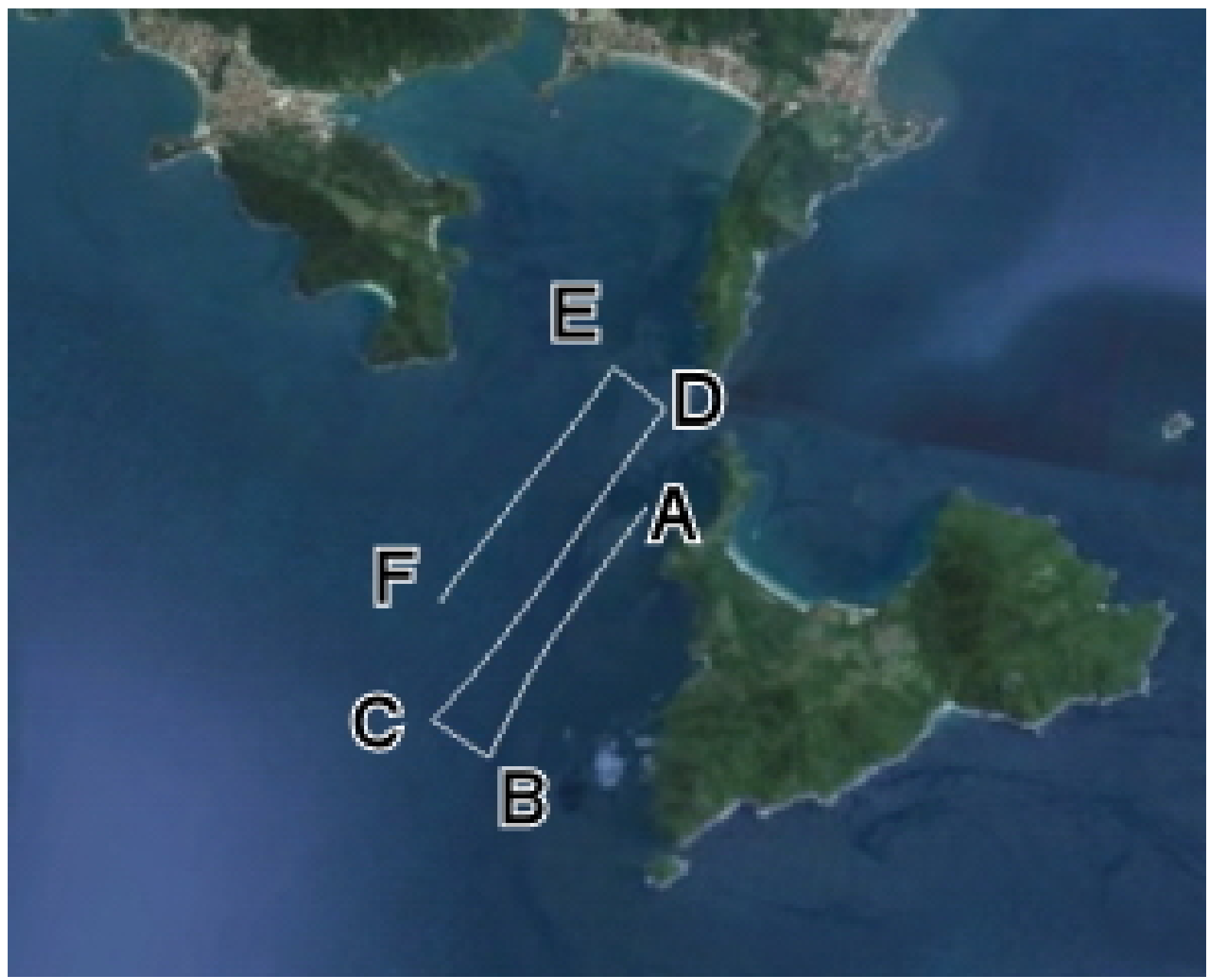

Figura 5.13 - Posição do veículo estimada pelo sistema de navegação apresentada sobre o mapa da região.

para os ângulos de subida e descida foram $+17^{\circ} \mathrm{e}-17^{\circ}$.

\subsubsection{Controle de Profundidade}

A Figura $\underline{5.16}$ mostra uma parte do trecho "B-C"da manobra, executado em controle de profundidade com referência de $2 \mathrm{~m}$. É possível verificar que, embora exista a presença de oscilações de alta frequência nos atuadores, o controlador foi capaz de manter a profundidade estável em torno do valor de referência.

\subsubsection{Controle de Rumo}

A Figura $\underline{5.17}$ apresenta a variação do rumo do veículo ao longo da manobra. Verificase que nos trechos de manobra no plano vertical ("A-B", "C-D"e "E-F") houve um pior desempenho do controle de rumo, que pode ser provocado pelo acoplamento dos movimentos horizontal e vertical devido à rolagem do veículo induzida pelo propulsor e por um possível 


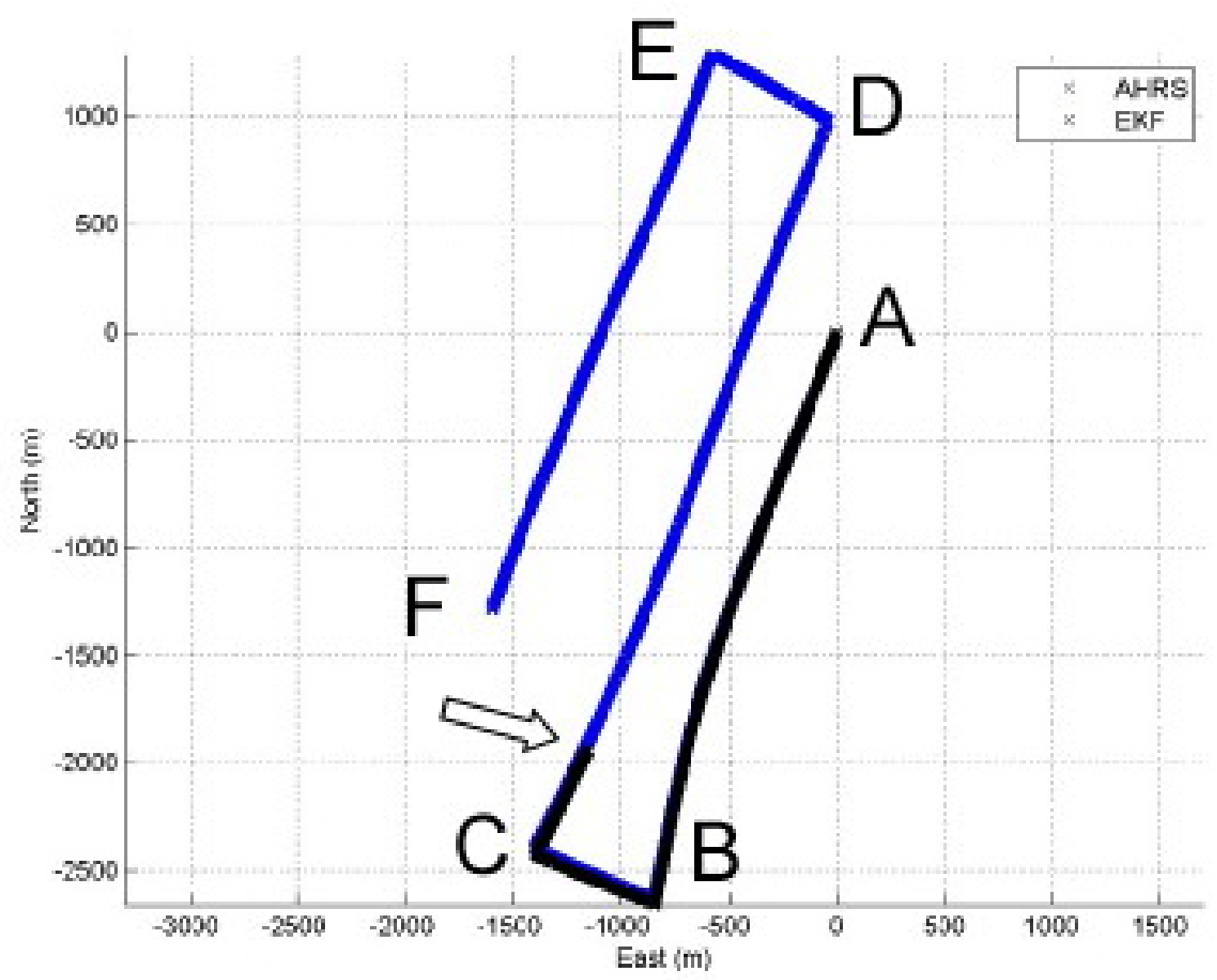

Figura 5.14 - Resultado dos algoritmos de navegação por EKF e dead-reckoning através dos dados da AHRS.

desalinhamento entre os sensores e atuadores.

A Figura $\underline{5.18}$ mostra um trecho de variação do rumo em detalhe, juntamente com a ação de controle realizada pelo leme. É possível identificar um desempenho satisfatório do controlador durante os períodos de mudança de rumo analisando o gráfico do detalhe. A variação de 90 graus no rumo ocorre em aproximadamente 7 segundos, sem sobressinal significativo e oscila em baixa frequência em torno do valor de referência.

\subsubsection{Sensores Oceanográficos}

A Figura $\underline{5.19}$ apresenta a variação temporal, ao longo de toda a manobra, da medição de profundidade, temperatura e condutividade obtidos pela sonda multi-parâmetros. Na Figura 5.20 é possível visualizar, num trecho da manobra, os dados com maiores detalhes.

A Figura $\underline{5.21}$ apresenta um perfil de temperatura da coluna d'água, com sua variação em função da profundidade. É possível identificar que, em torno dos $8 \mathrm{~m}$, há uma variação maior de temperatura, que pode indicar a formação de uma camada fina. As Figuras $\underline{5.22}$ 

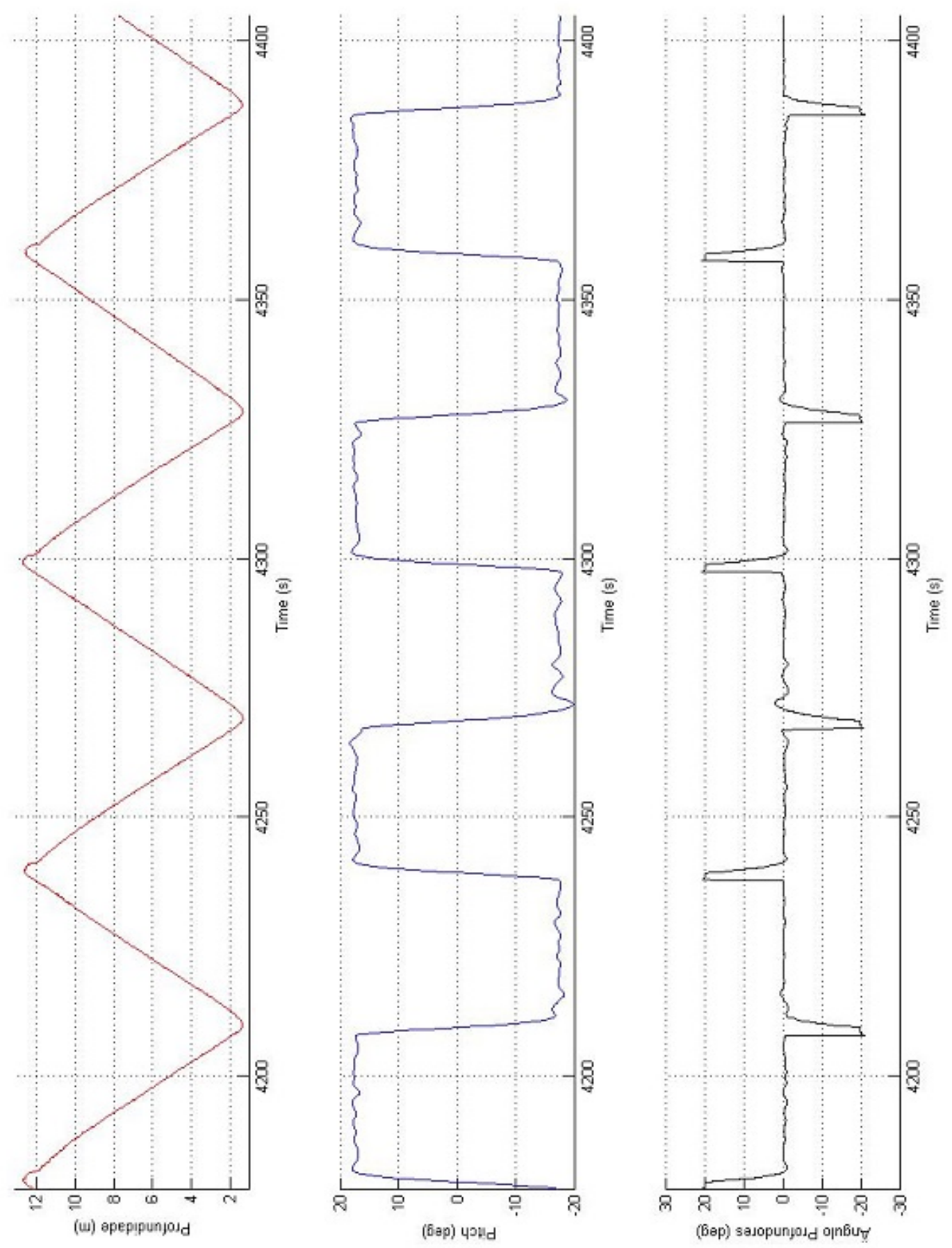

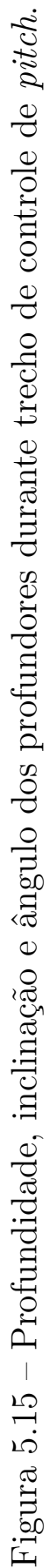




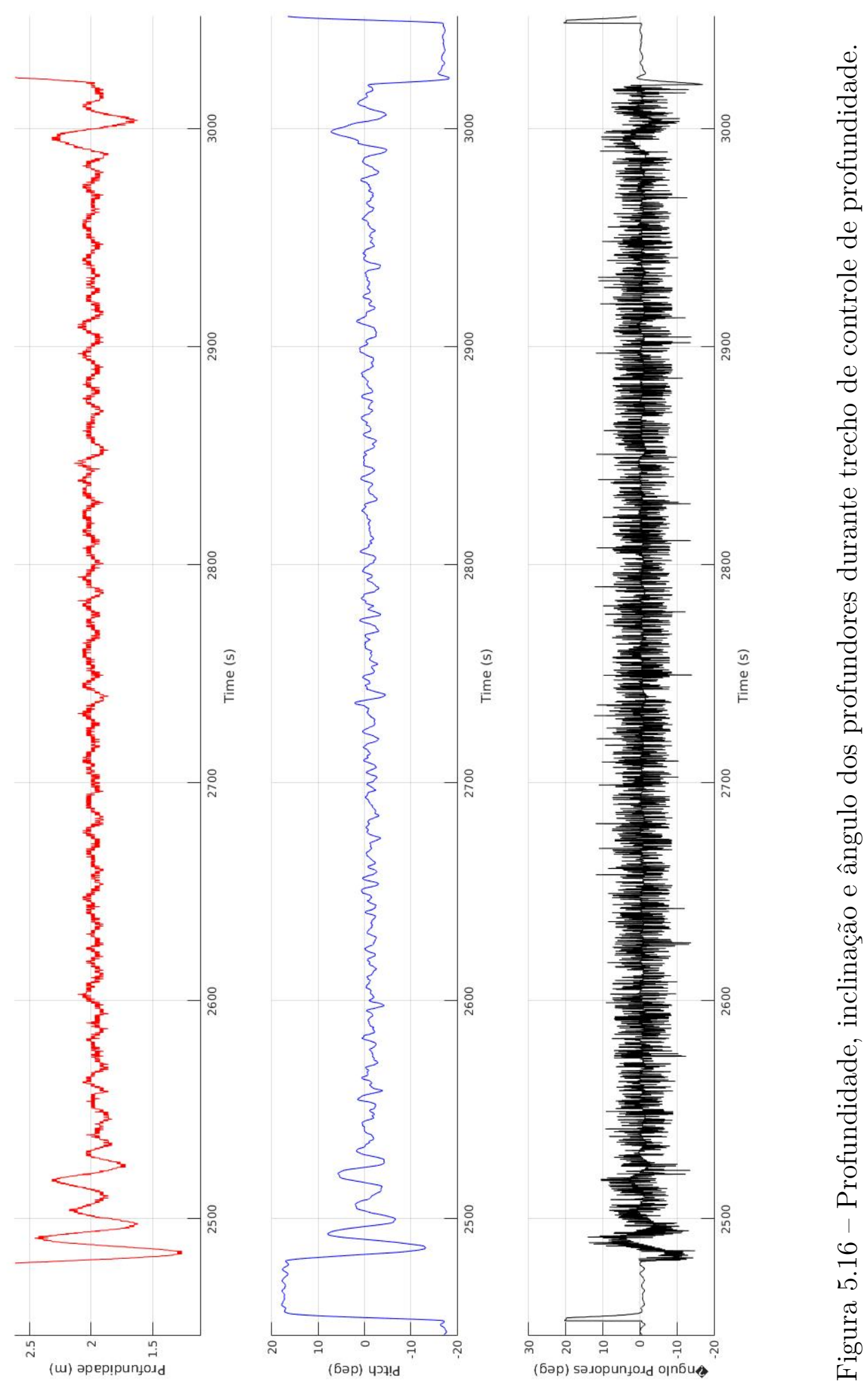




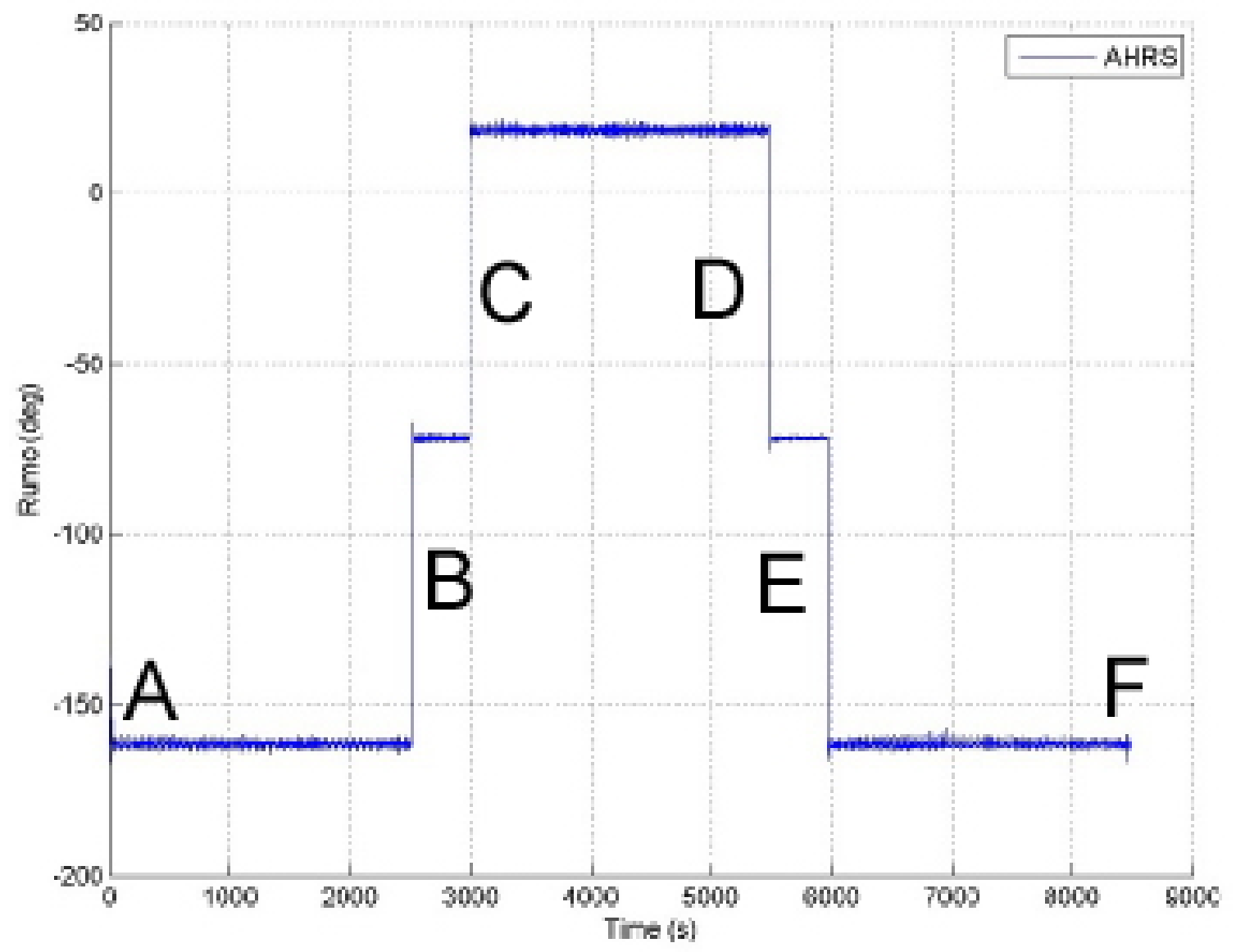

Figura 5.17 - Rumo obtido da AHRS.

e $\underline{5.23}$ permitem comparar a distribuição dos perfis de temperatura e da salinidade obtidas em dois dias de ensaios. A Figura 5.24 mostra os dados coletados pelos sensores ópticos. Para detecção das camadas é necessária a análise e processamento destes dados em conjunto com as medidas de profundidade, temperatura e salinidade obtidos. As indicações M1, M2, M3 e M4 referem-se aos canais de leituras analógicos da sonda, utilizados para aquisição dos sensores de clorofila, ficoeritrina, matéria orgânica em suspensão e retroespalhamento óptico.

\subsection{Análise do sistema embarcado}

Com a realização dos ensaios de campo foi possível identificar e corrigir diversas falhas no sistema, além de verificar pontos que poderiam ser modificados para facilitar a operação, como a adição de um reed-switch para ligar e desligar o veículo, adição de uma vela para suporte das antenas de comunicação, e instalação de lastros para ajustes de flutuabilidade, inclinação e rolagem. O capítulo anterior expõe o resultado do sistema ao final destas missões, já com as modificações realizadas. 

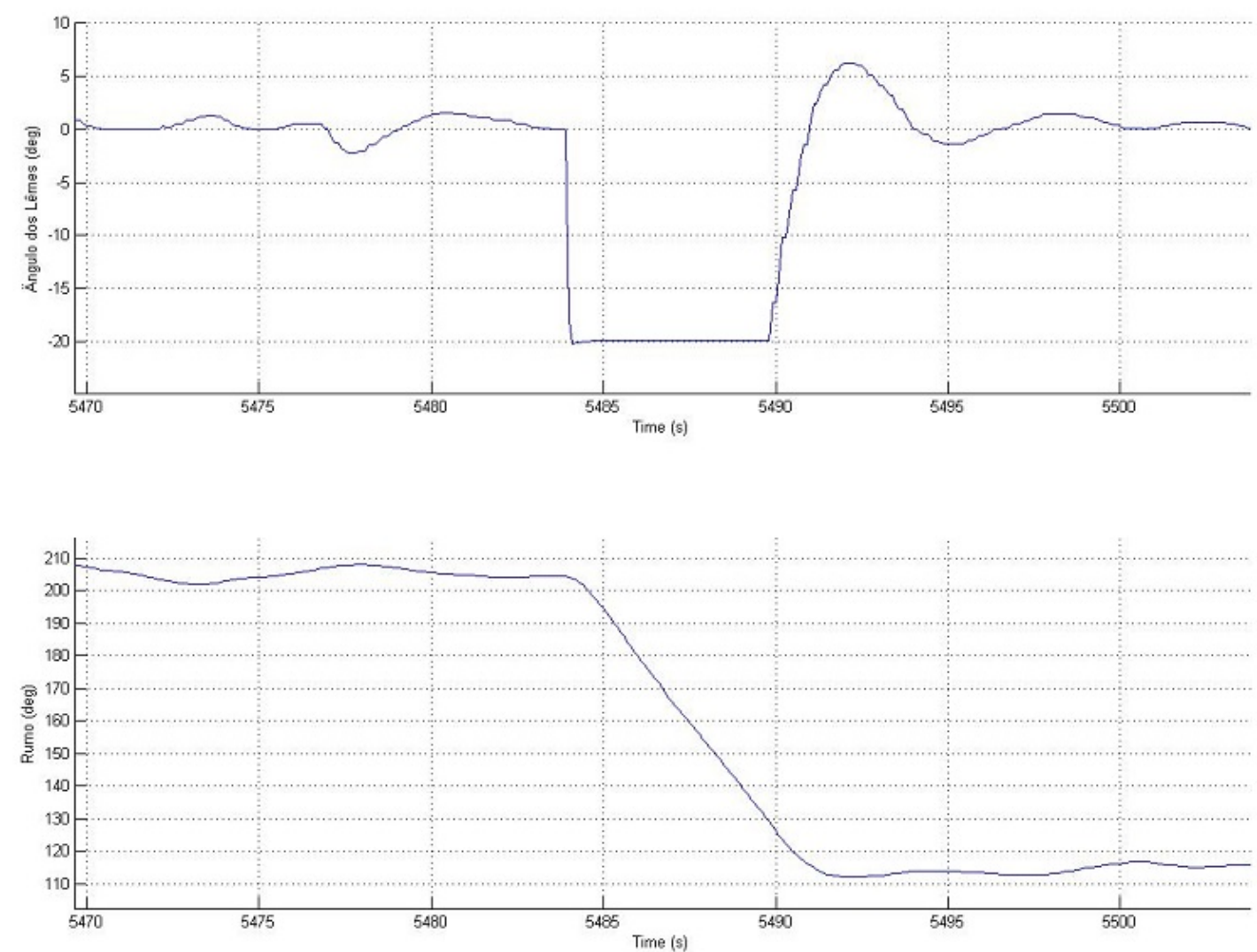

Figura 5.18 - Detalhe da variação do rumo e ângulo dos lemes.

\subsubsection{Desempenho da arquitetura de controle}

Alguns eventos ocorridos nos ensaios realizados permitiram identificar benefícios da arquitetura de controle utilizada. A seguir são apresentados exemplos de funcionamentos satisfatórios do sistema.

\subsubsection{Intertravamentos de segurança}

Os intertravamentos de segurança implementados no veículo foram fundamentais para segurança das operações. Como exemplo, pode-se citar a execução de uma manobra para regulagem de parâmetros dos controladores na qual uma reação de emersão inicializada pelo sistema de segurança, em função do limite de profundidade, evitou que o veículo se chocasse com o fundo devido ao sobressinal do controlador.

Outro exemplo de reação da arquitetura foi durante uma manobra realizada em que ocorreu um desbalanceamento significativo de uma das células de bateria, e uma reação 

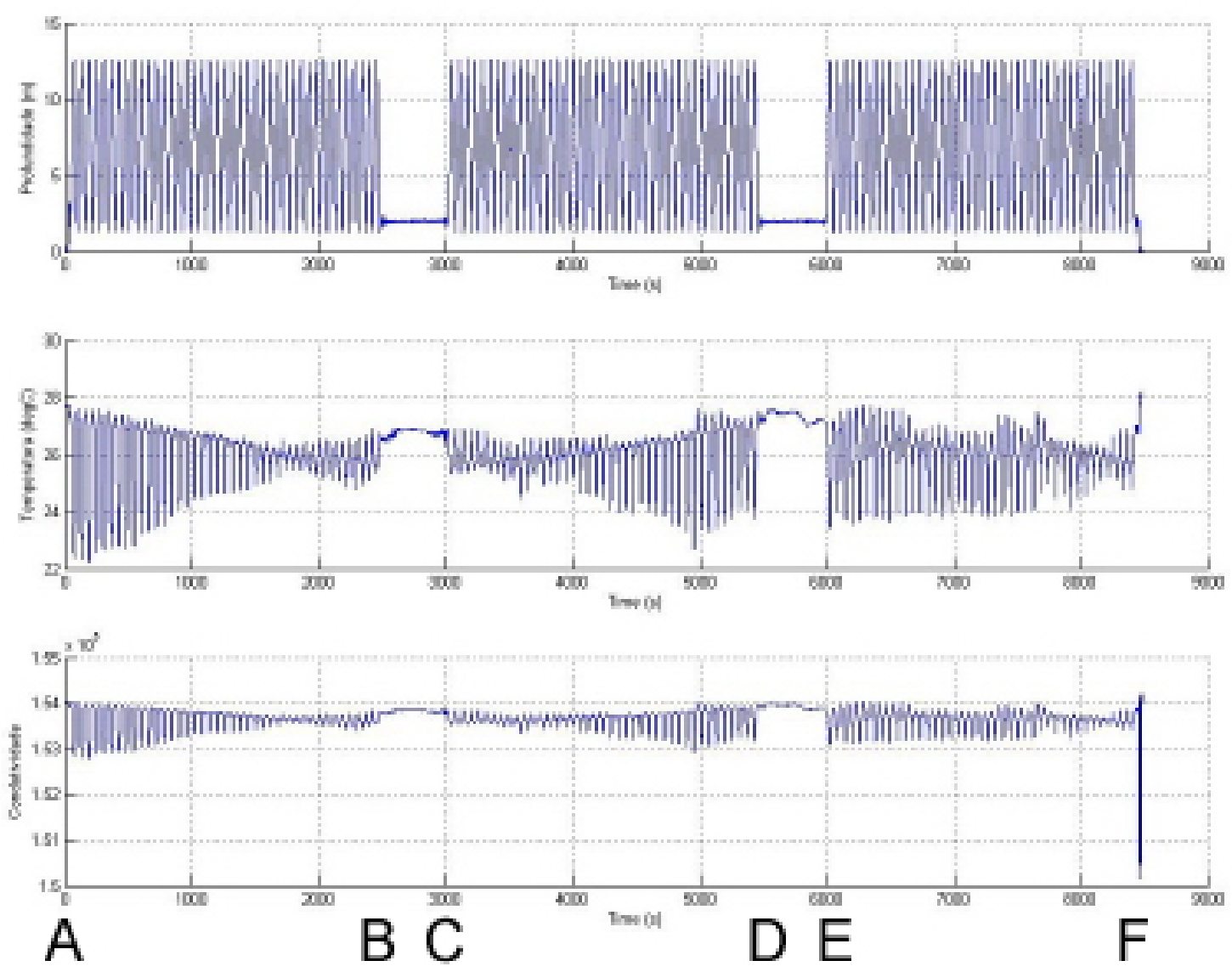

Figura 5.19 - Dados de temperatura e condutividade durante a manobra.

de emersão fez com que o veículo encerrasse a manobra e retornasse à superfície, evitando a descarga excessiva da célula que poderia danificá-la.

\subsection{Análise das operações}

A seguir é apresentada uma série de discussões relativas às operações e suas relações com as características do veículo. São listadas diversas ocorrências identificadas durante as operações, bem como sugestões para facilitar os procedimentos.

\subsubsection{Vibrações e impactos}

Durante a realização das missões é comum a ocorrência de vibrações e impactos no veículo. Vibrações ocorrem principalmente durante o transporte, tanto na estrada quanto na movimentação entre estes e o laboratório.

Impactos também podem ocorrer durante procedimentos de colocar ou retirar o veículo na água, bem como com a incidência de marolas na movimentação do barco. 

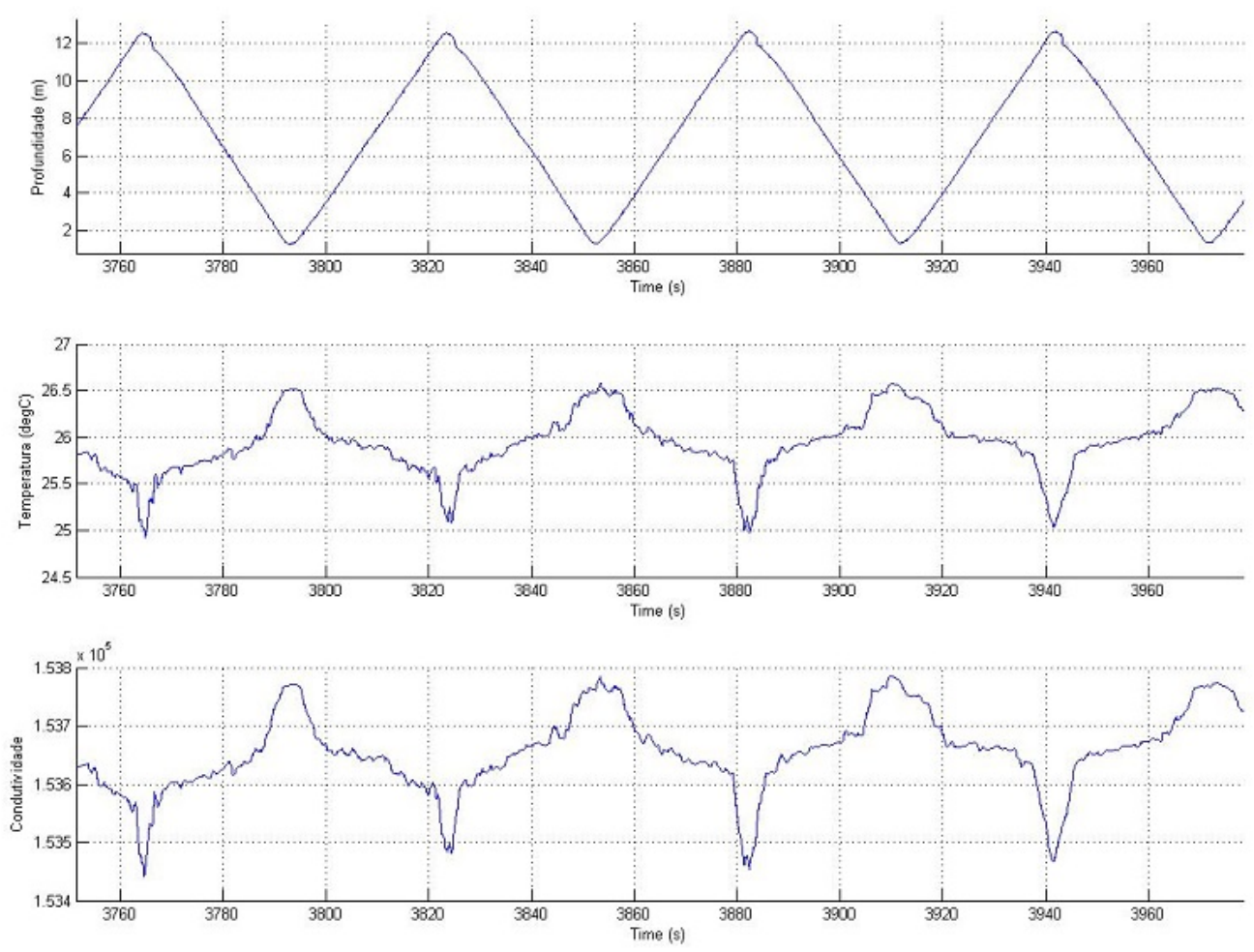

Figura 5.20 - Detalhe da variação da profundidade, temperatura e condutividade ao longo do tempo.

É fundamental levar em conta tais ocorrências durante o desenvolvimento dos diversos aspectos do veículo. O casco do veículo deve ser projetado de forma a ter boa resistência mecânica, ao mesmo tempo sem aumentar consideravelmente seu peso, influenciando principalmente na escolha de materiais e mecanismos de fixação.

No projeto do sistema embarcado, é importante o uso de conectores com travas mecânicas, além de levar em conta mecanismos para fixação dos componentes no interior dos vasos de pressão.

Alguns equipamentos são especialmente sensíveis a impactos, como as unidades de medição inercial baseadas em sistemas ópticos e sensores de velocidade por efeito doppler. É recomendável, quando possível, retirar tais equipamentos durante o transporte e acondicioná-los em embalagens protegidas com plástico-bolha ou espumas, por exemplo.

A instalação de elementos amortecedores no interior do vaso de pressão pode ser uma opção interessante para os casos em que os equipamentos não podem ser retirados, tomando cuidado para que tal amortecimento não afete a dinâmica dos sensores de movimento. 


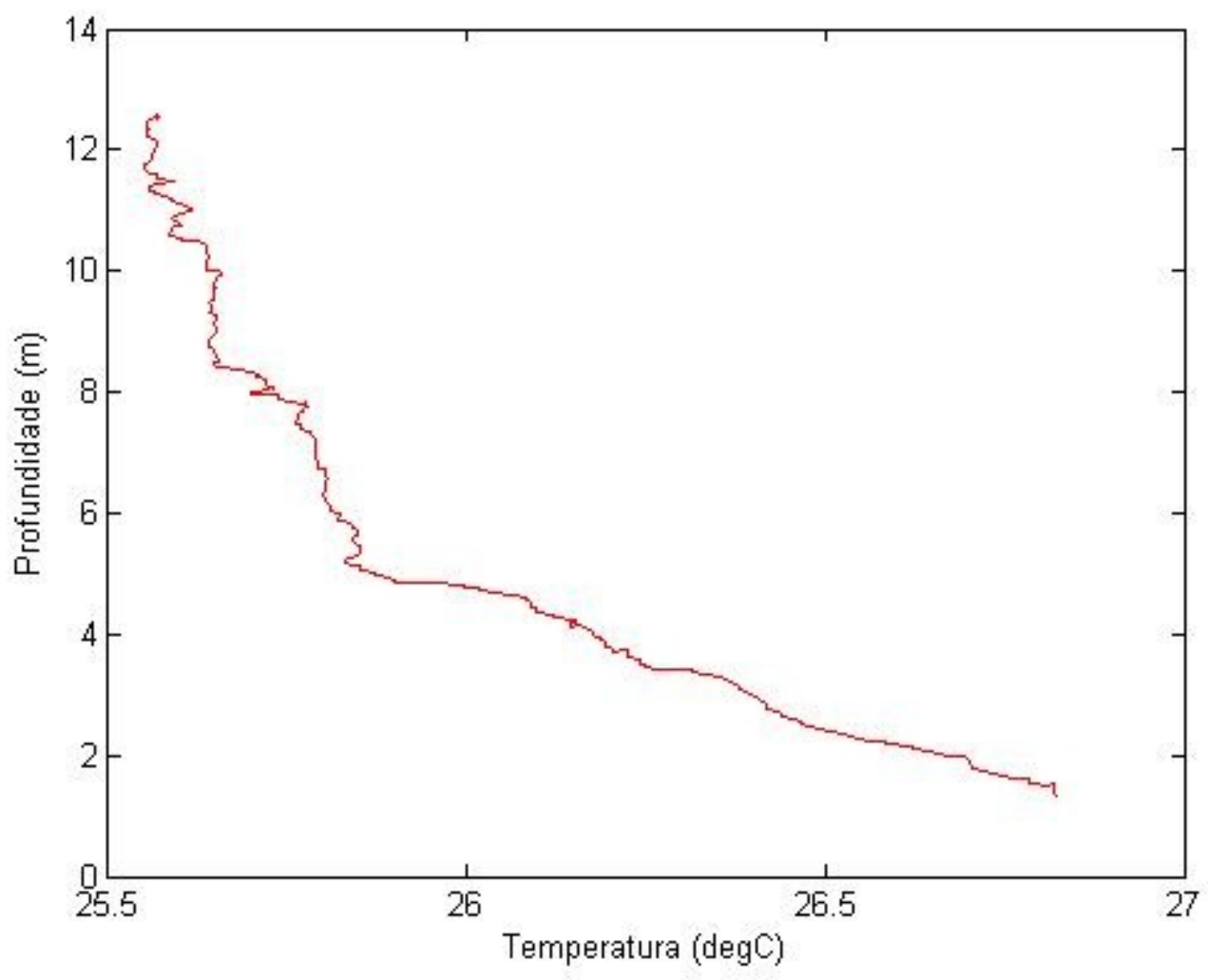

Figura 5.21 - Perfil de temperatura ao longo de uma descida.

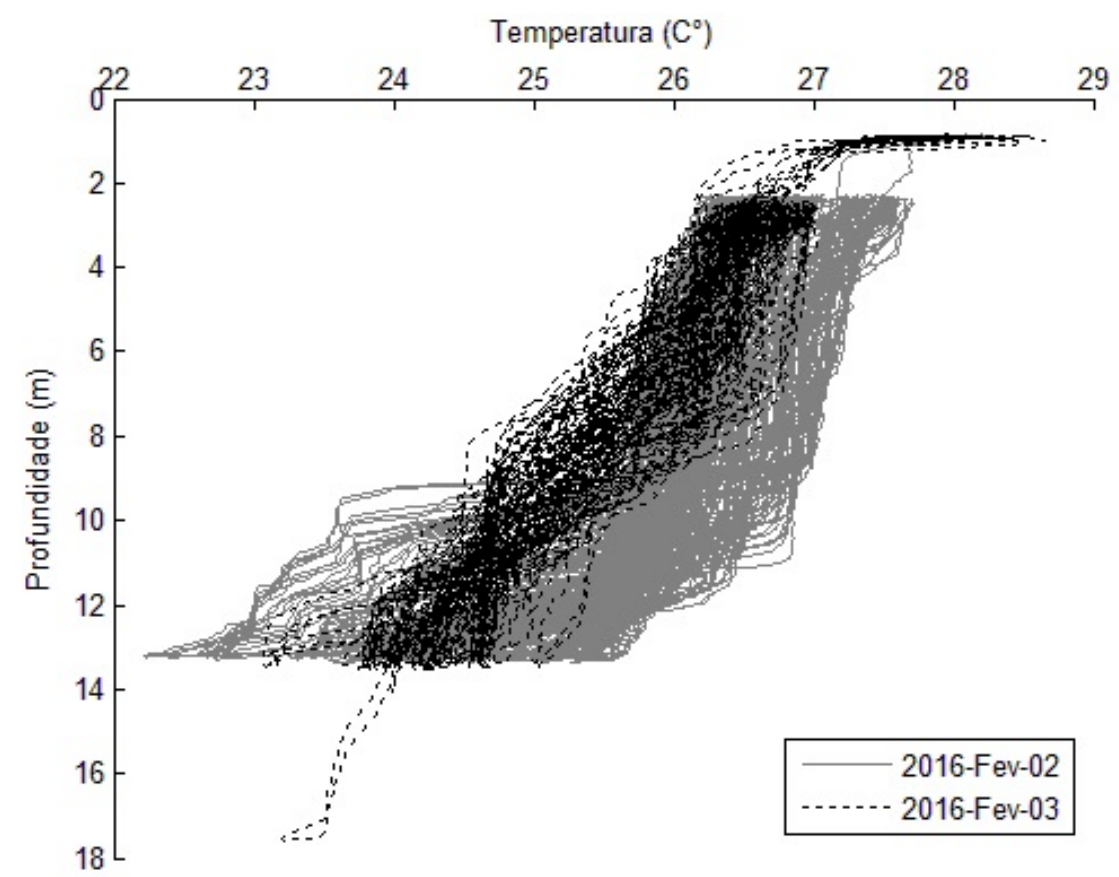

Figura 5.22 - Comparação da distribuição dos perfis de temperatura da região. 


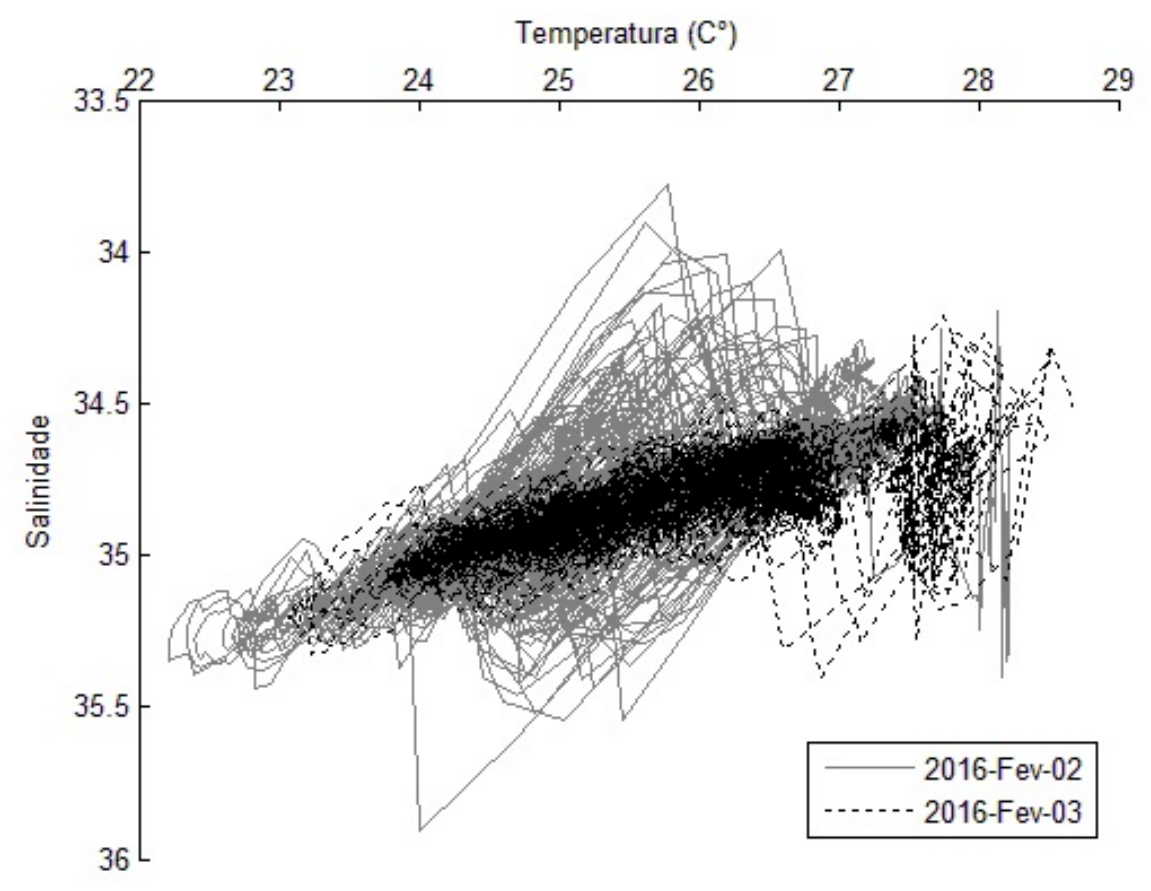

Figura 5.23 - Comparação da distribuição da salinidade em função da temperatura da região.

\subsubsection{Transporte}

Embora o veículo possua dimensões razoavelmente pequenas, seu transporte enfrenta uma série de dificuldades. O uso de um "berço"com rodas foi uma boa solução em diversas situações, mas apresentou dificuldades em trechos como escadas, pisos irregulares e na transferência do veículo entre o pier e a embarcação. Alguns pontos de melhorias observados foram:

- Uso de pneus de borracha ao invés de rodízios plásticos, aumentando a absorção de vibrações em pisos irregulares.

- Prolongamento das alças do berço, protegendo o contato do hélice ou do nariz do veículo

- Projeto do berço desmontável, facilitando seu armazenamento quando não está em uso

- possibilidade de remoção das rodas, ou travamento destas, pra acomodação do berço na embarcação

- instalação de pontos de fixação na estrutura do casco do veículo, permitindo prender o cabo do guincho 

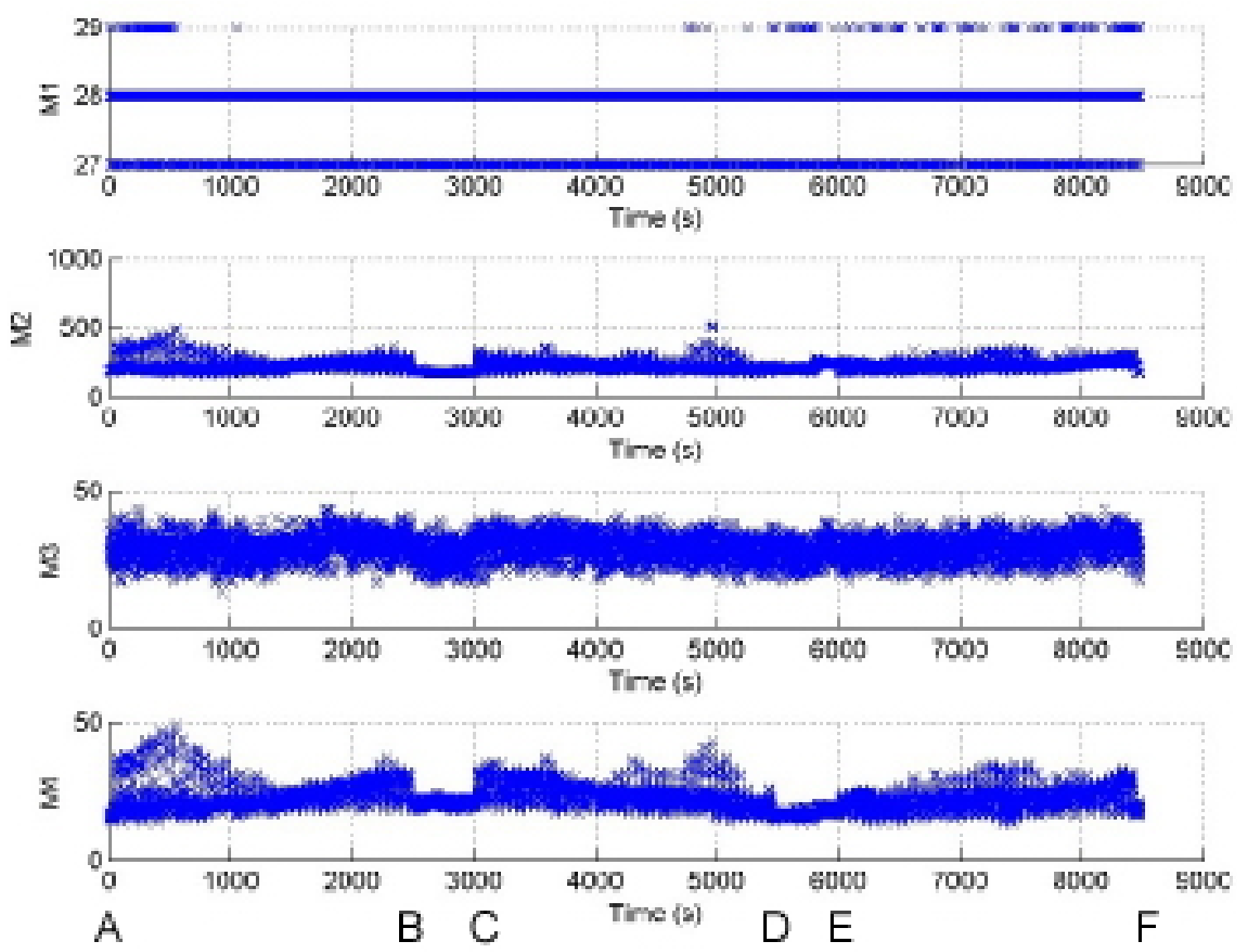

Figura 5.24 - Dados obtidos pelos sensores ópticos.

\subsubsection{Facilidade de Manutenção}

Por se tratar de um projeto em desenvolvimento, é comum a necessidade de realizar manutenções no sistema, tanto em laboratório quanto a bordo da embarcação. Assim, deve-se procurar facilitar tais atividades sempre que possível no projeto.

\subsubsection{Acesso aos componentes}

A primeira etapa durante um procedimento de manutenção costuma ser a abertura do casco do veículo. Esta etapa poderia ser facilitada criando acessos individuais aos vasos de pressão, como separação da tampa do corpo paralelo em dois trechos, um sobre o vaso principal, outro sobre o vaso de manobra.

A maior incidência de manutenções ocorreu no vaso principal, e tal separação evitaria a necessidade de retirada do leme superior do veículo nessas atividades, evitando também a necessidade de mais uma ferramenta, possibilidade de perda de parafusos e riscos de quebra do leme. 


\subsubsection{Abertura dos vasos}

A segunda etapa na manutenção consiste na abertura das tampas dos vasos de pressão. Um procedimento para facilitar esta etapa consiste em soltar os parafusos de fixação de uma das tampas e utilizar uma bomba manual para injetar pressão no interior do vaso, fazendo com que esta tampa se solte. A segunda tampa precisa ser solta de forma manual, o que pode ser facilitado com a instalação de alças ou pontos para fixação de puxadores. Um ponto importante a ser considerado na abertura das tampas dos vasos de pressão é o tensionamento nos fios de ligação entre a eletrônica interna e os conectores instalados nas tampas.

Uma estratégia para evitar que este movimento danifique as conexões seria fixar uma das tampas na prateleira que contem os equipamentos, e concentrar nela os conectores.

Outras possibilidades seriam o alívio de carga em chicotes ou recursos de distribuição de tensões mecânicas nos pigtails e chicotes.

\subsubsection{Recarga de baterias}

Ao final das missões, faz-se necessário realizar a recarga dos conjuntos de baterias de alimentação do veículo. O uso de baterias de polímeros de lítio traz alguns benefícios, como menor tempo de recarga comparado às diversas outras tecnologias. No entanto, esta tecnologia também traz complicações como a necessidade de um maior cuidado na configuração dos carregadores e acompanhamento do processo, uma vez que falhas podem ser catastróficas, provocando vazamento de gases tóxicos e gerando incêndios.

É interessante possuir dois jogos de baterias, de forma que ao final da missão possa ser feita uma rápida substituição e o veículo possa ser preparado para a próxima missão enquanto é feita a recarga das baterias que estavam em uso.

Alguns veículos comerciais possuem vasos de baterias independentes da eletrônica. Embora esta solução possa implicar num aumento das dimensões do veículo, e causar dificuldades no ajuste de pesos e centros, tal arranjo tem diversos benefícios, como não precisar expor a eletrônica durante a recarga, e ter uma separação física que pode impedir o dano a sensores causados por eventuais falhas em baterias.

\subsubsection{Reprogramação dos módulos}

Outra atividade bastante comum durante as manutenções é a reprogramação dos módulos de controle. Existem diversos métodos para tal, como interfaces JTAG, programação ISP e gravação do programa através de cartões de memória.

Alguns pontos importantes a serem observados durante a reprogramação são: velocidade de carregamento do programa, checagem do programa gravado e disponibilidade de conectores com fácil acesso. Além disso, é importante manter um controle cuidadoso das versões do 
software, que pode ser facilitado através de sistemas de controle de versões.

\subsubsection{Segurança das operações}

Durante as operações, é fundamental tomar medidas de forma a garantir a segurança das operações, minimizando a possibilidade de ocorrência de falhas, danos ao veículo ou mesmo a perda deste.

\subsubsection{Procedimentos operacionais}

A definição de procedimentos operacionais é uma boa forma de aumentar a segurança, proporcionando repetibilidade nos ensaios, reduzindo a probabilidade de falhas humanas e facilitando a detecção de problemas antes do início das manobras, além de minimizar os danos causados nestes casos. No Apêndice A.1 são apresentadas diversas sugestões que podem ser utilizadas para o estabelecimento destes procedimentos.

\subsubsection{Manutenção periódica}

Existem diversas falhas que podem ocorrer em decorrência da não observação da manutenção, como inundação dos vasos de pressão, falha de componentes e mau-contato de conectores.

Assim, um ponto importante para aumentar a segurança das operações é o estabelecimento de um calendário de manutenção periódica dos sistemas e de um relatório de uso dos equipamentos.

\subsubsection{Sistemas de localização}

Um dos principais pontos para se atentar na segurança das operações é a localização do veículo ao final da manobra. Para isso, é importante prover o veículo de sistemas de comunicação e localização e garantir seu bom desempenho.

\subsection{Comunicação a longa distância}

Uma dificuldade observada é o alcance da comunicação do rádio quando o veículo está flutuando na superfície da água, causada por diversos fatores. Um fator fácil de ser observado que reduz o alcance da comunicação é a dificuldade de encontrar antenas submersíveis com alto ganho de transmissão. Existem poucos fabricantes de antenas submersíveis, e 
as encontradas são de uso genérico, com ganhos relativamente baixos. Outro problema observado é a redução do alcance da comunicação em função da proximidade da antena com a superfície da água. Para aumentar a distância de comunicação é comum o uso de estruturas superiores, conhecidas como velas, para instalação das antenas em pontos mais elevados.

\subsection{Localizador Acústico}

O localizador acústico é fundamental para aumento da segurança das operações, permitindo localizar o veículo no caso de diversas falhas que possam fazer com que o veículo não retorne à superfície, como perda de flutuabilidade, falhas nos atuadores e inundação de vasos de pressão. Para garantir o bom desempenho do localizador deve-se realizar ensaios na região para determinar a melhor frequência de operação, evitando frequências com alta incidência de interferências causadas por equipamentos na região. 


\section{Considerações Finais}

\subsection{Trabalhos Futuros}

Tratando-se de um projeto extenso de desenvolvimento, é inevitável que sejam identificados uma série de trabalhos futuros. As sugestões foram agrupadas de acordo com o principal benefício gerado, entre: aumentar a capacidade do veículo, aumentar a segurança e facilitar as manutenções.

\subsubsection{Aumento da capacidade}

Entende-se como aumentar a capacidade do veículo a adição de novas funcionalidades que permitam que o veículo desempenhe novas missões, mais complexas, com maior capacidade de aquisição de dados, autonomia, etc.

\subsubsection{Interface Ethernet}

Embora o barramento CAN tenha se mostrado uma boa solução para executar a comunicação interna entre os módulos do veículo, o protocolo Ethernet é um padrão bastante utilizado na indústria para interface com equipamentos, principalmente quando estes geram grandes quantidades de dados. Assim, para adição de novos sensores, seria benéfico adicionar um módulo com interface Ethernet.

\subsubsection{Atualização dos microcontroladores}

Os microcontroladores utilizados são satisfatórios para as necessidades atuais do veículo, no entanto, sua arquitetura já está ultrapassada, existindo novos microcontroladores que possuem melhor desempenho, menor consumo de energia, e maior número de interfaces, como os de arquitetura Cortex M3. A substituição dos microcontroladores é um processo longo e delicado, uma vez que todos os códigos desenvolvidos precisariam ser adaptados e testados nas novas arquiteturas. Porém, este trabalho poderia permitir um aumento da autonomia do veículo, realização de algoritmos mais complexos e reduzir a quantidade de módulos necessários, facilitando a manutenção do sistema. Esta modificação poderia ser realizada gradativamente, com a substituição de um módulo de controle por vez, facilitando a depuração do sistema.

\subsubsection{Atualização no sistema de conversão e distribuição de energia}

Os conversores CC-CC utilizados foram dimensionados considerando uma carga inicial, que cresceu com a expansão do veículo. Um estudo sobre a arquitetura de conversão e 
distribuição de energia poderia gerar resultados benéficos, como aumentar a eficiência, simplificar o cabeamento e reduzir os níveis de ruídos presentes nos barramentos.

\subsubsection{Integrar novas cargas científicas}

Uma forma de aumentar a capacidade do veículo seria a adição de novas cargas científicas, como sonares de batimetria, sonares de varredura lateral, sub-bottom profilers e outros. A adição destes novos equipamentos não é trivial, uma vez que devem ser analisados seus impactos em diversos aspectos, como consumo de energia, emissão de EMI (Interferência Elétro Magnética), arrasto hidrodinâmico, estruturas de fixação, interfaces de controle e armazenamento de dados.

\subsubsection{Alinhamento dos sensores}

Para aumentar o desempenho dos sistemas de navegação inercial utilizados poderia ser realizado um projeto para garantir um alinhamento mais preciso entre os sensores do veículo, mais especificamente entre o DVL e as unidades de medição inercial. Outra alternativa seria estimar seu desalinhamento através de algoritmos e efetuar as rotações nas suas medições, obtendo todas num mesmo referencial estabelecido.

\subsubsection{Atuadores dianteiros}

A adição de atuadores horizontais na região frontal do veículo poderia facilitar o processo de submersão do veículo, além de permitir a implementação de algoritmos de controle mais complexos e de maior desempenho, com controle de pitch e profundidade, ou evitar a influência de ondas na profundidade do veículo, por exemplo [160].

\subsubsection{Sistemas de navegação acústica}

A instalação de equipamentos de navegação acústica, como um USBL, aumentaria o desempenho dos sistemas de navegação, permitindo a execução de manobras mais longas com melhor estimativa de posição. Além disso, a localização obtida, aliada a um modem acústico, facilitaria a localização e acompanhamento do veículo ao longo da manobra.

\subsubsection{Novos controladores}

Para aumentar o desempenho do veículo em manobras, ou permitir a realização de novas missões, alguns novos controladores poderiam ser implementados. A adição de um controle de velocidade, utilizando os dados fornecidos pelo DVL para realimentação, poderia garantir uma melhor regularidade da manobra e aumentar a previsibilidade de seu trajeto. Estudos poderiam ser feitos também para determinar velocidades que maximizem o alcance, por exemplo. 
Atualmente, as curvas das manobras são feitas em função da determinação do ângulo dos lemes. Assim, não há previsão do raio da curva na incidência de correntezas, nem garantia de que o ângulo determinado será suficiente para vencê-las.

Um controlador de velocidade angular, utilizado dados dos giroscópios para realimentação, poderia aumentar a capacidade de giro do veículo, permitir curvas mais suaves e, com um controle de velocidade linear, determinar o raio de curvatura.

Através da leitura de altitude do DVL e dos dados de inclinação do veículo, ou com a instalação de um altímetro, poderiam ser implementadas manobras com controle de altitude em relação ao leito, permitindo a execução de novas missões e também a adição de novos intertravamentos de segurança, evitando a colisão do veículo com o leito.

\subsubsection{Aumento da segurança}

A seguir são apresentadas algumas ideias que poderiam aumentar a segurança do veículo em operações, evitando danos aos equipamentos ou a possibilidade de perda do veículo.

\subsubsection{Comunicação acústica}

A adição de um modem acústico no veículo possibilitaria manter contato durante a execução das manobras, obter uma estimativa de sua posição, monitorar seus parâmetros e a execução da missão, além de permitir que o operador aborte a missão devido a fatores externos, como identificação de embarcações ou redes no trajeto do veículo.

\subsubsection{Manobra de retorno}

Conforme exposto na Seção A.1.3.7, um dos pontos de dificuldade nas operações é a localização do veículo ao final da realização da manobra, correndo-se inclusive o risco de perda do veículo. Para auxiliar nesse processo, poderia ser definido um ponto de encontro através de coordenadas obtidas no GPS, e programar o veículo para navegar até este ponto ao final da missão, usando os sinais de GPS que estão disponíveis quando ele encontra-se na superfície.

O ponto de encontro deverá ser demarcado próximo à região esperada para término da manobra, evitando que o veículo faça grandes deslocamentos na superfície, sujeito a colisões com outras embarcações, pedras ou com o continente.

\subsubsection{Barramento CAN redundante}

A adição de um segundo barramento CAN na arquitetura de controle permitiria implementar uma redundância no caso de falhas, com um custo pequeno, uma vez que o cabeamento é simples e diversos microcontroladores já possuem duas interfaces CAN disponíveis.

Em operação normal os barramentos poderiam ter funções distintas, como um barramento de dados e outro de controle, evitando a ocorrência de colisões de mensagens, mas caso 
seja identificada uma falha, o barramento intacto poderia ser utilizado para garantir a segurança do veículo.

\subsubsection{Testes de EMI}

Com a adição de novos sensores e equipamentos, pode ser interessante a realização de testes de imunidade à interferências eletromagnéticas, principalmente dos módulos de controle, evitando falhas que podem ocorrer de forma aleatória, difíceis de serem detectadas.

\subsubsection{Vaso de baterias}

A separação das baterias num vaso dedicado poderia ser uma alternativa para evitar que eventuais falhas provoquem danos nos equipamentos dos veículos, uma vez que falhas em baterias de polímero de lítio podem provocar incêndios.

\subsubsection{Intertravamentos}

Os intertravamentos de segurança se mostraram bastante importantes para garantir a segurança das operações, como pode ser visto na Seção $\underline{5.2 .1 .1}$. A adição de novos intertravamentos, permitindo identificar mais falhas e situações de riscos, poderia aumentar ainda mais a segurança do veículo. Alguns exemplos são: distância máxima do fundo, falha de manter os controladores em torno dos set-points desejados e ocorrências de falhas intermitentes.

\subsubsection{Recuperação de falhas}

Atualmente, no caso de ocorrência de qualquer falha detectada através dos intertravamentos de segurança, o veículo aborta a missão e executa uma manobra de emersão. Poderiam ser implementadas funcionalidades para procurar se recuperar no caso destas ocorrências, reiniciando os controladores defeituosos ou ativando manobras alternativas, por exemplo.

\subsubsection{Desvio de obstáculos}

Com a instalação de um sonar na proa do veículo, poderiam ser implementadas funcionalidades de desvio de obstáculos, evitando a colisão do veículo com embarcações, bancos de areia ou pedras, por exemplo.

\subsubsection{Sistema de monitoramento das baterias}

Uma forma de aumentar a segurança seria a adição de um sistema embarcado de monitoramento das baterias, com leitura das tensões individuais das células, monitoramento de corrente e balanceamento de carga. 
Tal sistema poderia fornecer dados para implementação de novos intertravamentos de segurança, evitando a descarga excessiva de uma célula, por exemplo.

\subsubsection{Estimativa da manobra na interface}

Para evitar falhas humanas na determinação do rumo da manobra, que poderia causar uma colisão do veículo com o continente, poderia ser implementada uma simulação da manobra estimada do veículo na interface, permitindo identificar previamente a possibilidade de choques. Este resultado seria simplificado, não levando em conta, por exemplo, a incidência de correntezas e ventos, o que deveria ser levado em conta pelo operador, responsável pela tomada de decisão final.

\subsubsection{Comunicação via satélite}

A instalação de um módulo de comunicação via satélite, como Iridium, InmarSat e Globalstar, podem oferecer mais uma alternativa para localização do veículo, independentemente da presença de sinais GPRS, por exemplo. A implementação desta funcionalidade é complicada, pois depende de assinaturas mensais e instalação de novos modens e antenas, mas teoricamente permitiria comunicar-se com o veículo de qualquer local do mundo, desde que ele se encontre na superfície. Esta solução praticamente eliminaria a possibilidade de não localizar o veículo ao final de ua manobra, aumentando a segurança das operações consideravelmente.

\subsubsection{Lastro de emergência}

Um possível sistema de segurança a ser considerando é um lastro, ou flutuador, de emergência. A liberação do lastro ou acionamento do flutuador poderia ser feita através de um sistema puramente mecânico, através de limites de pressão, ou com atuadores eletromecânicos, como válvulas solenoides. Também seria recomendável o uso de um sistema de energia independente, possibilitando a atuação mesmo em caso de falhas nas baterias principais do veículo.

\subsubsection{Facilitar manutenções}

As propostas a seguir têm como objetivo facilitar as manutenções do veículo, realizadas tanto em laboratório quanto durante ensaios de campo.

\subsubsection{Estrutura tipo rack}

Uma forma de melhorar o arranjo dos equipamentos nas prateleiras seria a elaboração de um projeto dos módulos de controle e de conversão de energia com fixação numa estrutura do tipo rack, facilitando a remoção e substituição de módulos e o acesso à conectores. 


\subsubsection{Fixação da prateleira}

Para evitar possíveis danos nos cabos que fazem conexão com os conectores das tampas do vaso, poderia ser feita a fixação da prateleira numa das tampas, preferencialmente a frontal, onde está a maior quantidade de conectores e são usados prensa-cabos para conexão com as antenas.

\subsubsection{Simuladores Hardware-in-the-loop}

Para permitir a realização de mais testes de bancada, poderiam ser desenvolvidos módulos para simulação do tipo hardware-in-the-loop que, aliados a um simulador, poderiam fornecer os dados dos sensores para a arquitetura de controle, simulando a realização de manobras completas.

\subsubsection{Acesso externo ao barramento principal}

Para permitir identificar problemas no veículo sem a abertura do vaso, poderia ser adicionado um conector externo para acesso ao barramento principal de comunicação. Com o uso de uma interface CAN-USB, por exemplo, poderia-se verificar a ocorrência de falhas e colisões de mensagens, monitorar parâmetros, enviar parâmetros ou até mesmo reprogramar módulos.

\subsection{Experiências de desenvolvimento e manutenção}

Ao longo do projeto, algumas características da arquitetura se destacaram de forma favorável, sendo consideradas fundamentais para o bom desenvolvimento.

A adoção de uma arquitetura de controle distribuída contribuiu fortemente para a modularidade do sistema. A possibilidade de adicionar ou remover módulos de controle que se conectam a um barramento permite que o veículo carregue apenas a carga necessária para execução da sua missão. A possibilidade de dedicar um módulo inteiramente novo ao desenvolvimento de uma nova funcionalidade contribui de forma significativa para a facilidade de desenvolvimento, permitindo que seja desenvolvida e testada sem preocupações com a concorrência de outros programas e, uma vez validada, pode-se estudar sua integração em um dos módulos já disponíveis.

A expansibilidade do sistema através da instalação de novos módulos permitiu a integração e substituição de diversos equipamentos, bem como a realização de missões para avaliação de desempenho simultâneo de diferentes sensores. Inicialmente composta por três módulos, o veículo já chegou a comportar oito módulos de processamento numa mesma missão.

O uso de um sistema operacional de tempo real possibilitou que o código embarcado fosse desenvolvido também de forma modular, facilitando as modificações no sistema. A transferência de funcionalidades entre os módulos foi realizada diversas vezes, sempre de 
forma fácil e sem grandes problemas de integração.

Para facilitar o processo de leitura dos dados armazenados, o armazenamento de dados foi transferido para o mesmo módulo responsável pela comunicação. Tal mudança foi facilmente realizada e testada no software embarcado.

\subsection{Conclusão}

Neste trabalho foi apresentado um estudo relacionando os requisitos da aplicação oceanográfica de AUVs e os impactos no desenvolvimento dos sistemas destes veículos. Foi feito um levantamento de requisitos da aplicação e estabelecidas relações destes com as características das arquiteturas de controle e os sistemas embarcados. Foi feito um estudo da arquitetura de controle CANARMES, desenvolvida para o AUV Pirajuba, de forma a orientar a adaptação do veículo para realização de um estudo de identificação de camadas finas.

Tal adaptação foi feita buscando atender aos requisitos impostos pela aplicação oceanográfica sem comprometer significativamente as características desejadas no projeto da arquitetura CANARMES, e apresentada na forma de um estudo de caso.

A realização desta adaptação e de diversos ensaios de campo, assim como a experiência obtida na manutenção do sistema obtida ao longo dos anos, possibilitou identificar pontos fortes, limitações e falhas no sistema desenvolvido, que foram apresentados ao longo do texto para orientar novos desenvolvimentos de veículos submarinos para tal aplicação.

Com a experiência obtida neste projeto, foi proposta também uma série de sugestões para a elaboração de procedimentos operacionais, que podem ser implementados de forma a aumentar a segurança, repetibilidade e confiabilidade das missões, bem como facilitar a realização de testes e manutenções.

Embora o estudo tenha focado em aplicações oceanográficas, que representam grande parte das aplicações atuais, os resultados obtidos podem ser estendidos para usos semelhantes. Por exemplo, diversos requisitos são relacionados à operação em águas rasas, podendo ser aplicados também em missões de caráter civil, como mapeamento de reservatórios de usinas hidrelétricas. Outros requisitos referem-se mais especificamente aos equipamentos de carga-científica utilizados, que em grande parte são os mesmos para aplicações da indústria off-shore, como sonares de varredura lateral.

Os estudos apresentados neste trabalho devem servir para nortear o desenvolvimento de AUVs para aplicações oceanográficas e para estabelecer procedimentos operacionais no uso destes veículos de uma forma geral.

A relação de trabalhos futuros sugeridos a seguir podem ser utilizadas para a elaboração de novas dissertações, trabalhos de conclusão de curso ou de iniciação científica, dando continuidade ao desenvolvimento da tecnologia. 


\section{A Apêndice}

\section{A.1 Sugestões para procedimentos operacionais}

Nesta seção é apresentada uma série de sugestões para elaboração de procedimentos operacionais, visando aumentar a segurança e o sucesso das missões de levantamento de dados.

\section{A.1.1 Testes de bancada}

Antes de iniciar a fase de testes na água, é fundamental a realização de testes em bancada, inicialmente com o veículo aberto e depois montado. Alguns problemas comumente observados em tais testes são: orientação dos sensores de movimento, inversão dos sinais dos sensores ou atuadores, falhas de conexão entre equipamentos e bugs de programação.

É possível simular a movimentação do veículo para testar o funcionamento colocando-o sobre um suporte com rodas, ou mesmo movimentando os vasos ou sensores com a mão. A análise da reação dos atuadores aos movimentos impostos permite identificar se os controladores estão atuando no sentido correto de correção da manobra.

Para simular o controle de profundidade, duas técnicas foram utilizadas nos ensaios: injetar um sinal analógico utilizando uma fonte de bancada no ponto de leitura de tensão do sensor de profundidade, ou a despressurização do interior do vaso de pressão, uma vez que o sensor de pressão utilizado mede a pressão relativa entre o meio externo e interno do vaso. A segunda técnica permite também identificar falhas na conexão do sensor, no entanto, necessita que o veículo esteja montado e fechado no vaso de pressão, dificultando o acesso para medições e verificação do ponto de falha, servindo mais como uma validação a ser executada antes da realização de ensaios.

Os sensor mais difícil de ser testado durante testes de bancada é o sensor de velocidade por efeito doppler, por necessitar estar imerso em água com uma distância mínima do fundo de aproximadamente $0.5 \mathrm{~m}$. Para validar sua interface, é possível programar um microcontrolador com interface serial para enviar mensagens seguindo o mesmo protocolo, mas o teste definitivo exige que o veículo seja colocado num tanque de água ou numa piscina.

\section{A.1.2 Testes em águas confinadas}

Após a realização de testes de bancada, deve-se realizar ensaios em águas confinadas, como piscinas, onde não há risco de perda do veículo. Nestes ensaios podem-se identificar falhas como aquecimentos no interior do vaso, problemas de mau-contato que podem ocorrer com 
a movimentação do veículo, realizar ajustes de parâmetros dos controladores e manobras como imersão e emersão. Para a realização de ensaios em águas confinadas, é importante estabelecer um local seguro para realização de manutenções do equipamento próximo ao local de ensaio, evitando assim que o veículo precise ser transportado ao laboratório devido à ocorrência de pequenas falhas.

\section{A.1.3 Testes de campo}

Com a validação do equipamento feita nos testes de águas confinadas, procede-se então a realização de ensaios de campo, em locais perto da costa. Idealmente, deve-se procurar por um local que apresente as seguintes características:

- Águas com alta transparência/boa visibilidade;

- Profundidade suficiente para a missão desejada, mas não grande a ponto de dificultar eventuais mergulhos para recuperação do equipamento;

- Disponibilidade de locais fechados para instalação da infra-estrutura de manutenção;

- Disponibilidade de embarcações para realização da missão;

- Acesso a uma praia para realização de pequenos testes de funcionamento;

- Baixa incidência de ondas;

- Baixos custos de hospedagem para a equipe.

\section{A.1.3.1 Transporte ao local de ensaio}

Para transportar o veículo entre o laboratório da universidade e o local de ensaio, é importante remover os equipamentos sensíveis a vibrações e impactos, conforme descrito na Seção $\underline{5.3 .2}$.

O veículo pode ser transportado desmontado, com suas seções acondicionadas individualmente, ou montado, desde que fixo sobre suportes projetados para distribuir o peso, sem sobrecarregar as uniões das seções.

Além do veículo e seus equipamentos de uso imediato, é recomendável levar peças sobressalentes sempre que disponíveis, e equipamentos para manutenção e diagnósticos de problemas, como multímetros, osciloscópios, ferros de solda e ferramentas manuais.

Além disso, deve-se dispor de materiais que possam ser úteis nas operações como cordas, mosquetões, anilhas, boias, parafusos diversos, etc. 


\section{A.1.3.2 Montagem e testes do sistema}

Uma vez realizado o transporte do equipamento e da equipe, deve-se estabelecer um local para efetuar a montagem do veículo e realização de testes de bancada. É importante realizar novamente os testes que foram realizados em laboratório para identificar defeitos que podem ter sidos causados pelo transporte, como mau-contato de conectores, ou mesmos erros de montagem.

Recomenda-se simular a realização das manobras previstas conforme indicado na Seção $\underline{\text { A.1.1, }}$ antes e depois de fechar o veículo, pois os esforços necessários e riscos de acidentes são muito maiores caso um defeito seja identificado já na embarcação. Se possível, é recomendável fazer pequenas manobras de testes na praia, em pequenas profundidades, antes de carregar o veículo na embarcação. Essas manobras podem ajudar a identificar, por exemplo, problemas com controle de profundidade causados por falhas nos sensores ou atuadores, erros de montagem como a orientação do vaso de manobra.

\section{A.1.3.3 Verificações pré-operacionais}

Antes de iniciar a missão, deve-se fazer uma última verificação de diversos aspectos do veículo. A seguir é apresentada a lista de verificação utilizada durante as missões realizadas:

1. Verificar Carga das baterias:

Baterias principais;

Baterias do pinger;

Baterias das luzes de sinalização;

2. Verificação de Hardware:

Orientação dos sensores:

Unidade AHRS;

IMU;

Sensor de velocidade (DVL);

Conexão dos sensores:

Unidade AHRS;

IMU;

Sensor de velocidade (DVL);

GPS;

Profundímetro;

Orientação do Vaso de Manobras;

Conexão do vaso de Manobras com o Vaso Principal; 
Conexão do Propulsor com o Vaso de Manobras;

3. Teste de estanqueidade com bomba manual:

Vaso Principal;

Vaso de Manobras;

Verificar tampas de vedação;

4. Calibração da AHRS;

5. Verificação do Propulsor:

Hélice;

Cone;

Mola;

6. Regular flutuabilidade;

7. Calibração da IMU;

8. Realizar procedimento de Homing:

Calibrar posição dos lemes;

Calibrar posição dos profundores;

9. Retirar o offset do profundímetro;

10. Verificar parâmetros de Manobra;

11. Ler os estados dos microcontroladores;

\section{A.1.3.4 Acomodação na embarcação}

É importante determinar um bom local para acomodação do veículo na embarcação, de forma que fique de fácil acesso para colocação e remoção da água, e que seja protegido para não haver riscos de danificar seu hélice ou lemes.

Deve-se também definir um local para instalação da estação de controle, composta por um notebook, receptor de rádio, fontes de alimentação ou baterias. A antena do rádio deve ser instalada numa estrutura para fora do casco, preferencialmente com altura ajustável. Devem ser previstos locais para armazenamento seguro e para uso do receptor do pinger que poderá ser fundamental para a localização e resgate do veículo ao final da manobra. Devem ser acomodados também equipamentos de mergulho como cilindros, nadadeiras, máscaras, coletes e lastros, que poderão ser utilizados para recuperação do veículo se houver algum problema inesperado. 


\section{A.1.3.5 Procedimentos de lançamento}

Um dos pontos importantes durante a realização da missão é a operação de lançamento do veículo, ou seja, retirá-lo da embarcação e colocá-lo na água. Devido ao peso do veículo e presença de estruturas frágeis que se sobressaem do casco, como lemes e hélice, o uso de um guincho elétrico é recomendável.

Deve-se prever formas para fixação segura do cabo do guincho ao corpo do veículo, em posição tal que o veículo fique equilibrado quando içado, ou seja, com pontos de fixação simétricos em relação ao centro de gravidade.

Como a configuração do veículo é variável em função da missão, pode-se optar pelo uso de pontos de fixação ajustáveis.

Deve-se treinar os procedimentos de colocar e retirar o veículo da água, identificando possíveis riscos de colisões. Se for utilizado um guincho elétrico, verificar sua capacidade de carga, capacidade do cabo, alcance deste em relação à borda da embarcação, e elevação máxima, para não haver colisão do leme inferior com o casco do veículo.

\section{A.1.3.6 Início da manobra}

Uma vez com o veículo já na água, deve ser realizado um teste de alcance do rádio e do pinger, além de verificar a disponibilidade de sinais de GPRS, visando estabelecer a melhor técnica de localização do veículo ao final da missão.

Confirmar de forma manual se o veículo está com flutuabilidade levemente positiva, e se esta não é provocada pelos bolsões de ar que possam estar presos no interior do casco. Tais bolhas ou bolsões podem acabar se desprendendo durante a manobra do veículo, o que provocaria uma redução na sua flutuabilidade, fazendo com que o veículo possa afundar. Outra verificação importante é circular a região prevista para o ensaio e procurar por redes de pescadores, pedras, outras embarcações, etc.

A determinação do rumo inicial da manobra pode ser feita através de uma bússola manual, e sua leitura deve ser comparada à da bússola interna do veículo. O rumo encontrado na bússola manual, na bússola do veículo e o rumo determinado previamente através de mapas deve ser coerente, levando-se em conta pequenas variações e erros de leitura que possam ocorrer.

\section{A.1.3.7 Localização do veículo}

Ao final da missão, com o retorno do veículo para a superfície, deve-se localizá-lo o mais rápido possível, evitando que a correnteza afaste o veículo do local esperado.

É recomendável o uso de diversas técnicas nesta atividade, de forma que possa sempre haver alternativas em caso de falhas dos sistemas. Entre elas, pode-se citar o uso do pinger, 
sistemas de GPRS e comunicação de rádio, além da localização visual.

O sistema de GPRS pode ser utilizado para enviar a localização do veículo, obtida através de seu GPS, através de mensagens de texto. O veículo pode ser programado para enviar a mensagem para um número pré-definido, ou responder mensagens enviadas a ele com sua posição. Este sistema, no entanto, depende da disponibilidade de sinais no local, além de condições meteorológicas.

O pinger é um sistema acústico, com alcance em torno de três quilômetros, que permite determinar o rumo entre o localizador e o veículo, bem como uma estimativa de distância em função da intensidade do sinal recebido. Recomenda-se que sua operação seja feita por pessoal treinado, capaz de distinguir o sinal emitido pelo módulo dos ruídos e interferências do ambiente.

Uma fonte conhecida de ruídos são motores, portanto sempre que possível o motor da embarcação utilizada deverá estar desligado quando o pinger for utilizado.

Usualmente os pingers podem ser configurados para operar em diversas frequências, permitindo diferenciar diferentes módulos que possam estar operando em uma mesma região. A frequência utilizada também tem influência sobre o alcance do sinal e sobre o consumo de energia.

É recomendável realizar testes na região para determinar frequências com menor incidência de interferências.Este método tem a vantagem de também funcionar quando o veículo encontra-se submerso, diferentemente daqueles baseados em sinais eletromagnéticos.

A comunicação via rádio possui alcance menor do que GPRS, mas pode ser uma alternativa pois não depende do sinal no local. O veículo pode ser programado para enviar a sua posição obtida pelo GPS através do rádio. Com a disponibilidade de um GPS na embarcação, é fácil traçar uma rota que permita se aproximar do veículo.

A última etapa da localização é, invariavelmente, visual. O veículo deve ser pintado com cores que se destaquem no ambiente marinho: é usual o uso das cores amarelo e laranja, pois o olho humano possui maior sensibilidade a radiação da cor amarelo alaranjado.

Além disso, pode-se prover o veículo de luzes de sinalização contínuas ou estroboscópicas, para facilitar a sua visualização mesmo durante a noite. Outros mecanismos podem ser utilizados para auxiliar na localização, como o uso de binóculos e drones, permitindo visualizar o veículo a partir de maiores distâncias. 


\section{Referências}

1 YUH, J.; MARANI, G.; BLIDBERG, D. R. Applications of marine robotic vehicles. Intelligent service robotics, Springer, v. 4, n. 4, p. 221-231, 2011.

2 DUNBABIN, M.; MARQUES, L. Robots for environmental monitoring: Significant advancements and applications. IEEE Robotics \& Automation Magazine, IEEE, v. 19, n. 1, p. 24-39, 2012.

3 ZHANG, F.; MARANI, G.; SMITH, R. N.; CHOI, H. T. Future trends in marine robotics [tc spotlight]. IEEE Robotics \& Automation Magazine, IEEE, v. 22, n. 1, p. $14-122,2015$.

4 PEREIRA, F. L.; SOUSA, J. B.; MARTINS, C. G.; SILVA, E. P. da. Auv system requirements for coastal oceanography. In: IEEE. Autonomous Underwater Vehicle Technology, 1996. AUV'96., Proceedings of the 1996 Symposium on. [S.l.], 1996. p. 399-406.

5 TOMAN, M.; CURTRIGHT, A. E.; ORTIZ, D. S.; DARMSTADTER, J.; SHANNON, B. Unconventional fossil-based fuels: Economic and environmental trade-offs. [S.l.]: Rand Corporation, 2008.

6 BINGHAM, D.; DRAKE, T.; HILL, A.; LOTT, R. The application of autonomous underwater vehicle (auv) technology in the oil industry-vision and experiences. In: Fig XXII International Congress. [S.l.: s.n.], 2002. p. 19-26.

7 BARROS, E. D.; DANTAS, J.; FREIRE, L.; ZANONI, F.; OLIVEIRA, L.; VALE, R. New aspects in the pirajuba auv project. In: $A B C M$ (Ed.). COBEM 2011-21st International Congress of Mechanical Engineering. [S.l.: s.n.], 2011.

8 BARROS, E. D.; DANTAS, J. Effect of a propeller duct on auv maneuverability. Ocean Engineering, Elsevier, v. 42, p. 61-70, 2012.

9 PINHEIRO, A. R. M.; BARROS, E. A. d. Identification of hydrodynamic derivatives from auv pirajuba using extended kalman filter. In: 2013 Symposium on Computing and Automation for Offshore Shipbuilding. [S.l.: s.n.], 2013. p. 11-16.

10 CAETANO, W. D. S.; BARROS, E. A. D. Identification of auv's manoeuvrability using the nomoto's first order equation. In: IEEE. Computing and Automation for Offshore Shipbuilding (NAVCOMP), 2013 Symposium on. [S.l.], 2013. p. 17-22.

11 FREIRE, L. O. Desenvolvimento de uma arquitetura de controle descentralizada para veículos submarinos baseada em CAN, ARM e Engenharia de Sistemas-CANARMES. Tese (Doutorado) — Universidade de São Paulo.

12 SMITH, S. M.; DUNN, S. E. The ocean voyager ii: An auv designed for coastal oceanography. In: IEEE. Autonomous Underwater Vehicle Technology, 1994. AUV'94., Proceedings of the 1994 Symposium on. [S.l.], 1994. p. 139-147.

13 CURTin, T. B.; BELlinghaM, J. G.; CATIPOVIC, J.; WEBB, D. Autonomous oceanographic sampling networks. Oceanography, JSTOR, v. 6, n. 3, p. 86-94, 1993. 
14 YU, X.; DICKEY, T.; BELLINGHAM, J.; MANOV, D.; STREITLIEN, K. The application of autonomous underwater vehicles for interdisciplinary measurements in massachusetts and cape cod bays. Continental Shelf Research, Elsevier, v. 22, n. 15, p. 2225-2245, 2002.

15 TREMBANIS, A. C.; CARY, C.; SCHMIDT, V.; CLARKE, D.; CREES, T.; JACKSON, E. Modular autonomous biosampler (mab) - a prototype system for distinct biological size-class sampling and preservation. In: IEEE. Oceans, 2012. [S.1.], 2012. p. $1-6$.

16 ULlAH, B.; OVINIS, M.; BAHAROM, M. B.; JAVAID, M. Y.; IZHAR, S. S. Underwater gliders control strategies: A review. In: 2015 10th Asian Control Conference (ASCC). [S.l.: s.n.], 2015. p. 1-6.

17 SMITH, S. M.; DUNN, S. E.; HOPKINS, T. L.; HEEB, K.; PANTELAKIS, T. The application of a modular auv to coastal oceanography: case study on the ocean explorer. In: OCEANS '95. MTS/IEEE. Challenges of Our Changing Global Environment. Conference Proceedings. [S.l.: s.n.], 1995. v. 3, p. 1423-1432 vol.3.

18 SINGH, H.; YOERGER, D.; BRADLEY, A. Issues in auv design and deployment for oceanographic research. In: IEEE. Robotics and Automation, 1997. Proceedings., 1997 IEEE International Conference on. [S.1.], 1997. v. 3, p. 1857-1862.

19 HARVEY, J.; ZHANG, Y.; RYAN, J. Auvs for ecological studies of marine plankton communities. Sea Technology, Compass Publications, Inc.(Arlington), Ste. 1000 Arlington VA 22209 United States, v. 53, n. 9, p. 51-54, 2012.

20 ZHANG, Y.; MCEWEN, R. S.; RYAN, J. P.; BELLINGHAM, J. G. Design and tests of an adaptive triggering method for capturing peak samples in a thin phytoplankton layer by an autonomous underwater vehicle. IEEE Journal of Oceanic Engineering, IEEE, v. 35, n. 4, p. 785-796, 2010.

21 BARngROVER, C.; KASTNER, R.; DENEWILER, T.; MILLS, G. The stingray auv: A small and cost-effective solution for ecological monitoring. In: OCEANS'11 MTS/IEEE KONA. [S.l.: s.n.], 2011. p. 1-8. ISSN 0197-7385.

22 MAROUCHOS, A.; MUIR, B.; BABCOCK, R.; DUNBABIN, M. A shallow water auv for benthic and water column observations. In: IEEE. OCEANS 2015-Genova. [S.l.], 2015. p. $1-7$.

23 MARTINS, R.; SOUSA, J. B. de; AFONSO, C. C.; INCZE, M. L. Rep10 auv: Shallow water operations with heterogeneous autonomous vehicles. In: OCEANS 2011 IEEE Spain. [S.l.: s.n.], 2011. p. 1-6.

24 LUdVIGSEN, M.; THORSNES, T.; HANSEN, R. E.; SØRENSEN, A. J.; JOHNSEN, G.; LÅGSTAD, P. A.; ØDEGÅRD, Ø.; CANDELORO, M.; NORNES, S. M.; MALMQUIST, C. Underwater vehicles for environmental management in coastal areas. In: IEEE. OCEANS 2015-Genova. [S.1.], 2015. p. 1-6.

25 ROMERO, P.; SENSAlE-RODRIGUEZ, B.; ASTESSIANO, D.; CANETTI, R. Fisho: A cost-effective intelligent autonomous robot fish. In: 2013 16th International Conference on Advanced Robotics (ICAR). [S.l.: s.n.], 2013. p. 1-6. 
26 TAYLOR, M.; WILBY, A. Design considerations and operational advantages of a modular auv with synthetic aperture sonar. In: IEEE. OCEANS 2011. [S.1.], 2011. p. 1-6.

27 ClOITRE, A.; SUBRAMANIAM, V.; PATRIKALAKIS, N.; ALVARADO, P. V. y. Design and control of a field deployable batoid robot. In: 2012 4th IEEE RAS EMBS International Conference on Biomedical Robotics and Biomechatronics (BioRob). [S.l.: s.n.], 2012. p. 707-712. ISSN 2155-1774.

28 YU, H.; SHEN, A.; PENG, L. A new autonomous underwater robotic fish designed for water quality monitoring. In: 2012 Proceedings of International Conference on Modelling, Identification and Control. [S.1.: s.n.], 2012. p. 561-566.

29 YU, S. C.; HYUN, J.; KIM, D. Y.; PARK, M. K.; PYO, J. H.; CHO, P. C.; HWANG, C. S. The development of multi-functional autonomous amphibious vehicle. In: 2011 IEEE Symposium on Underwater Technology and Workshop on Scientific Use of Submarine Cables and Related Technologies. [S.l.: s.n.], 2011. p. 1-6.

30 SALUMäE, T.; RAAG, R.; REBANE, J.; ERNITS, A.; TOMING, G.; RATAS, M.; KRUUSMAA, M. Design principle of a biomimetic underwater robot u-cat. In: 2014 Oceans - St. John's. [S.l.: s.n.], 2014. p. 1-5. ISSN 0197-7385.

31 PENG, S.; YANG, C.; FAN, S.; ZHANG, S.; WANG, P.; XIE, Y.; CHEN, Y. A hybrid underwater glider for underwater docking. In: 2013 OCEANS - San Diego. [S.l.: s.n.], 2013. p. 1-7. ISSN 0197-7385.

32 JONES, C. P. Slocum glider persistent oceanography. In: 2012 IEEE/OES Autonomous Underwater Vehicles (AUV). [S.l.: s.n.], 2012. p. 1-6. ISSN 1522-3167.

33 YAHNKER, C. Overview of the development and advantages of new, larger fairings for the irobot seaglider. In: OCEANS'11 MTS/IEEE KONA. [S.l.: s.n.], 2011. p. 1-6. ISSN 0197-7385.

34 GOTTSCHALL, A. K. Design of an underwater glider for education and research. In: 2012 IEEE/OES Autonomous Underwater Vehicles (AUV). [S.l.: s.n.], 2012. p. 1-4. ISSN 1522-3167.

35 ARIMA, M.; OKASHIMA, T.; YAMADA, T. Development of a solar-powered underwater glider. In: 2011 IEEE Symposium on Underwater Technology and Workshop on Scientific Use of Submarine Cables and Related Technologies. [S.l.: s.n.], 2011. p. 1-5.

36 STANWAY, M. J.; KIEFT, B.; HOOVER, T.; HOBSON, B.; KLIMOV, D.; ERICKSON, J.; RAANAN, B. Y.; EBERT, D. A.; BELLINGHAM, J. White shark strike on a long-range auv in monterey bay. In: OCEANS 2015 - Genova. [S.l.: s.n.], 2015. p. $1-7$.

37 FIETZEK, P.; KRAMER, S.; ESSER, D. Deployments of the hydroc $(\operatorname{co} 2 / \operatorname{ch} 4)$ on stationary and mobile platforms - merging trends in the field of platform and sensor development. In: OCEANS'11 MTS/IEEE KONA. [S.l.: s.n.], 2011. p. 1-9. ISSN 0197-7385.

38 MULLISON, J.; SYMONDS, D.; TRENAMAN, N. Adcp data collected from a liquid robotics wave glider. In: 2011 IEEE/OES 10th Current, Waves and Turbulence Measurements (CWTM). [S.l.: s.n.], 2011. p. 266-272. 
39 BOWEN, A. D.; JAKUBA, M. V.; FARR, N. E.; WARE, J.; TAYLOR, C.; GOMEZ-IBANEZ, D.; MACHADO, C. R.; PONTBRIAND, C. An un-tethered rov for routine access and intervention in the deep sea. In: 2013 OCEANS - San Diego. [S.l.: s.n.], 2013. p. 1-7. ISSN 0197-7385.

40 MEINECKE, G.; RATMEYER, V.; RENKEN, J. Hybrid-rov - development of a new underwater vehicle for high-risk areas. In: OCEANS'11 MTS/IEEE KONA. [S.l.: s.n.], 2011. p. 1-6. ISSN 0197-7385.

41 MEINECKE, G.; ALBIEZ, J.; JOYEUX, S.; RATMEYER, V.; RENKEN, J. Orocos based control software of the new developed marum hybrid-rov for under-ice applications. In: 2013 OCEANS - San Diego. [S.1.: s.n.], 2013. p. 1-6. ISSN 0197-7385.

42 WANG, B.; WU, C.; GE, T. Control system of a novel underwater vehicle for global ocean science to the deepest ocean. In: Proceedings of the 32nd Chinese Control Conference. [S.1.: s.n.], 2013. p. 7268-7272.

43 LI, J. H.; LEE, M. J.; PARK, S. H.; KIM, J. G.; KIM, J. T.; SUH, J. H. Development of p-suro ii hybrid auv and its experimental study. In: 2013 MTS/IEEE OCEANS Bergen. [S.l.: s.n.], 2013. p. 1-6.

44 JOHANSSON, B.; SIESJö, J.; FURUHOLMEN, M. Seaeye sabertooth a hybrid auv/rov offshore system. In: OCEANS 2010 MTS/IEEE SEATTLE. [S.l.: s.n.], 2010. p. 1-3. ISSN 0197-7385.

45 CHOI, H.; CHUNG, S.; PARK, H.; SEO, J. Design and control of a convertible rov. In: 2012 Oceans - Yeosu. [S.1.: s.n.], 2012. p. 1-7.

46 ISHIBASHI, S.; KUMAGAI, T.; SATO, S.; YOSHIDA, H.; HYAKUDOME, T.; SUGESAWA, M.; NAKATANI, T.; OCHI, H.; WATANABE, Y.; SAWA, T.; NAKANO, Y.; OTA, Y.; UTSUGI, H. Development of the working-auv otohime. In: 2012 Oceans Yeosu. [S.l.: s.n.], 2012. p. 1-5.

47 LI, L.; GUO, J.; GUO, S. Characteristic evaluation on land for a novel amphibious spherical robot. In: 2015 IEEE International Conference on Mechatronics and Automation (ICMA). [S.l.: s.n.], 2015. p. 1100-1105. ISSN 2152-7431.

48 ZHANG, Y.; GODIN, M. A.; BELLINGHAM, J. G.; RYAN, J. P. Using an autonomous underwater vehicle to track a coastal upwelling front. IEEE Journal of Oceanic Engineering, IEEE, v. 37, n. 3, p. 338-347, 2012.

49 NOVI, M.; PACINI, F.; PAOLI, G.; BALlinI, G.; CAITI, A.; CORATO, F. D.; FENUCCI, D.; GRECHI, S.; REGGIANNINI, R.; SAVIOZZI, G.; CARRAI, F. Project v-fides: An innovative, multi purpose, autonomous underwater platform. In: OCEANS 2015 - Genova. [S.l.: s.n.], 2015. p. 1-9.

50 WOOLSEY, M.; JARNAGIN, R.; DIERCKS, A. R.; ASPER, V. L. New developments for the niust auvs. In: 2012 Oceans. [S.1.: s.n.], 2012. p. 1-4. ISSN 0197-7385.

51 HYAKUDOME, T.; YOSHIDA, H.; ISHIBASHI, S.; OCHI, H.; SAWA, T.; NAKANO, Y.; WATANABE, Y.; NAKATANI, T.; SUGESAWA, M.; OHTA, Y.; WATANABE, K.; OOMIKA, S.; NANBU, Y.; KOMUKU, M. M. Development of auv for scientific observation. In: 2012 Oceans. [S.1.: s.n.], 2012. p. 1-4. ISSN 0197-7385. 
52 MARTÍNEZ, A.; RODRÍGUEZ, Y.; HERNÁNDEZ, L.; GUERRA, C.; SAHLI, H. Hardware and software architecture for auv based on low-cost sensors. In: IEEE. Control Automation Robotics \& Vision (ICARCV), 2010 11th International Conference on. [S.1.], 2010. p. 1428-1433.

53 SHEA, D.; WILLIAMS, C.; HE, M.; CROCKER, P.; RIGGS, N.; BACHMAYER, R. Design and testing of the marport sqx-500 twin-pod auv. In: IEEE. Autonomous Underwater Vehicles (AUV), 2010 IEEE/OES. [S.1.], 2010. p. 1-9.

54 YOSHIDA, H.; HYAKUDOME, T.; ISHIBASHI, S.; OCHI, H.; WATANABE, Y.; SAWA, T.; NAKANO, Y.; OHMIKA, S.; SUGESAWA, M.; NAKATANI, T. Development of the cruising-auv jinbei. In: 2012 Oceans - Yeosu. [S.l.: s.n.], 2012. p. 1-4.

55 ISHIBASHI, S.; YOSHIDA, H.; HYAKUDOME, T.; SUGESAWA, M.; NAKATANI, T.; OTA, Y.; OCHI, H.; WATANABE, Y.; SAWA, T.; NAKANO, Y. et al. The development of an autonomous underwater vehicle "otohime" with the multiple operation. In: IEEE. Mechatronics and Automation (ICMA), 2013 IEEE International Conference on. [S.l.], 2013. p. 1588-1593.

56 AKIMOTO, K.; HENMI, Y.; SHIMASAKI, H.; YAKITA, K.; HOKAMURA, T.; MASUDA, T.; TAKEUCHI, T.; SHIBATA, K.; SHIBATA, M.; NAKANO, K. et al. Autonomous underwater vehicle (auv) investigations to protect valuable invertebrates. In: IEEE. Underwater Technology (UT), 2011 IEEE Symposium on and 2011 Workshop on Scientific Use of Submarine Cables and Related Technologies (SSC). [S.l.], 2011. p. 1-6.

57 WANG, H.-j.; FU, G.-x.; XU, J.-l.; LI, J. Spatio-temporal 3d terrain modeling and visualization based on measuring data of auv. In: IEEE. OCEANS 2011. [S.1.], 2011. p. $1-6$.

58 MACPHERSON, K.; WALKER, D.; DEVILLERS, R.; KENNEDY, N.; KING, P.; LEWIS, R.; MUNROE, J.; VARDY, A. The development of auv strategies for multidisciplinary use. In: 2014 Oceans - St. John's. [S.1.: s.n.], 2014. p. 1-7. ISSN 0197-7385.

59 OSTERLOH, C.; PIONTECK, T.; MAEHLE, E. Monsun ii: A small and inexpensive auv for underwater swarms. In: VDE. Robotics; Proceedings of ROBOTIK 2012; 7th German Conference on. [S.1.], 2012. p. 1-6.

60 ZHANG, M.; XU, Y.; LI, B.; WANG, D.; XU, W. A modular autonomous underwater vehicle for environmental sampling: System design and preliminary experimental results. In: IEEE. OCEANS 2014-TAIPEI. [S.1.], 2014. p. 1-5.

61 CAITI, A.; CORATO, F. D.; FENUCCI, D.; GRECHI, S.; NOVI, M.; PACINI, F.; PAOLI, G. The project v-fides: A new generation auv for deep underwater exploration, operation and monitoring. In: IEEE. Oceans-St. John's, 2014. [S.l.], 2014. p. 1-7.

62 LI, M.; WANG, M. Auv power supply system control and remote monitoring. In: IEEE. Control Conference (CCC), 2010 29th Chinese. [S.l.], 2010. p. 5037-5041.

63 KONDO, H.; SATO, M.; HOTTA, T.; WITHAMANA, A.; OSAKABE, M.; MATSUMOTO, Y. Development of a marine ecosystem and micro structure monitoring auv for plankton environment. In: 2014 IEEE/OES Autonomous Underwater Vehicles (AUV). [S.l.: s.n.], 2014. p. 1-5. ISSN 1522-3167. 
64 GODIN, M.; ZHANG, Y.; RYAN, J.; HOOVER, T.; BELlingHAM, J. Phytoplankton bloom patch center localization by the tethys autonomous underwater vehicle. In: IEEE. OCEANS 2011. [S.1.], 2011. p. 1-6.

65 ZHANG, Y.; MCEWEN, R. S.; RYAN, J. P.; BELLINGHAM, J. G. Design and tests of an adaptive triggering method for capturing peak samples in a thin phytoplankton layer by an autonomous underwater vehicle. IEEE Journal of Oceanic Engineering, IEEE, v. 35, n. 4, p. 785-796, 2010.

66 ZHANG, Y.; KIEFT, B.; MCEWEN, R.; STANWAY, J.; BELLINGHAM, J.; RYAN, J.; HOBSON, B.; PARGETT, D.; BIRCH, J.; SCHOLIN, C. Tracking and sampling of a phytoplankton patch by an autonomous underwater vehicle in drifting mode. In: IEEE. OCEANS'15 MTS/IEEE Washington. [S.l.], 2015. p. 1-5.

67 VANDROMME, P.; STEMMANN, L.; GARCİA-COMAS, C.; BERLINE, L.; SUN, X.; GORSKY, G. Assessing biases in computing size spectra of automatically classified zooplankton from imaging systems: A case study with the zooscan integrated system. Methods in Oceanography, Elsevier, v. 1, p. 3-21, 2012.

68 EICHHORN, M.; TAUBERT, R.; AMENT, C.; JACOBI, M.; PFUETZENREUTER, T. Modular auv system for sea water quality monitoring and management. In: 2013 MTS/IEEE OCEANS - Bergen. [S.l.: s.n.], 2013. p. 1-7.

69 BUSQUETS, J.; PROSERPIO, D.; MARTIN, F.-J.; BUSQUETS, J.-V. Low-cost auv alba13 as multi-sensor platform with water sampler capabilities, for application in multi-agent ocean research applications. In: IEEE. Oceans-St. John's, 2014. [S.1.], 2014. p. $1-8$.

70 CADENA, A. Development of a low cost autonomous underwater vehicle for antarctic exploration. In: IEEE. Technologies for Practical Robot Applications (TePRA), 2011 IEEE Conference on. [S.1.], 2011. p. 76-81.

71 AllotTA, B.; BAineS, S.; BARTOlini, F.; BEllaVia, F.; COLOMBO, C.; CONTI, R.; COSTANZI, R.; DEDE, C.; FANFANI, M.; GELLI, J. et al. Design of a modular autonomous underwater vehicle for archaeological investigations. In: IEEE. OCEANS 2015-Genova. [S.1.], 2015. p. 1-5.

72 FROST, G.; MAURELLI, F.; LANE, D. M. Reinforcement learning in a behaviour-based control architecture for marine archaeology. In: IEEE. OCEANS 2015-Genova. [S.1.], 2015. p. 1-5.

73 MAKI, T.; SATO, Y.; MATSUDA, T.; KUME, A.; SAKAMAKI, T.; URA, T. Auv tri-ton - a hover-capable platform for $3 \mathrm{~d}$ visualization of complicated surfaces. In: IEEE. Underwater Technology Symposium (UT), 2013 IEEE International. [S.1.], 2013. p. 1-6.

74 HILDEBRANDT, M.; HILLJEGERDES, J. Design of a versatile auv for high precision visual mapping and algorithm evaluation. In: 2010 IEEE/OES Autonomous Underwater Vehicles. [S.l.: s.n.], 2010. p. 1-6. ISSN 1522-3167.

75 HILDEBRANDT, M.; GAUDIG, C.; CHRISTENSEN, L.; NATARAJAN, S.; PARANHOS, P.; ALBIEZ, J. Two years of experiments with the auv dagon - a versatile vehicle for high precision visual mapping and algorithm evaluation. In: 2012 IEEE/OES Autonomous Underwater Vehicles (AUV). [S.l.: s.n.], 2012. p. 1-9. ISSN 1522-3167. 
76 PYO, J.; JOE, H.-G.; KIM, J.-H.; ELIBOL, A.; SON-CHEOL, Y. Development of hovering-type auv "cyclops" for precision observation. In: IEEE. Oceans-San Diego, 2013. [S.1.], 2013. p. 1-5.

77 NOVI, G. D.; MELCHIORRI, C.; GARCIA, J.; SANZ, P.; RIDAO, P.; OLIVER, G. New approach for a reconfigurable autonomous underwater vehicle for intervention. IEEE Aerospace and Electronic Systems Magazine, IEEE, v. 25, n. 11, p. 32-36, 2010.

78 PALOMERAS, N.; GARCÍA, J.; PRATS, M.; FERNÁNDEZ, J.; SANZ, P.; RIDAO, P. A distributed architecture for enabling autonomous underwater intervention missions. In: IEEE. Systems conference, 2010 4th annual IEEE. [S.1.], 2010. p. 159-164.

79 RIBAS, D.; RIDAO, P.; TURETTA, A.; MELCHIORRI, C.; PALLI, G.;

FERNÁNDEZ, J. J.; SANZ, P. J. I-auv mechatronics integration for the trident fp7 project. IEEE/ASME Transactions on Mechatronics, IEEE, v. 20, n. 5, p. 2583-2592, 2015 .

80 SANZ, P. J.; PRATS, M.; RIDAO, P.; RIBAS, D.; OLIVER, G.; ORTIZ, A. Recent progress in the rauvi project: A reconfigurable autonomous underwater vehicle for intervention. In: IEEE. Elmar, 2010 Proceedings. [S.l.], 2010. p. 471-474.

81 UPADHYAY, V.; GUPTA, S.; DUBEY, A. C.; RAO, M. J.; SIDDHARTHA, P.; GUPTA, V.; GEORGE, S.; BOBBA, R.; SIRIKONDA, R.; MALOO, A.; IDICHANDY, V. G. Design and motion control of autonomous underwater vehicle, amogh. In: 2015 IEEE Underwater Technology (UT). [S.l.: s.n.], 2015. p. 1-9.

82 LOC, M. B.; CHOI, H. S.; KIM, J. Y.; YOON, J. Design and control of an auv with weight balance. In: 2012 Oceans - Yeosu. [S.l.: s.n.], 2012. p. 1-8.

83 KIM, B.; JUN, B.-H.; LEE, P.-M. Concise behavior arbitration mechanism for the isimi100 auv. In: IEEE. Underwater Technology (UT), 2011 IEEE Symposium on and 2011 Workshop on Scientific Use of Submarine Cables and Related Technologies (SSC). [S.1.], 2011. p. 1-6.

84 KIM, B.; LEE, P.-M.; JUN, B.-H.; PARK, J.-Y.; SHIM, H. Design and implementation of control architecture for the isimi6000 autonomous underwater vehicle. In: IEEE. Autonomous Underwater Vehicles (AUV), 2012 IEEE/OES. [S.1.], 2012. p. 1-5.

85 ZHAO, N.; XU, D.; GAO, J.; YAN, W. Application of can-bus to the control system of the testbed auv. In: IEEE. Computer Engineering and Technology (ICCET), 2010 2nd International Conference on. [S.l.], 2010. v. 2, p. V2-645.

86 LI, J.-H.; YOON, B.-H.; OH, S.-S.; CHO, J.-S.; KIM, J.-G.; LEE, M.-J.; LEE, J.-W. Development of an intelligent autonomous underwater vehicle, p-suro. In: IEEE. OCEANS 2010 IEEE-Sydney. [S.1.], 2010. p. 1-5.

87 STILINOVIĆ, N.; NAđ, Đ.; MIŠKOVIĆ, N. Auv for diver assistance and safety — design and implementation. In: IEEE. Oceans 2015-Genova. [S.1.], 2015. p. 1-4.

88 HUANG, X.; LI, Y.; JIN, S. A control system based on data exchange using ethernet and canbus for deep water auv. In: IEEE. Control Conference (ASCC), 2013 9th Asian. [S.1.], 2013. p. 1-5. 
89 SCHMIDT, T.; GELZE, J.; LEHR, H.; MISCHNICK, D.; OLENEW, E.; PRERADOVIĆ, O.; KÖRNER, G.; KÖRNER, H.-M.; THIEDE, C.; KRÜGER, S. et al. A pressure-tolerant auv for deep sea applications. In: IEEE. OCEANS 2011. [S.l.], 2011. p. $1-4$.

90 HYAKUDOME, T.; FURUYAMA, Y.; BABA, T.; KASAYA, T.; OOMIKA, S.; ISHIBASHI, S.; YOSHIDA, H.; TSUKIOKA, S.; MATSUURA, M.; AOKI, T. The experimental results about maneuverability and survey ability of auv "urashima". In: IEEE. OCEANS 2010. [S.1.], 2010. p. 1-6.

91 PACINI, F.; PAOLI, G.; FAZIO, A. D.; SGRÒ, G.; PERILlO, M.; ROSSETTI, F.; NARDINI, L. Project "v-fides": Free flooded vehicle for deep sea exploration. In: IEEE. OCEANS 2015-Genova. [S.l.], 2015. p. 1-5.

92 LEHARDY, P. K.; MOORE, C. Deep ocean search for malaysia airlines flight 370. In: IEEE. Oceans-St. John's, 2014. [S.l.], 2014. p. 1-4.

93 YOSHIDA, H.; HYAKUDOME, T.; ISHIBASHI, S.; OCHI, H.; WATANABE, T.; SAWA, T.; NAKANO, Y.; OHMIKA, S.; SUGESAWA, M.; MATSUURA, M. Development of two-type auvs for deep-sea carbon dioxide observations and hydrothermal plume exploration. In: IEEE. Underwater Technology (UT), 2011 IEEE Symposium on and 2011 Workshop on Scientific Use of Submarine Cables and Related Technologies (SSC). [S.1.], 2011. p. 1-3.

94 YOSHIDA, H.; HYAKUDOME, T.; ISHIBASHI, S.; SAWA, T.; NAKANO, Y.; OCHI, H.; WATANABE, Y.; NAKATANI, T.; OTA, Y.; SUGESAWA, M. et al. An autonomous underwater vehicle with a canard rudder for underwater minerals exploration. In: IEEE. Mechatronics and Automation (ICMA), 2013 IEEE International Conference on. [S.l.], 2013. p. 1571-1576.

95 COCCHI, L.; CARMiSCIANO, C.; PALANGIO, P.; GUALDESI, L. S3mag-low magnetic noise auv for multipurpose investigations. In: IEEE. OCEANS 2015-Genova. [S.1.], 2015. p. 1-4.

96 BUSQUETS, J.; ZILIC, F.; ARON, C.; MANZOLIZ, R. Auv and asv in twinned navigation for long term multipurpose survey applications. In: IEEE. OCEANS-Bergen, 2013 MTS/IEEE. [S.l.], 2013. p. 1-10.

97 NAKATANI, T.; ISHIBASHI, S.; HYAKUDOME, T.; SUGESAWA, M.; OTA, Y.; OCHI, H.; WATANABE, Y.; SAWA, T.; NAKANO, Y.; KUMAGAI, T.; SATO, S.; YOSHIDA, H. Working-auv otohime and its sea trials at sagami bay. In: 2013 IEEE International Underwater Technology Symposium (UT). [S.l.: s.n.], 2013. p. 1-5.

98 YAN, Z.; ZHAO, Y.; CHEN, T.; JIANG, L. Fault recovery based mission scheduling of auv for oceanographic survey. In: IEEE. Intelligent Control and Automation (WCICA), 2012 10th World Congress on. [S.1.], 2012. p. 4071-4076.

99 LEE, P. M.; JUN, B. H.; LEE, P. Y.; KIM, W. S.; YU, S. C. Recent r amp;d activities on underwater vehicles in korea for ocean exploration and observation. In: OCEANS 2015 - Genova. [S.l.: s.n.], 2015. p. 1-8. 
100 CLARKE, M. E.; WHITMIRE, C.; FRUH, E.; ANDERSON, J.; TAYLOR, J.; ROONEY, J.; FERGUSON, S.; SINGH, H. Developing the seabed auv as a tool for conducting routine surveys of fish and their habitat in the pacific. In: Proceedings of. [S.l.: s.n.], 2010.

101 ABREU, N.; MATOS, A.; RAMOS, P.; CRUZ, N. Automatic interface for auv mission planning and supervision. In: IEEE. OCEANS 2010. [S.l.], 2010. p. 1-5.

102 FURLONG, M. E.; PAXTON, D.; STEVENSON, P.; PEBODY, M.; MCPHAIL, S. D.; PERRETT, J. Autosub long range: A long range deep diving auv for ocean monitoring. In: IEEE. Autonomous Underwater Vehicles (AUV), 2012 IEEE/OES. [S.1.], 2012. p. $1-7$.

103 ZHOU, J.; BIAN, X.; ZHANG, W.; TANG, Z. Current profile data aided positioning for autonomous underwater vehicles. In: IEEE. OCEANS 2011. [S.l.], 2011. p. 1-5.

104 XU, H.; LI, G.; LIU, J. Reliability analysis of an autonomous underwater vehicle using fault tree. In: IEEE. Information and Automation (ICIA), 2013 IEEE International Conference on. [S.1.], 2013. p. 1165-1170.

105 DAS, J.; PY, F.; MAUGHAN, T.; O'REILlY, T.; MESSIE, M.; RYAN, J.; RAJAN, K.; SUKHATME, G. S. Simultaneous tracking and sampling of dynamic oceanographic features with autonomous underwater vehicles and lagrangian drifters. In: SPRINGER. Experimental Robotics. [S.1.], 2014. p. 541-555.

106 BUSQUETS, J.; BUSQUETS, J. V.; ZILIC, F.; PÉREZ, F.; GONZALEZ, F.; ARON, C.; TAMPIER, G.; LAZO, C.; MANZOLIZ, R.; PATRONI, E. et al. Low cost auv in multiple deployment configurations for oceanographic research. In: IEEE. OCEANS-Bergen, 2013 MTS/IEEE. [S.1.], 2013. p. 1-9.

107 RIBAS, D.; PALOMERAS, N.; RIDAO, P.; CARRERAS, M.; MALLIOS, A. Girona 500 auv: From survey to intervention. IEEE/ASME Transactions on Mechatronics, IEEE, v. 17, n. 1, p. 46-53, 2012.

108 ELVANDER, J.; HAWKES, G. Rovs and auvs in support of marine renewable technologies. In: IEEE. Oceans, 2012. [S.1.], 2012. p. 1-6.

109 MAKI, T.; SATO, Y.; MATSUDA, T.; SHIROKU, R.-T.; SAKAMAKI, T. Auv tri-ton 2: An intelligent platform for detailed survey of hydrothermal vent fields. In: IEEE. Autonomous Underwater Vehicles (AUV), 2014 IEEE/OES. [S.1.], 2014. p. 1-5.

110 MCCARTER, B.; PORTNER, S.; NEU, W. L.; STILWELL, D. J.; MALLEY, D.; MINIS, J. Design elements of a small auv for bathymetric surveys. In: IEEE. Autonomous Underwater Vehicles (AUV), 2014 IEEE/OES. [S.l.], 2014. p. 1-5.

111 SAHU, B. K.; SUBUDHI, B. The state of art of autonomous underwater vehicles in current and future decades. In: IEEE. Automation, Control, Energy and Systems (ACES), 2014 First International Conference on. [S.l.], 2014. p. 1-6.

112 GOLDBERG, D. Huxley: a flexible robot control architecture for autonomous underwater vehicles. In: IEEE. OCEANS, 2011 IEEE-Spain. [S.l.], 2011. p. 1-10. 
113 KITTS, C.; ADAMEK, T.; VLAHOS, M.; MAHACEK, A.; POORE, K.; GUERRA, J.; NEUMANN, M.; CHIN, M.; RASAY, M. An underwater robotic testbed for multi-vehicle control. In: IEEE. Autonomous Underwater Vehicles (AUV), 2014 IEEE/OES. [S.l.], 2014. p. 1-8.

114 LOUEIPOUR, M.; HADIAN, H. Effect of considering sensors and actuators modeling on the design of pid controllers for an autonomous underwater vehicle. In: The 2nd International Conference on Control, Instrumentation and Automation. [S.l.: s.n.], 2011. p. 582-587.

115 MCCARTER, B.; BRIGGS, R.; PORTNER, S.; STILWELL, D.; NEU, W.; COE, R.; DUELLEY, R.; MALLEY, D.; MIMS, J. Design and testing of a self-mooring auv. In: 2012 Oceans. [S.l.: s.n.], 2012. p. 1-8. ISSN 0197-7385.

116 CRUZ, N. A.; MATOS, A. C.; FERREIRA, B. M. Modular building blocks for the development of auvs - from mares to trimares. In: IEEE. Underwater Technology Symposium (UT), 2013 IEEE International. [S.1.], 2013. p. 1-8.

117 DEMARCO, K.; WEST, M. E.; COLLINS, T. R. An implementation of ros on the yellowfin autonomous underwater vehicle (auv). In: IEEE. OCEANS 2011. [S.l.], 2011. p. $1-7$.

118 CROWELL, J. Design challenges of a next generation small auv. In: IEEE. Oceans-San Diego, 2013. [S.1.], 2013. p. 1-5.

119 TECK, T. Y.; CHITRE, M.; VADAKKEPAT, P. Hierarchical agent-based command and control system for autonomous underwater vehicles. In: IEEE. Autonomous and Intelligent Systems (AIS), 2010 International Conference on. [S.1.], 2010. p. 1-6.

120 HAROUTUNIAN, M.; MURPHY, A. J. Mission based optimum system selector for bio-inspired unmanned untethered underwater vehicles. In: IEEE. Autonomous Underwater Vehicles (AUV), 2012 IEEE/OES. [S.1.], 2012. p. 1-9.

121 HAN, Y.; HE, B.; SHA, Q. A distributed motion control system for the cranger autonomous underwater vehicle. In: 2010 2nd International Asia Conference on Informatics in Control, Automation and Robotics (CAR 2010). [S.l.: s.n.], 2010. v. 1, p. 322-325. ISSN 1948-3414.

122 CHE, J.; CERNIO, J.; PRAINITO, J.; ZUBA, M.; CAO, C.; CUI, J.-H.; KAZEROUNIAN, K. An advanced autonomous underwater vehicle design and control strategy. In: IEEE. Oceans, 2012. [S.1.], 2012. p. 1-6.

123 MORENO, E.; CHUNG, S. Y. Seadrone: A modular and reconfigurable underwater robot for task optimization. In: OCEANS 2014 - TAIPEI. [S.l.: s.n.], 2014. p. 1-7.

124 MING-CHUNG, F.; SHUN-MIN, W. Rapid development of auv system based on real-time and fpga frame. In: IEEE. Underwater Technology (UT), 2011 IEEE Symposium on and 2011 Workshop on Scientific Use of Submarine Cables and Related Technologies (SSC). [S.1.], 2011. p. 1-5.

125 NISHIDA, Y.; KOJIMA, J.; ITO, Y.; TAMURA, K.; SUGIMATSU, H.; KIM, K.; SUDO, T.; URA, T. Development of an autonomous buoy system for auv. In: OCEANS 2015 - Genova. [S.1.: s.n.], 2015. p. 1-6. 
126 PAULL, L.; SAEEDI, S.; SETO, M.; LI, H. Auv navigation and localization: A review. IEEE Journal of Oceanic Engineering, v. 39, n. 1, p. 131-149, Jan 2014. ISSN 0364-9059.

127 KRISHNAMURTHY, P.; KHORRAMI, F. A self-aligning underwater navigation system based on fusion of multiple sensors including dvl and imu. In: IEEE. Control Conference (ASCC), 2013 9th Asian. [S.1.], 2013. p. 1-6.

128 KARIMI, M.; BOZORG, M.; KHAYATIAN, A. A comparison of dvl/ins fusion by ukf and ekf to localize an autonomous underwater vehicle. In: IEEE. Robotics and Mechatronics (ICRoM), 2013 First RSI/ISM International Conference on. [S.1.], 2013. p. $62-67$.

129 PALOMERAS, N.; EL-FAKDI, A.; CARRERAS, M.; RIDAO, P. Cola2: A control architecture for auvs. IEEE Journal of Oceanic Engineering, v. 37, n. 4, p. 695-716, Oct 2012. ISSN 0364-9059.

130 ZUBA, M.; VILLA, C.; BYRD, A.; FEDGE, C.; LE, S.; MO, H.; PENG, Z.; CHE, J.; CUI, J.-H. A control system for ofdm networked autonomous underwater vehicles. In: IEEE. Oceans, 2012. [S.l.], 2012. p. 1-6.

131 KEMnA, S.; HAMILTON, M. J.; HUGHES, D. T.; LEPAGE, K. D. Adaptive autonomous underwater vehicles for littoral surveillance. Intelligent service robotics, Springer, v. 4, n. 4, p. 245-258, 2011.

132 TECK, T. Y.; CHITRE, M. Hierarchical multi-agent command and control system for autonomous underwater vehicles. In: IEEE. Autonomous Underwater Vehicles (AUV), 2012 IEEE/OES. [S.1.], 2012. p. 1-6.

133 BRIGGS, R.; MCCARTER, B.; NEU, W. L.; STILWELL, D. J. Design elements of a prototype self-mooring auv. In: IEEE. OCEANS 2010. [S.l.], 2010. p. 1-8.

134 ZHANG, F.; DUAN, X.; BAO, H. Can bus based for auv internal communication system design. In: IEEE. Electronics, Communications and Control (ICECC), 2011 International Conference on. [S.1.], 2011. p. 2579-2583.

135 ZHANG, G.; WAN, L.; LI, J.; CHEN, H. Control system design based on multi-sensors fusion for auv. In: IEEE. Intelligent Systems and Applications (ISA), 2011 3rd International Workshop on. [S.1.], 2011. p. 1-4.

136 QIN, Z.; GU, J. Multi-thread technology based autonomous underwater vehicle. In: IEEE. Control and Automation (ICCA), 2010 8th IEEE International Conference on. [S.l.], 2010. p. 898-903.

137 HO, C.; SARIPALLI, S. Where do you sample?-an autonomous underwater vehicle story. In: IEEE. Robotic and Sensors Environments (ROSE), 2011 IEEE International Symposium on. [S.1.], 2011. p. 119-124.

138 CHOI, Y.-H.; LEE, J.-W.; HONG, S.-H.; SUH, J.-H.; KIM, J.-G. The development of the modular autonomous underwater navigation system based on opros. In: IEEE. Ubiquitous Robots and Ambient Intelligence (URAI), 2014 11th International Conference on. [S.l.], 2014. p. 625-628. 
139 ZOU, J.; GUNDRY, S.; KUSYK, J.; SAHIN, C. S.; UYAR, M. U. Bio-inspired topology control mechanism for autonomous underwater vehicles used in maritime surveillance. In: IEEE. Technologies for Homeland Security (HST), 2013 IEEE International Conference on. [S.1.], 2013. p. 201-206.

140 SPEARS, A.; WEST, M.; COLLINS, T. Autonomous control and simulation of the videoray pro iii vehicle using moos and ivp helm. In: IEEE. Oceans-San Diego, 2013. [S.l.], 2013. p. 1-10.

141 LI, H.; YIN, B.; WANG, S.; YANG, Q. Design of underwater robot controller based on can bus. In: IEEE. Electronic and Mechanical Engineering and Information Technology (EMEIT), 2011 International Conference on. [S.l.], 2011. v. 9, p. 4906-4909.

142 PIZA, R.; SALT, J.; CUENCAY, A.; CASANOVA, V. Control network architecture for an autonomous underwater vehicle divisamos project. In: IEEE. OCEANS, 2011 IEEE-Spain. [S.1.], 2011. p. 1-5.

143 HU, G.; TAY, W. P.; WEN, Y. Cloud robotics: architecture, challenges and applications. IEEE Network, v. 26, n. 3, p. 21-28, May 2012. ISSN 0890-8044.

144 SU, R.; VENKATESAN, R.; LI, C. A new node coordination scheme for data gathering in underwater acoustic sensor networks using autonomous underwater vehicle. In: 2013 IEEE Wireless Communications and Networking Conference (WCNC). [S.l.: s.n.], 2013. p. 4370-4374. ISSN 1525-3511.

145 KIM, B.; JUN, B.-H.; PARK, J.-Y.; LEE, P.-M. Real-time process without rtos for the isimi100 autonomous underwater vehicle. In: IEEE. OCEANS, 2012-Yeosu. [S.1.], 2012. p. 1-4.

146 WOLF, M. Computers as components: principles of embedded computing system design. [S.l.]: Elsevier, 2012.

147 AHMADZADEH, S. R.; LEONETTI, M.; CARRERA, A.; CARRERAS, M.; KORMUSHEV, P.; CALDWELL, D. G. Online discovery of auv control policies to overcome thruster failures. In: IEEE. Robotics and Automation (ICRA), 2014 IEEE International Conference on. [S.1.], 2014. p. 6522-6528.

148 TEUBLER, T.; SHUANG, L.; HELLBRÜCK, H. Integrating expert system clips into dune for auv control. In: IEEE. OCEANS 2015-Genova. [S.1.], 2015. p. 1-6.

149 PFUETZENREUTER, T.; RENKEWITZ, H. Consys-a new software framework for underwater vehicles. In: IEEE. OCEANS 2010 IEEE-Sydney. [S.l.], 2010. p. 1-6.

150 VALAVANIS, K. P.; GRACANIN, D.; MATIJASEVIC, M.; KOLLURU, R.; DEMETRIOU, G. A. Control architectures for autonomous underwater vehicles. IEEE Control Systems Magazine, v. 17, n. 6, p. 48-64, 1997.

151 CHOWDHURY, D.; NANDY, S.; RAY, R.; SHOME, S. Behavior-based control applied to underwater vehicles to achieve local goals. In: IEEE. Underwater Technology (UT), 2015 IEEE. [S.l.], 2015. p. 1-6.

152 HAN, J.; OK, J.; CHUNG, W. K. An ethology-based hybrid control architecture for an autonomous underwater vehicle for performing multiple tasks. IEEE Journal of Oceanic Engineering, IEEE, v. 38, n. 3, p. 514-521, 2013. 
153 OLIVEIRA, L. M. D. Propulsor para veículos submarinos não tripulados São Paulo (2013). Monografia (Trabalho de Conclusão de Curso) — Escola Politécnica da Universidade de São Paulo, 2013.

154 VIVANCO, P. J. C. Desenvolvimento do sistema de navegação de um AUV baseado em filtro estendido de Kalman. Tese (Dissertação de Mestrado) - Universidade de São Paulo, 2014.

155 DANTAS, J. L. D.; BARROS, E. A. de; BOAS, F. V.; MUTSCHELER, F. A.; UMEDA, C. H. Experimental research on auv manoeuvrability. In: $A B C M$ (Ed.). COBEM 2011-21st International Congress of Mechanical Engineering. [S.l.: s.n.], 2011.

156 DAnTAS, J. L.; CAETANO, W. S.; VAlE, R. T.; BARROS, E. A. de. Analysis of identification methods applied to free model tests of the pirajuba auv. IFAC Proceedings Volumes, Elsevier, v. 46, n. 33, p. 185-190, 2013.

157 DANTAS, J. L. D.; CAETANO, W. da S.; VALE, R. T. da S.; OLIVEIRA, L. M. de; PINHEIRO, A. R. M.; BARROS, E. A. de. Experimental research on underwater vehicle manoeuvrability using the auv pirajuba. In: International Congress of Mechanical Engineering (COBEM 2013), Ribeirão Preto-SP, Brasil. [S.l.: s.n.], 2013.

158 AMIANTI, G. Arquitetura de software aviônico de um VANT com requisitos de homologação. Tese (Doutorado) — Universidade de São Paulo, 2008.

159 ZHANG, L.; XU, D.; LI, J.; JIANG, L. Design and experiment of automatic pilot for long-rang auvs. In: Industrial Electronics and Applications, 2008. ICIEA 2008. 3rd IEEE Conference on. [S.l.: s.n.], 2008. p. 1824-1827.

160 DANTAS, L. D.; BARROS, E. A. D.; JOSE, J. Longitudinal Control of Pirajuba Autonomous Underwater Vehicle, Using Techniques of Robust Control LQG / LTR. Engineering, 2003. 